ISABELA APARECIDA FORNACIARI

\title{
INVESTIGAÇÕES NO CAMPO DA PROGRAMAÇÃO SEMAFÓRICA
}

\begin{abstract}
Dissertação apresentada á Escola de Engenharia de São Carlos, da Universidade de São Paulo, como parte dos requisitos para a obtenção do título de Mestre em Ciências, Programa de Pós-graduação em Engenharia de transportes. Área de concentração: Planejamento e operações de Sistemas de Transportes.
\end{abstract}

Orientador: Professor Titular Doutor Antonio Clóvis Pinto Ferraz

São Carlos

2010. 
AUTORIZO A REPRODUÇÃO E DIVULGAÇÃO TOTAL OU PARCIAL DESTE TRABALHO, POR QUALQUER MEIO CONVENCIONAL OU ELETRONICO, PARA FINS DE ESTUDO E PESQUISA, DESDE QUE CITADA A FONTE.

Ficha catalográfica preparada pela Seçăo de Tratamento da Informaçăo do Serviço de Biblioteca - EESC/USP

Fornacíari, Isabela Aparecida

Investigaçठ̄es no campo da programaçăo semafórica /

Isabela Aparecida Fornaciari ; orientador Antonio Clóvis

Pinto Ferraz. -- såo Carlos, 2010.

Dissertação (Mestrado-Programa de Pós-Graduação em Engenharia de Transportes e Área de Concentração em Planejamento e operaçōes do Sistema de Transportes) -Escola de Engenharia de Săo Carlos da Universidade de São Paulo, 2010.

1. Engenharia de tráfico. 2. Semáforos. 3. Pedestres. 4. Tempo de travessia. 5. Simulação. Integration. 6. corsin. I. Titulo. 
Candidato(a): Tecnólogo ISABELA APARECIDA FORNACIARI.

Dissertação defendida e julgada em 29.10.2010 perante a Comissão Julgadora:

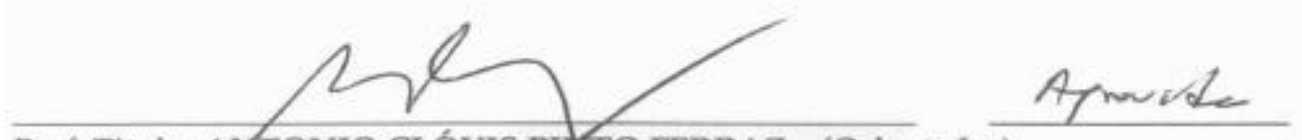

Prof. Titular AXTONIO CLÓVIS PIXTO FERRAZ - (Orientador)

(Escola de Engenharia de São Carlos/USP)

Hanfor

Prof?. Dr'. MARIA TERE\$A FRANÇOSO

(Universidade Estadual de Campinas/UNICAMP)
Aprovada

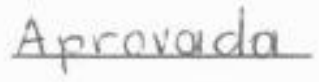

Prof. Associada LUZENIRA ALVES BRASILEIRO

(Universidade Estadual Paulista "Julio de Mesquita Filho"/UNESP/Campus de llha Solteira)
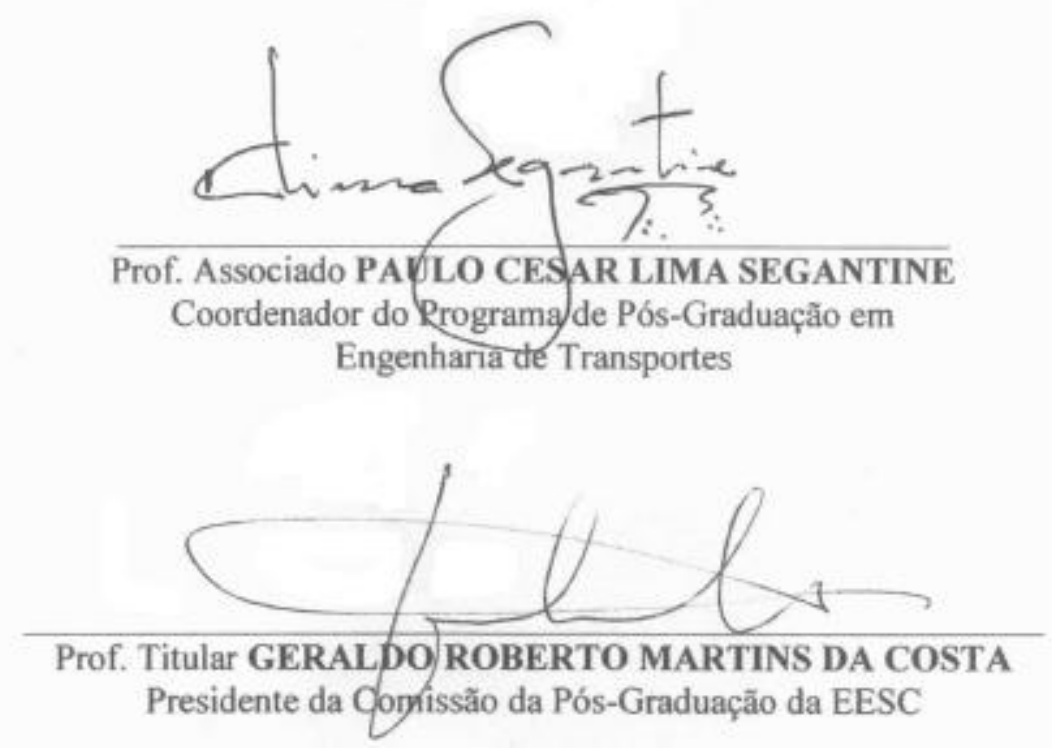
"Dedico essa dissertação a todos os professores que contribuíram para minha formação. $E$ a todos que acreditaram em mim." 



\section{AGRADECIMENTOS}

Agradeço primeiramente ao professor Coca.

De maneira especial a Barbara que tanto me ouviu, me aconselhou nos momentos de dúvidas e ansiedades.

Aos meus pais e minhas irmãs Gabriela e Daniela que de maneira direta ou indireta me ajudaram nesse longo processo.

Agradeço especialmente ao Cassiano pela paciência, ajuda e amizade nesses anos.

Aos amigos de NEST que me farão muita falta: Luciana, Tiago e Candido e as amigas Monique e Madalena pelo incentivo, paciência e compreensão.

E a todos os amigos que fiz aqui e tenho certeza que ficaram para sempre no meu coração. 



\section{RESUMO}

FORNACIARI, I. A. Investigações no campo da programação semafórica. 2010. 131f. Dissertação (Mestrado) - Escola de Engenharia de São Carlos, Universidade de São Paulo, São Carlos, 2010.

Neste trabalho são investigados alguns aspectos relacionados com a programação de tempos de semáforos isolados. A seguir são comentados os principais resultados obtidos. Os valores obtidos na cidade de São Carlos são os seguintes: tempo médio total (no início e no final) perdido no verde mais amarelo por fase veicular nos semáforos igual a 3,12s (interseção em nível e fluxo sem conversão); velocidade média dos pedestres na travessia em semáforos igual a $1,28 \mathrm{~m} / \mathrm{s}$ e velocidade correspondente ao 85 percentil igual a $1,00 \mathrm{~m} / \mathrm{s}$. Com exceção de alguns casos especiais, os valores do atraso fornecidos pelos métodos: Webster, HCM-2000, Simulador Integration e Simulador Corsim são da mesma magnitude e, portanto, perfeitamente viáveis de serem utilizados nos estudos práticos. Na determinação dos tempos que compõem a fase destinada à travessia de pedestres em semáforos, os métodos Ferraz e MUTCD são mais indicados que os métodos Webster/Denatran e CET-SP, uma vez que proporcionam adequada segurança sem "assustar" os pedestres e com o mínimo de prejuízo à capacidade do fluxo veicular. O emprego de fase exclusiva para pedestres em semáforos com duas fases veiculares leva aos seguintes acréscimos aproximados nos valores do atraso médio dos veículos: $40 \%$ para fluxos veiculares até $1000 \mathrm{v} / \mathrm{h}, 25 \%$ para fluxos veiculares da ordem de 1100 $\mathrm{v} / \mathrm{h}$ e $20 \%$ para fluxos veiculares da ordem de $1200 \mathrm{v} / \mathrm{h}$.

Palavras-Chaves: Semáforos, Pedestres, Tempo de travessia, Simulação, Integration, Corsim. 



\begin{abstract}
FORNACIARI, I. A. Research on the signal programming field. 2010. $131 \mathrm{f}$. Dissertação (Mestrado) - Escola de Engenharia de São Carlos, Universidade de São Paulo, São Carlos, 2010.

In this research some aspects related to time programming of single traffic lights are investigated. The main results are commented as follows. The values obtained in the city of São Carlos are: total average lost time (in the beginning and in the end) in the green and yellow phases in each vehicular signal phase equal to 3.12s (level intersection and flow without conversion), pedestrians average speed on the traffic lights crossing equal to $1.28 \mathrm{~m} / \mathrm{s}$ and speed corresponding to the $85^{\circ}$ percentile equal to $1.00 \mathrm{~m} / \mathrm{s}$. Except for some special cases, the values of the delay provided by the Webster, HCM-2000, Simulator Integration and Simulator Corsim methods are of the same magnitude and, therefore, they are perfectly feasible to use in practical studies.In determining the periods of the pedestrian crossing stage for the traffic signals, the Ferraz and MUTCD methods are more indicated than the Webster/Denatran and CET-SP methods, since they provide appropriate safety without "scaring" the pedestrians and with minimal damage to the vehicular flow capacity. The use of exclusive pedestrian phase at two vehicular stage signals leads to the following approximate increases in the values of the vehicles average delay: $40 \%$ to vehicle flow up to $1000 \mathrm{v} / \mathrm{h}, 25 \%$ for vehicle flow about $1100 \mathrm{v} / \mathrm{h}$, and $20 \%$ for vehicle flow about $1200 \mathrm{v} / \mathrm{h}$. In this research some aspects related to time programming of single traffic lights are investigated
\end{abstract}

Keyword: Traffic lights, Pedestrians, Crossing time, Simulation, Integration, Corsim. 



\section{SUMÁRIO}

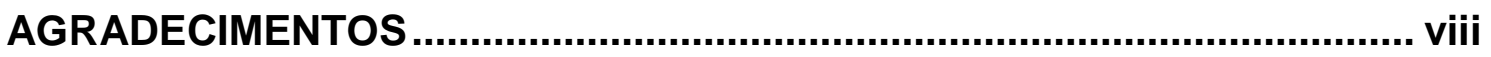

RESUMO

ABSTRACT............................................................................................... xii

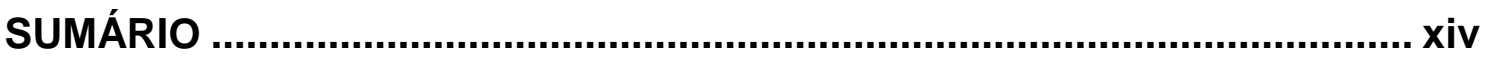

ÍNDICE DE FIGURAS ....................................................................... xviii

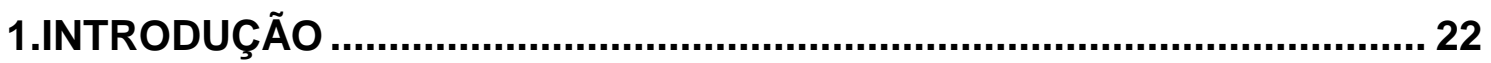

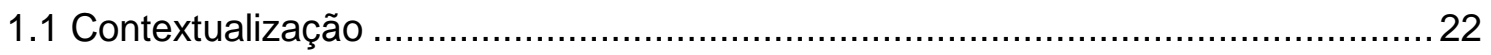

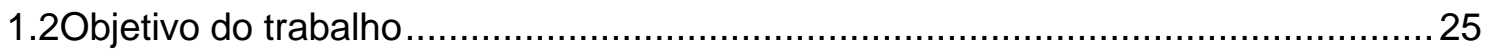

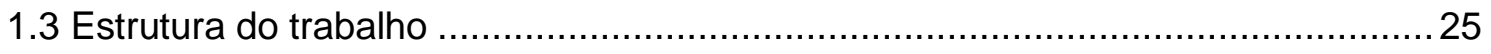

2. FUNDAMENTOS SOBRE SEMÁFOROS................................................ 28

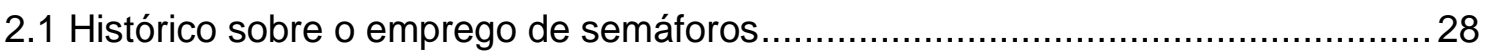

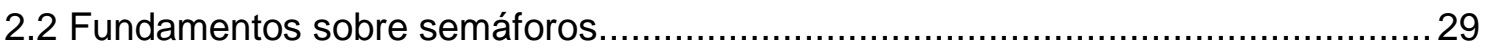

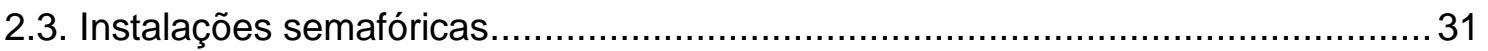

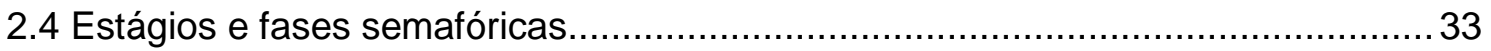

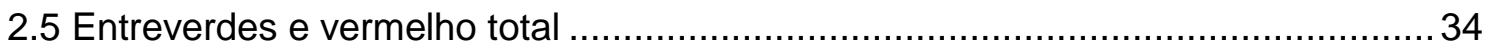

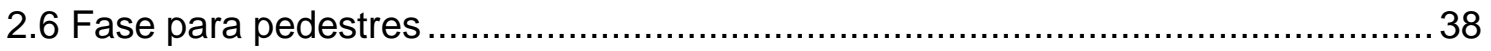

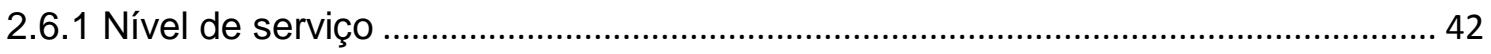

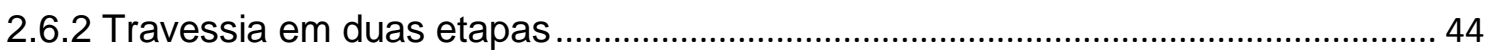

2.6.3 Estágio de pedestres demandado por botoeiras ................................................... 45

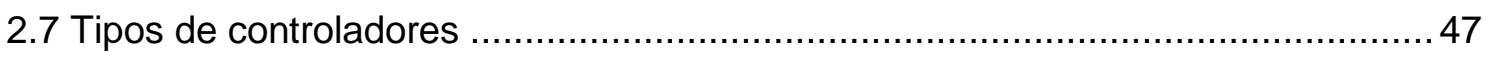

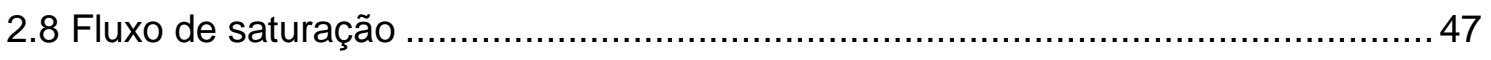

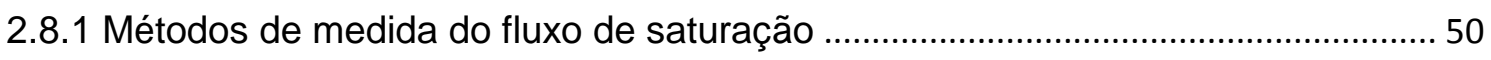

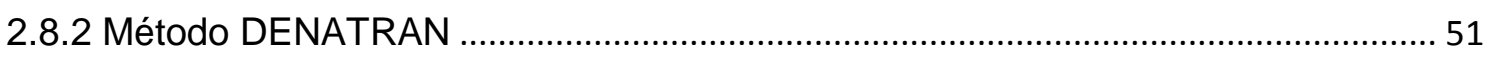

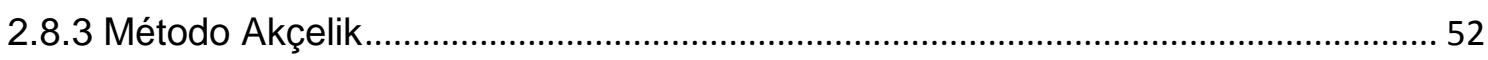

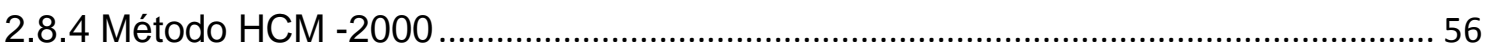

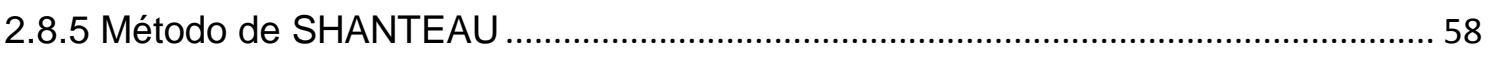

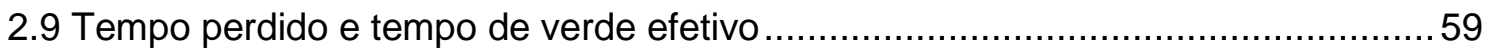

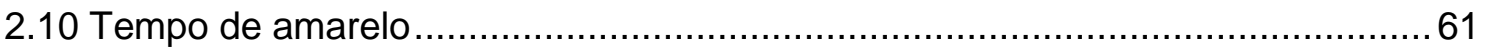

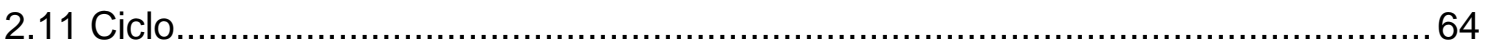

2.12 Parâmetros de desempenho em semáforos isolados......................................69

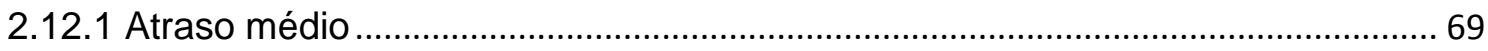




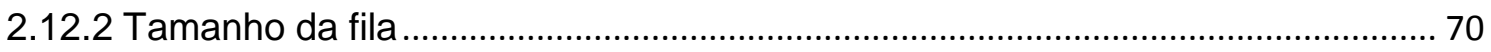

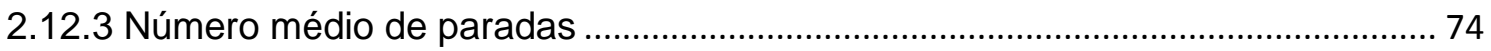

2.12.4 Proporção de veículos que param pelo menos uma vez ...................................... 74

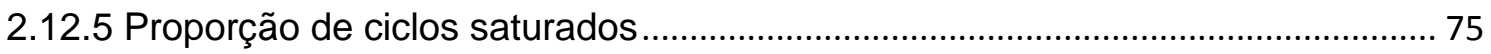

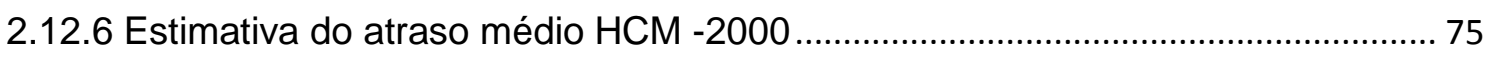

2.12.7 Nível de serviço para cruzamentos semaforizados ............................................... 79

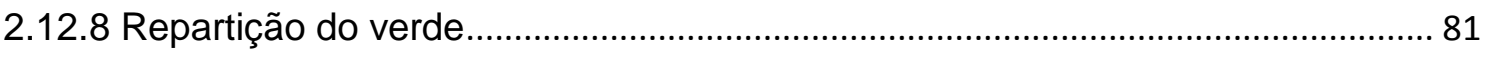

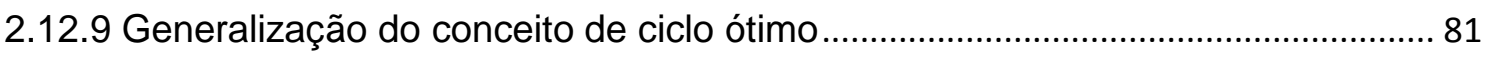

3. SIMULADORES DE TRÁFEGO .......................................................... 86

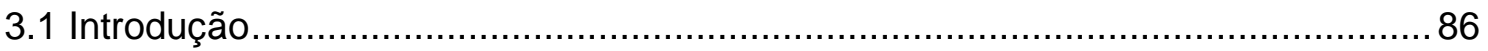

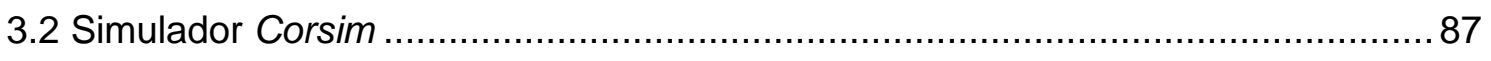

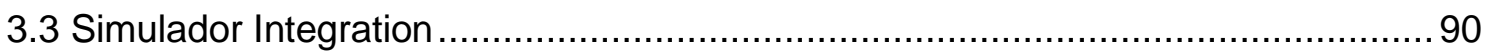

4.RESULTADOS E ANÁLISES DAS PESQUISAS DE CAMPO...................... 94

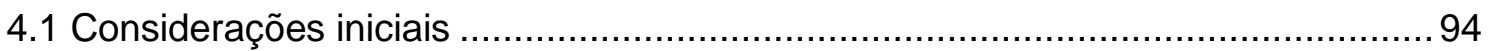

4.2 Tempo perdido no início da fase e fluxo de saturação .........................................94

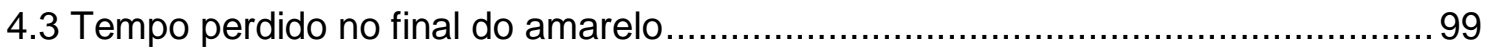

4.4 Tempo total perdido por fase e fluxo de saturação................................................ 99

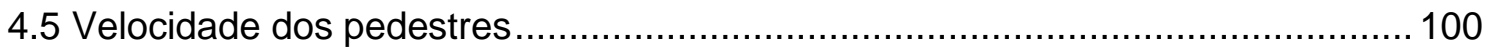

5.ANÁLISE DOS RESULTADOS DO ATRASO FORNECIDOS POR

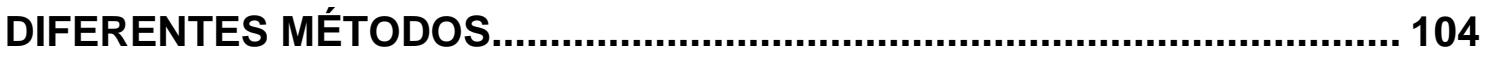

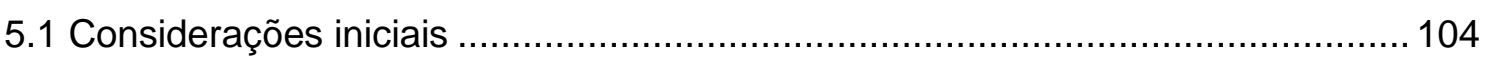

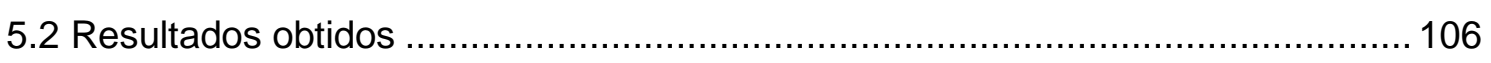

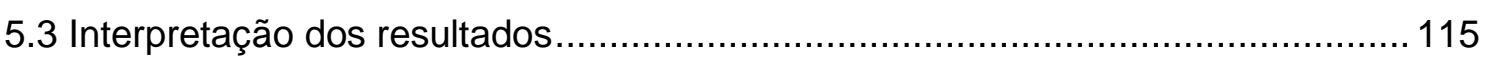

6.DETERMINAÇÃO DOS TEMPOS DA FASE PARA A TRAVESSIA DE PEDESTRES....................................................................................... 116

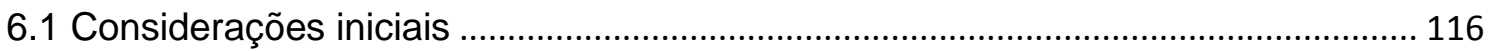

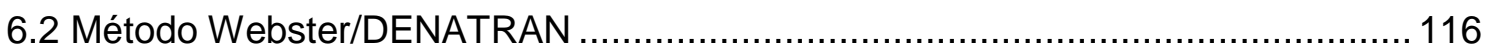

6.3 Método CET-SP ..................................................................................... 117

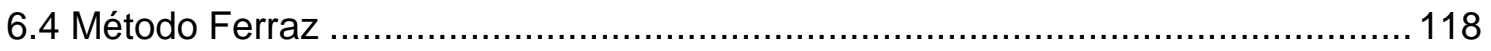

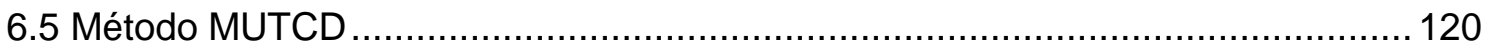

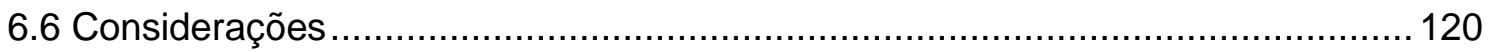

7.CENÁRIOS SIMULADOS E ANÁLISE DOS RESULTADOS OBTIDOS ... 124

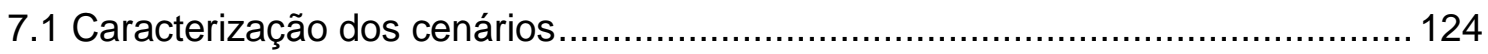

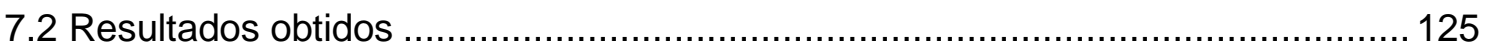


8. CONCLUSÕES

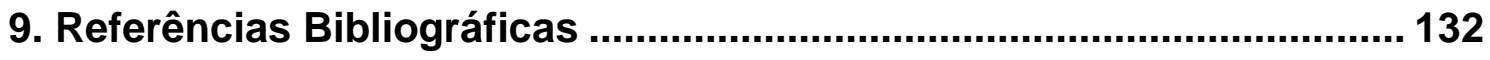





\section{ÍNDICE DE FIGURAS}

Figura 2. 1 - Conceito de vermelho total e entreverdes. ........................................ 35

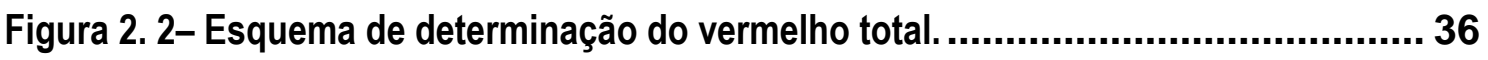

Figura 2. 3- Semáforo de fase para pedestres com informador de tempo - Florianópolis -

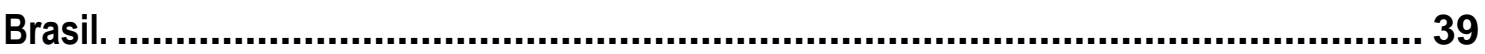

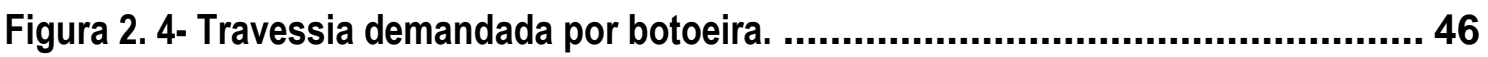

Figura 2. 5- Representação gráfica do fluxo de saturação. ..................................... 50

Figura 2. 6- Histograma de descarga de fila- DENATRAN. ...................................... 52

Figura 2. 7- Formulário de contagem de fluxo de saturação...................................... 54

Figura 2. 8- Gráfico proposto por Shanteau (1988). .............................................. 59

Figura 2. 9- Representação do ciclo ótimo segundo Webster.................................. 68

Figura 2. 10- Proporção de ciclos saturados, com base em Webster e Cobbe (1966). ..... 75

Figura 2. 11- Variação típica dos principais parâmetros em função do ciclo.................. 82

Figura 3. 1 - Representação gráfica de um cruzamento semáforizado simulado

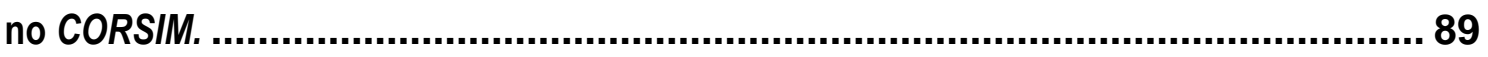

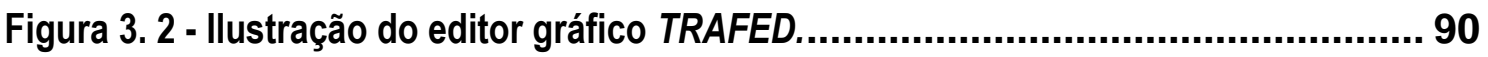

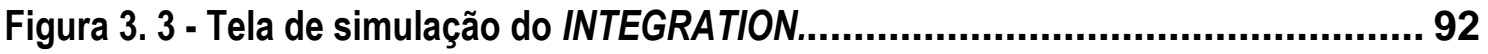

Figura 4. 1 - Headways numa fila de veículos num semáforo................................... 94

Figura 4.2 - Distribuição da velocidade dos pedestres....................................... 102

Figura 5.1 - Croqui da interseção estudada.................................................... 104

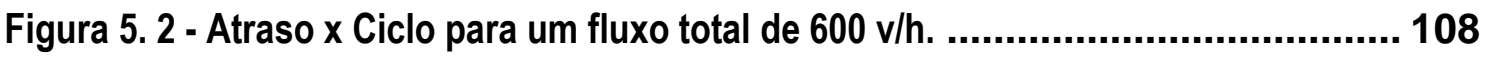

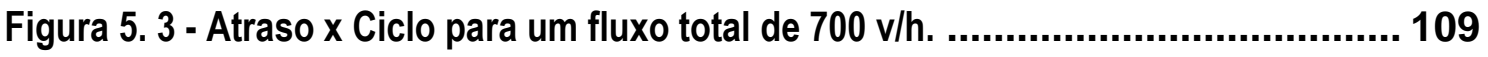

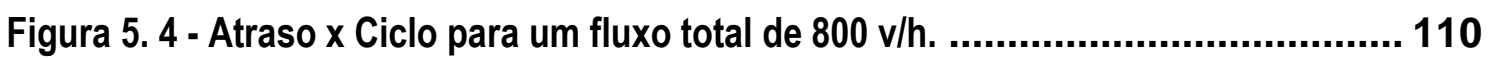

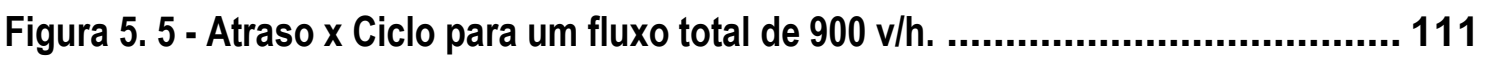




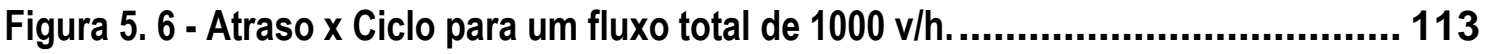

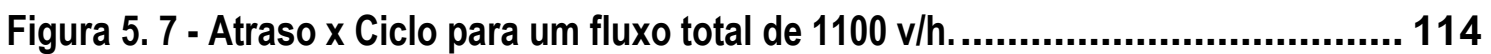

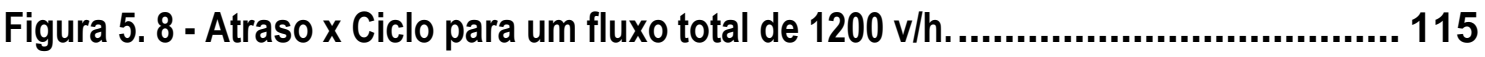

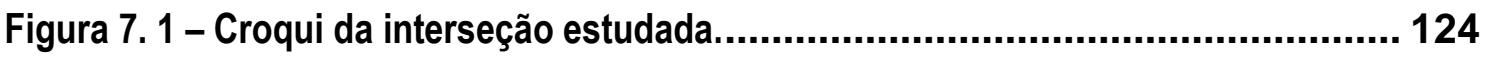

Figura 7.2 - Curvas de ciclo ótimo x Fluxo de veículos. ....................................... 127

Figura 7. 3 - Curvas de ciclo ótimo x Fluxo de veículos.......................................... 127

Figura 7. 4 - Variação do ciclo ótimo em função do fluxo de veículos........................ 129 


\section{ÍNDICE DE TABELAS}

Tabela 2. 1- Critérios para a instalação de semáforos para pedestres. ...................... 40

Tabela 2. 2 - Valores associados aos níveis de serviço nos três métodos. ................... 44

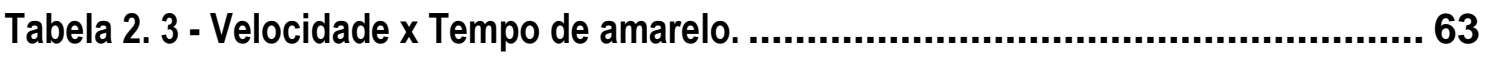

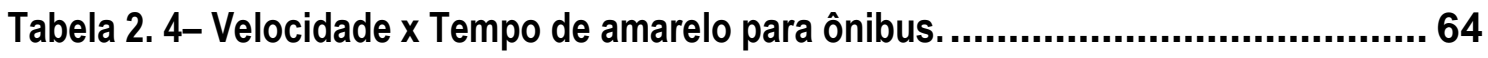

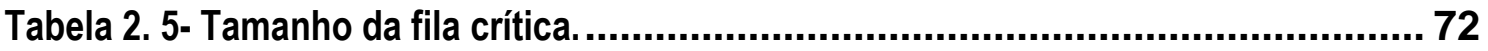

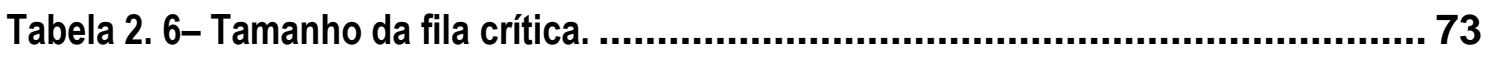

Tabela 2. 7- Características dos tipos de chegada dos veículos. ............................... 76

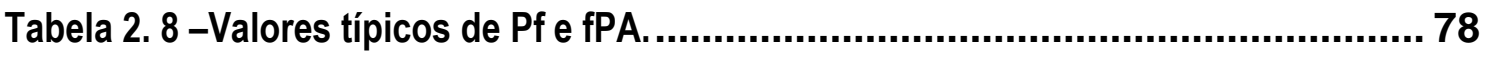

Tabela 2. 9 - Valores de I em função dos valores de x do fluxo que segue em frente relativo

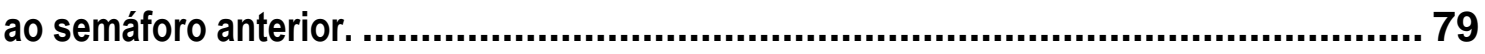

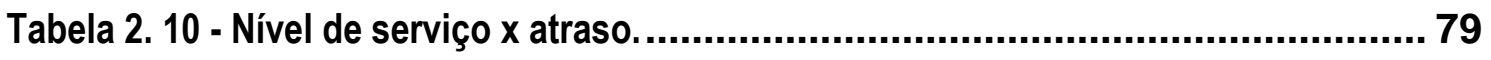

Tabela 2. 11- Nível de serviço $x$ tempo parado. ................................................ 80

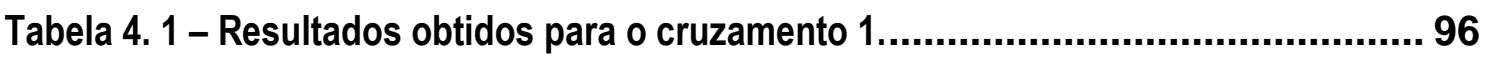

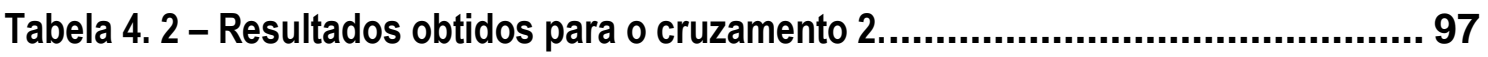

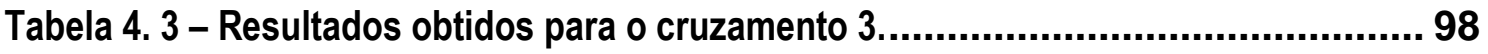

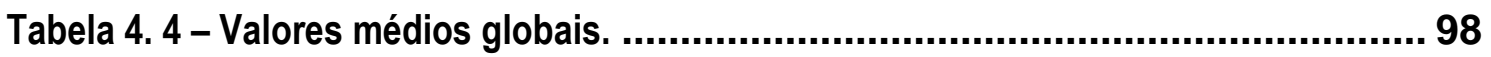

Tabela 4. 5 - Instante de passagem após o aparecimento da luz amarela e

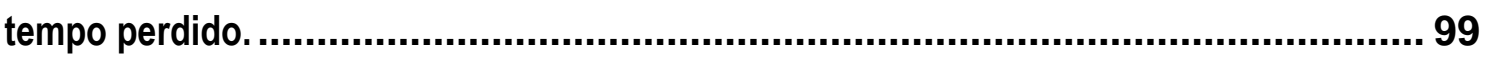

Tabela 4. 6 - Distribuição da velocidade em função da quantidade de pedestres. ......... 101

Tabela 5. 1- Valores da capacidade em função do tempo de ciclo do semáforo............ 106

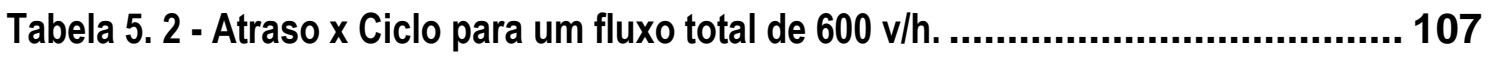

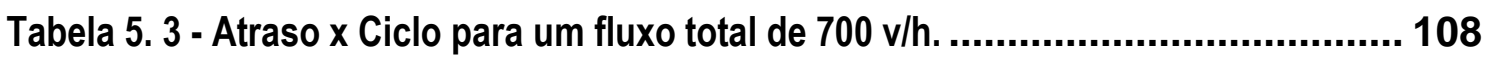

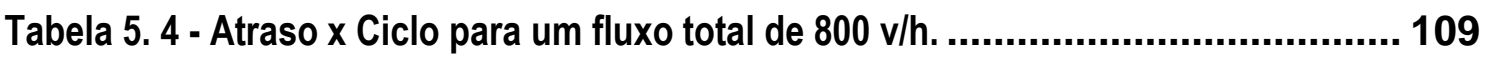

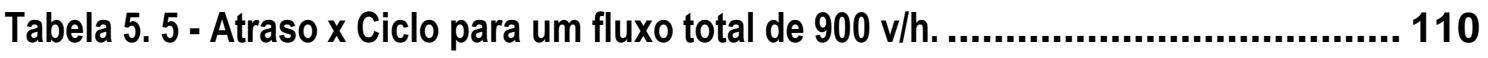


Tabela 5. 6 - Atraso x Ciclo para um fluxo total de $1000 \mathrm{v} / \mathrm{h}$.

Tabela 5. 7 - Atraso x Ciclo para um fluxo total de $1100 \mathrm{v} / \mathrm{h}$.

Tabela 5.8 - Atraso x Ciclo para um fluxo total de $1200 \mathrm{v} / \mathrm{h}$.

Tabela 6. 1 - Tempo de vermelho piscante, segundo CET 118

Tabela 6.2 - Velocidade mínima nos dois métodos. 122

Tabela 6. 3 - Duração das indicações luminosas que compõe a fase de pedestre. 123

Tabela 7. 1 - Ciclo $\mathrm{x}$ atraso com fase de pedestres. 126

Tabela 7.2 - Ciclo $\mathrm{x}$ atraso sem fase de pedestres. 126

Tabela 7.3 - Valores do ciclo ótimo e faixa de valores do ciclo para uso na prática. .... 128 


\section{INTRODUCÃ̃O}

\subsection{Contextualização}

O sistema viário e rodoviário é composto de vias com fluxo contínuo e de vias com fluxo interrompido.

O fluxo contínuo é caracterizado pela ausência de impedimentos externos a corrente de tráfego como sinais de parada obrigatória e semáforos; o tráfego flui livre sendo interrompido apenas por acidentes, manobras e/ou excesso de veículos em relação à capacidade.

As vias com fluxo interrompido são caracterizadas pela presença de impedimentos externos à corrente de tráfego como sinais de parada obrigatória, dê a preferência ou semáforos; condições que tornam obrigatória a parada por parte dos veículos nas interseções.

Nas interseções com um volume pequeno de veículos e pedestres, a operação é realizada com uma das vias como preferencial, isto é, com prioridade de passagem mediante o emprego de sinal de parada obrigatória ou dê a preferência. Para fluxos maiores é indicado o emprego de semáforos visando, sobretudo, reduzir o atraso (tempo perdido) por veículos e/ou pedestres na interseção.

A alternância do direito de passagem nas interseções em nível com um significativo volume de tráfego de veículos e/ ou pedestres por intermédio de sinais luminosos (semáforos) é uma importante alternativa de controle de 
tráfego. Pesquisas indicam que cerca de $50 \%$ dos tempos de viagem nas grandes cidades e $30 \%$ do consumo de gasolina são gastos nos semáforos, esperando que o sinal passe do período de vermelho para o verde (DENATRAN, 1979).

O controle semaforizado em interseções viárias surgiu devido à necessidade de se alternar o direito de passagem para diferentes fluxos de tráfego de forma a melhorar a fluidez e as condições de segurança em locais nos quais o volume de veículos e/ou de pedestres se tornaram significativamente grandes (CAMPOS, 2005, apud PORTO JUNIOR, 2008).

Considerando os aspectos segurança, atraso (tempo perdido), número de paradas, consumo de combustível e emissão de poluentes, os semáforos devem ser implantados em interseções com volume de tráfego acima de certos valores, como, por exemplo, aqueles estabelecidos no Manual Americano MUTCD-2003 (Manual on Uniform Traffic Control Devices), no Manual do DENATRAN, nas normas da CET-SP, etc.

Antes da implantação de semáforos os técnicos devem analisar critérios como: melhoria das sinalizações horizontais e verticais, remoção de interferências que prejudiquem a visibilidade da sinalização existente, melhoria na iluminação das vias, controle das velocidades nas aproximações e etc. Essas medidas podem resolver os problemas de congestionamento nas vias nos horários de pico e reduzir o número de acidentes sem a necessidade da implantação de semáforo (DENATRAN, 1979). 
Semáforos instalados em locais sem necessidade e, ou inadequados quase sempre ocasionam problemas como:

- Aumento da espera e do número de paradas;

- Aumento da frequência de acidentes;

- Aumento das violações das leis de trânsito;

- Redução da capacidade.

Uma gestão adequada do sistema de semáforos é uma forma de melhorar a fluidez e a segurança do trânsito.

Os programas semafóricos (número e disposição das fases e duração dos tempos) em sistemas de tempo fixo são estabelecidos com base em dados históricos de fluxo de tráfego, e com mudanças na programação conforme o período do dia e o dia da semana.

Nos semáforos atuados pelo tráfego, em que os fluxos de veículos são medidos em tempo real (on line) por intermédio de detectores apropriados, a duração dos tempos do semáforo pode ser alterada dentro de pequenos períodos.

Neste trabalho, são investigadas algumas questões específicas relacionadas com a programação semafórica. 


\subsection{Objetivo do trabalho}

Este trabalho tem os seguintes objetivos principais:

1. Determinar, mediante pesquisas de campo os parâmetros básicos para o dimensionamento de programações semafóricas na cidade de São Carlos. As seguintes grandezas foram investigadas: tempo perdido, fluxo de saturação e velocidade da travessia de pedestres.

2. Analisar a compatibilidade dos resultados dos atrasos experimentados em semáforos isolados de tempo fixo de 2 fases fornecidos pelos seguintes métodos: HCM 2000 (Highway Capacity Manual), Webster, Simulador Integration e Simulador Corsim.

3. Analisar os métodos utilizados no dimensionamento da fase destinada à travessia de pedestres em semáforos e concluir qual o mais adequado.

4. Definir as faixas de valores do tempo de ciclo indicadas para diferentes valores do fluxo de veículos, utilizando o Simulador Integration, para semáforos com 2 fases veiculares, sem e com fase exclusiva para pedestres (neste caso, portanto, com 3 fases).

\subsection{Estrutura do trabalho}

O trabalho encontra-se dividido em 9 capítulos, cujos conteúdos são sintetizados a seguir.

O Capítulo 1 apresenta a introdução ao tema, os objetivos do trabalho e a estruturação da dissertação.

Os Capítulos 2 e 3 contém uma breve revisão bibliográfica sobre o tema semáforos e sobre simuladores de tráfego, respectivamente. 
No Capítulo 4 são descritas as pesquisas feitas no campo e apresentados os resultados obtidos.

No capítulo 5 são comparados os valores dos atrasos obtidos em diferentes métodos e discutida a compatibilidade dos resultados.

No capítulo 6 são apresentados os quatro métodos utilizados na definição da fase destinada à travessia de pedestres em interseções semaforizadas e indicado o mais adequado.

No capítulo 7 são apresentados os resultados do simulador Integration comparando a operação com 2 fases veiculares e com 3 fases, sendo duas veiculares e uma fase exclusiva para pedestres, para os mesmos volumes veiculares. Também são indicados os valores de ciclo ótimo e a faixa de valores indicada na prática para cada situação.

No capítulo 8 são apresentadas as considerações finais do trabalho.

O capítulo 9 contém as referências bibliográficas. 



\section{FUNDAMENTOS SOBRE SEMÁFOROS}

\subsection{Histórico sobre o emprego de semáforos}

Em 10 de Dezembro de 1868, foi implantado o primeiro semáforo em Westminster, Londres. Concebido por J. P. Knight, engenheiro especialista em assuntos ferroviários, esse semáforo tinha dois braços móveis que eram acionados movendo cabos a partir de uma torre. O sistema era parecido com o dos sinais que regulavam o trânsito ferroviário e tinha duas lâmpadas de gás com uma luz vermelha e outra verde. Não teve existência longa, uma vez que em 2 de Janeiro de 1869, por causa de um acidente, explodiu provocando a morte de um agente policial.

Esse acidente causou a estagnação de experimentos desse tipo por quase meio século,somente no início do século XX,em Cleveland nos Estados Unidos, um outro semáforo foi implantado. As evoluções nos métodos de controle do tráfego por semáforos evoluíram de sistemas operados manualmente para semáforos automáticos com tempo fixo.

No início da década de 1930, houve uma primeira tentativa de implantação de um semáforo atuado pelo tráfego nos Estados Unidos. Foram instalados microfones ao lado da rua onde os motoristas deveriam buzinar. Porém, muitas objeções foram feitas a esse sistema, e um método que utilizava contatos elétricos colocados nos trajetos dos veículos foi tentado posteriormente. Esse 
sistema utilizava tubos pneumáticos com a passagem dos veículos deslocando o ar pelo tubo que acionava um contato elétrico situado em um compartimento ao lado da rua.

O primeiro sinal atuado por veículos foi implantado na Grã-Bretanha em 1932, no cruzamento das ruas Gracechurch e Cornhill, em Londres. Infelizmente, a história se repetiu, pois quando os sinais foram colocados em funcionamento houve uma explosão devido à infiltração de gás para o gabinete do controlador. Apesar desse infeliz incidente os sinais atuados por veículos logo se tornaram realidade e três anos depois do primeiro sistema interligado, um sistema constituído inteiramente por sinais atuados por veículos foi instalado em Londres e Glasgow (WEBSTER e COBBE, 1966).

\subsection{Fundamentos sobre semáforos}

Semáforos são dispositivos reguladores do trânsito urbano, acionados por meio de corrente elétrica, executando luzes intermitentes por meio das quais o trânsito é orientado. É um dispositivo útil para o controle e segurança tanto de veículos como de pedestres. Portanto, a verificação do funcionamento de semáforos é de extrema importância, não somente para a instalação individual, como também para a escolha dos equipamentos e dos planos de funcionamento dos mesmos (DNER, 1971).

A sinalização semafórica faz parte do sistema de sinalização viária e é composto de indicações luminosas que podem ser alternadas ou intermitentes, 
acionadas por sistemas elétricos/eletrônicos, cuja função é controlar os cruzamentos. De acordo com Brasil (2008), são divididos em 2 grupos:

- Sinalização semafórica de regulamentação;

- Sinalização semafórica de advertência.

Os semáforos de tempo fixo são utilizados em interseções onde os padrões de trânsito são relativamente estáveis e as variações de fluxo podem se adaptar aos programas previstos, sem ocasionar demoras ou congestionamentos excessivos. As principais vantagens dos semáforos fixos são:

- Facilitar a coordenação com semáforos adjacentes, com mais precisão que os semáforos atuados pelo tráfego;

- Não depender dos detectores de tráfego.

Em geral, o custo dos equipamentos de controle de semáforos de tempo fixo é menor que de controladores de semáforos atuados pelo tráfego (SPÍNDOLA e GRISALES, 1995).

A sinalização semafórica de regulamentação tem a função de efetuar o controle do trânsito numa interseção ou seção de via, através de indicações luminosas, alternando o direito de passagem dos fluxos de veículos e pedestres. As indicações luminosas são compostas de cores preestabelecidas agrupadas num único conjunto, podendo ser dispostas verticalmente ou horizontalmente.

Para controle de fluxo de pedestres são utilizadas duas indicações luminosas de forma quadrada vermelha e verde: a luz de cor vermelha indica que os pedestres não podem atravessar; a luz vermelha piscante indica que a fase durante a qual os pedestres podem atravessar está acabando e que os 
pedestres que ainda não iniciaram a travessia não comecem a cruzar a via e os que estão atravessando terminem o mais rápido possível; e o foco verde indica que os pedestres podem atravessar.

Para o controle de fluxos de veículos são utilizadas três indicações luminosas com foco de forma circular nas cores vermelha, amarela e verde, sendo que o foco de cor vermelha indica a obrigatoriedade de o veículo parar; o foco de cor amarela indica que o condutor deve ter "atenção", ou seja, o condutor deverá parar o veículo com segurança na faixa de retenção ou passar com comodidade e segurança; e o foco na cor verde indica a permissão de prosseguir (BRASIL, 2008).

A sinalização semafórica de advertência tem a função de advertir a existência de obstáculos ou situações perigosas, devendo o condutor reduzir a velocidade, aumentar a atenção e adotar medidas de precaução compatíveis com a segurança. O foco da sinalização de emergência é de formato circular com uma ou duas luzes de cor amarela que podem ter o funcionamento intermitente ou piscante alternado. O uso do foco em amarelo piscante em alguns horários do dia é admitido em situações específicas, como por exemplo,

na tentativa de diminuir a violência nos semáforos durante a madrugada (BRASIL, 2008).

\subsection{Instalações semafóricas}

A instalação de um semáforo deve ser bem analisada, uma vez que existem vantagens e desvantagens agregadas ao seu uso. 
Os semáforos nem sempre reduzem os atrasos e melhoram a segurança da via, como normalmente costuma-se pensar; mesmo quando instalados adequadamente há um aumento no número de colisões traseiras em alguns casos, além disso, a instalação de semáforos pode reduzir a capacidade da interseção e aumentar o atraso (SETTI, 2002).

As vantagens de se implantar adequadamente um semáforo são:

- Reduzir a frequência de determinados tipos de acidentes, especialmente as colisões transversais;

- Proporcionar fluidez e ordem ao tráfego de veículos nas interseções;

- Possibilitar o fluxo contínuo de pelotões em vias arteriais, através da operação de semáforos coordenados;

- Permitir que veículos e pedestres atravessem com segurança correntes de tráfego pesadas ou vias largas; e

- Controlar o trânsito de uma forma mais eficiente.

A implantação de semáforos em locais desnecessários ou semáforos mal projetados podem acarretar problemas como:

- Aumento na frequência de acidentes;

- Atrasos excessivos o que aumenta os efeitos da poluição causada pelos veículos parados e;

- Incentivo ao desrespeito à sinalização.

De acordo com a FHWA (2003), são estabelecidos oito critérios principais para a instalação de semáforos:

1. Volume de veículos nas 8 principais horas do dia; 
2. Volume de veículos nas 4 horas mais congestionadas do dia;

3. Fator de hora pico;

4. Volume de pedestres;

5. Travessia de escolares;

6. Semáforos coordenados;

7. Histórico de acidentes;

8. Rede viária.

Webster e Cobbe (1966) apontam 3 objetivos básicos para a implantação de semáforos: reduzir os conflitos e atrasos, reduzir os acidentes e economizar tempo. No Brasil, há os critérios desenvolvidos pelo DENATRAN (1979), CONASET (2005) e CET - SP (1998).

\subsection{Estágios e fases semafóricas}

Estágio designa cada uma das diferentes configurações de movimentos nos cruzamentos semaforizados, durante um estágio a indicação luminosa de todos os grupos focais não se altera. Sempre que houver mudança de indicação luminosa interrompendo um ou mais fluxos para permitir o movimento de outros fluxos que estavam interrompidos, passa-se de um estágio para outro.

O termo fase é utilizado para designar cada uma das diferentes configurações de movimentos onde pelo menos um dos fluxos continua em movimento, ainda que um ou mais fluxos sejam interrompidos para permitir o movimento de outro ou outros fluxos que estavam interrompidos. 
As várias configurações distintas dentro de uma mesma fase são denominadas de subfases. Assim, as subfases coincidem com os estágios (BEZERRA, 2007).

\subsection{Entreverdes e vermelho total}

Entreverdes é o período entre o fim do verde de uma fase e o início de verde de outra fase; o tempo de entreverdes é o tempo de amarelo mais o tempo de vermelho geral, como mostrado na equação abaixo e na Figura 2.1.

$$
I=Y+R_{t}
$$

Sendo:

I: Duração do entreverdes, em segundos;

$Y$ : Duração do amarelo, em segundos;

$R_{t}$ : Duração do vermelho total, em segundos.

Denomina-se vermelho total (global) o intervalo de tempo em que a indicação é feita simultaneamente para a fase veicular que está terminando e a que está se iniciando. Esse tempo é utilizado para promover a "limpeza da caixa", ou seja, a saída dos veículos que entraram no cruzamento no final do amarelo e ainda não terminaram a travessia. 


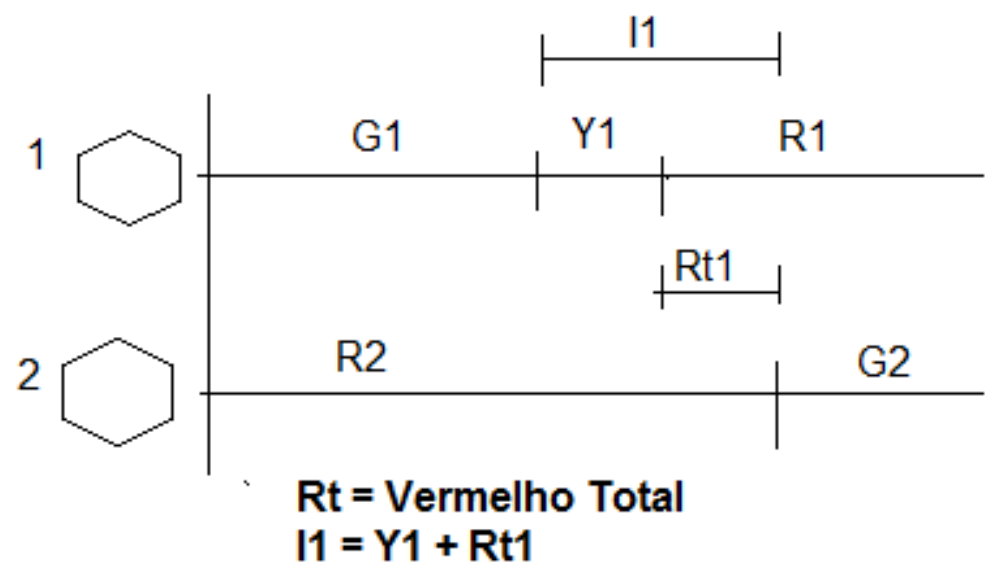

Figura 2. 1 - Conceito de vermelho total e entreverdes.

Fonte: Bezerra (2007).

Vermelho total é um período de curta duração onde todos os grupos focais da interseção ficam entre 1 a 2 segundos no estágio de foco vermelho. O período de vermelho geral é comumente usado para dar uma maior segurança na fluidez dos veículos no cruzamento. A duração do tempo de vermelho de limpeza não poderá exceder 6 segundos (FWHA, 2008).

O intervalo de vermelho total é um tempo adicional que permite que os veículos que perderam o direito de passagem saiam e limpem a interseção antes que os veículos que receberam o direito de passagem, comecem a entrar na mesma. Esse tempo de vermelho total pode também ser usado para criar uma fase exclusiva para pedestres (SPÍNDOLA e GRISALES, 1995).

O tempo de vermelho total é o tempo necessário para que os veículos que estavam na situação mais crítica no tempo de amarelo e que optaram por cruzar a via, em vez de parar consigam passar pela área de conflito do cruzamento antes que os veículos da via transversal iniciarem a travessia. 
De acordo com a CET-SP (2002), o vermelho total deve ser calculado pela seguinte equação:

$$
T_{V t}=\frac{L+C}{v}
$$

Sendo:

$T_{V t}:$ Tempo de vermelho total (s);

$L:$ Largura da via transversal $(\mathrm{m})$.

$C$ : Comprimento do veiculo $(\mathrm{m})$.

$v:$ Velocidade do veículo $(\mathrm{m} / \mathrm{s})$

Para Ferraz (2005), o tempo de duração do vermelho total deve ser calculado de modo a permitir que o último veículo saia da área da interseção antes do sinal ficar verde para os fluxos conflitantes.

Conforme ilustrado na Figura 2.2, a duração do vermelho total, é calculada pela seguinte equação.

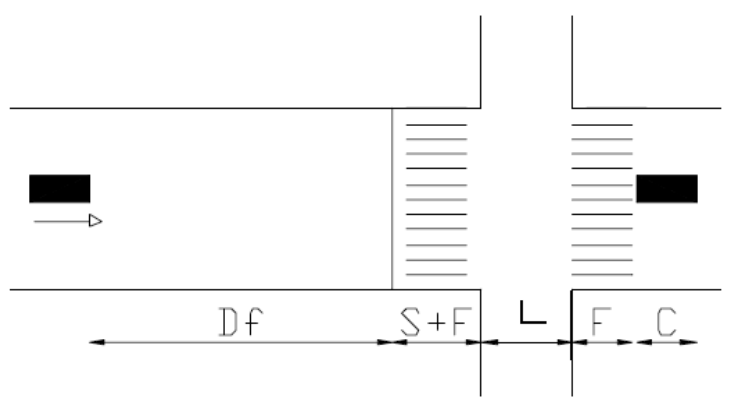

Figura 2. 2- Esquema de determinação do vermelho total. 


$$
\mathrm{Rt}=\frac{\mathrm{S}+2 \mathrm{~F}+\mathrm{L}+\mathrm{C}}{\mathrm{V}}
$$

Sendo:

Rt : Vermelho total em segundos;

$\mathrm{S}$ : Distância da linha de retenção até a faixa de pedestres em $\mathrm{m}$ (usualmente $1,40 \mathrm{~m})$

F : Largura da faixa de pedestres em $\mathrm{m}$ (usualmente igual a $4 \mathrm{~m}$ );

L : Largura da via a ser cruzada em m;

C : Comprimento do veículo em m (normalmente adotada igual a $6 \mathrm{~m}$ );

$\mathrm{V}$ : Velocidade de aproximação em $\mathrm{m} / \mathrm{s}$.

De acordo com Ferraz (2005), essa expressão não leva em conta que tanto veículos como pedestres não partem imediatamente após a luz ficar verde, em razão do tempo de percepção e reação.

Assim, a expressão abaixo é a preconizada por Ferraz (2005) a ser utilizada na determinação do vermelho total.

$$
\mathrm{Rt}=\frac{\mathrm{S}+2 \mathrm{~F}+\mathrm{L}+\mathrm{C}}{\mathrm{V}}-\mathrm{Tpr}
$$


Sendo:

Rt, S, F, L, C e V: Já definidos anteriormente;

Tpr : Tempo de percepção e reação (neste caso adotado igual a 1s).

\subsection{Fase para pedestres}

Existe uma distinção entre os dois tipos de tempos de travessias para pedestres: o de travessia em paralelo e o estágio exclusivo de pedestres. A travessia em paralelo é realizada quando se aproveita o tempo de verde veicular da via paralela ao seu movimento; é utilizado em interseções simples e de mão única. O estágio exclusivo para pedestres existe quando se cria na programação semafórica uma fase exclusiva para permitir as travessias, deve ser realizada sempre após a fase veicular da via principal e ser feita através de indicações focais executadas por grupos focais específicos.

A fase exclusiva para pedestres deve ser utilizada em interseções onde realmente há um grande fluxo de pedestres; essa fase foi originalmente desenvolvida pelo engenheiro de tráfego Henry Barnes na cidade de Nova York em 1960, na região de Manhattan por causa do grande fluxo de pedestres nessa área (ROESS, et al, 2004).

O semáforo com fase exclusiva para pedestres é composto por 2 focos de seção quadrada, os focos são das mesmas cores dos focos para veículos, porém alguns focos tem representações de bonecos em posições de movimentos. A Figura 2.3 mostra um semáforo com foco de fase exclusiva para 
pedestres, esses focos são de seção quadrada com figuras de bonecos em movimento, em alguns lugares há um contador de tempo em forma regressiva acima da figura do boneco verde que informa ao pedestre o tempo restante para a sua travessia. Esse método é interessante, pois o pedestre não precisa "correr" para atravessar a via, uma vez que ele é sempre informado se há muito ou pouco tempo para efetuá-la.

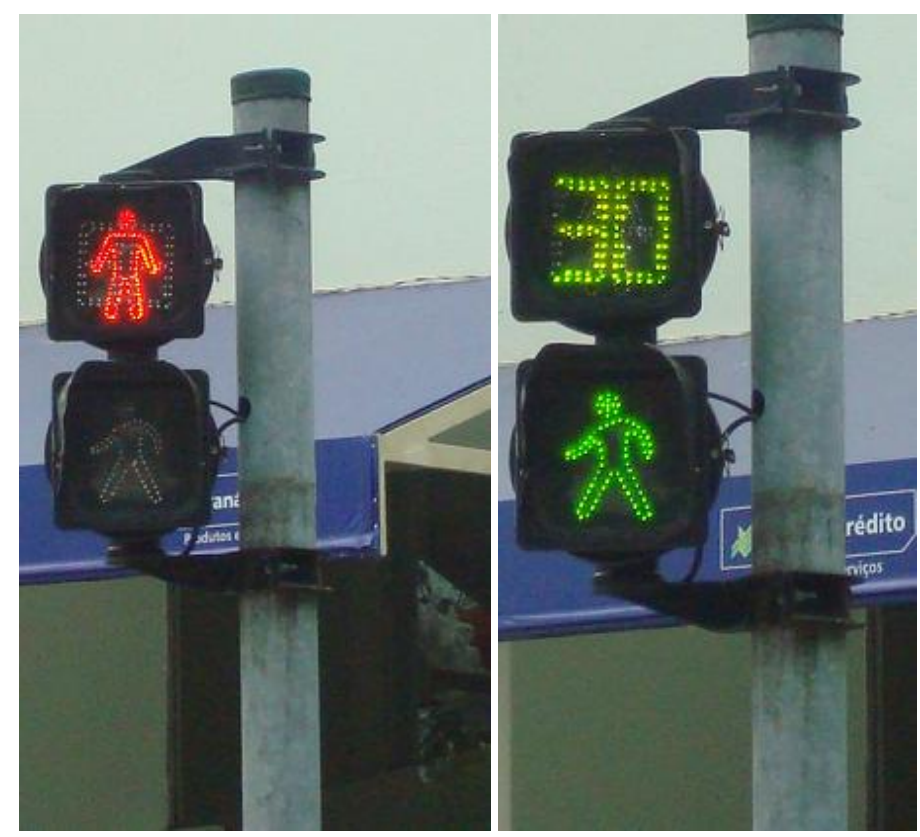

Figura 2. 3- Semáforo de fase para pedestres com informador de tempo - Florianópolis - Brasil.

A fase exclusiva para pedestres deve ser aplicada quando há um volume mínimo de pedestres para realizar a travessia na interseção. Os critérios para a instalação são um volume de 100 ped/h durante pelo menos quatro horas do dia ou igual e/ou maior do que a 190 ped/h durante a hora pico (FHWA, 2003).

Segundo o DENATRAN (1979), a instalação de semáforos para pedestres deve ser realizada quando a travessia de pedestres for acima de 250 pedestres por hora cruzando uma via com $600 \mathrm{v} / \mathrm{h}$ ou mais em ambos os sentidos. Existem 
algumas diferenças entre os critérios estabelecidos pelo MUTCD (2003) e pelo DENATRAN (1979); os quais podem ser vistos na Tabela 2.1 .

Tabela 2. 1- Critérios para a instalação de semáforos para pedestres.

\begin{tabular}{|c|c|c|c|}
\hline \multicolumn{2}{|c|}{ DENATRAN (1979) } & \multicolumn{2}{c|}{ MUTCD (2003) } \\
\hline $\begin{array}{c}\text { Volume de Veículos } \\
\text { nos 2 sentidos da Via } \\
\text { (v/h) }\end{array}$ & $\begin{array}{c}\text { Volume de Pedestres } \\
\text { em ambos os sentidos } \\
\text { da Via (ped/h) }\end{array}$ & $\begin{array}{c}\text { Volume de Pedestres na Via } \\
\text { Principal Durante pelo Menos }\end{array}$ & $\begin{array}{c}\text { Volume de Pedestres } \\
\text { na Hora Pico da Via }\end{array}$ \\
(ped/h)
\end{tabular}

A determinação da sequência de estágio específico para pedestres requer extrema cautela, pois uma escolha inadequada pode expor os pedestres a riscos.

O método correto para dimensionar o tempo de travessia dos pedestres em condições normais sem "corridinhas" e nem paradas no meio da travessia deve ser realizado com medições em campo em amostras representativas.

De acordo com a CET-SP (2002), em locais onde não for possível de serem realizadas medições satisfatórias é correto adotar uma velocidade média de $1,2 \mathrm{~m} / \mathrm{s}$ para o pedestre. Para a obtenção do tempo de verde basta dividir a largura em metros da via como mostrado na seguinte equação.

$$
T_{\text {ped }}=\frac{L}{1,20}[S]
$$


Sendo:

$T_{p e d}:$ Tempo destinado à travessia de pedestres (s);

L: Largura da interseção em metros.

Não existe consenso a respeito dos valores de velocidade dos pedestres. Webster e Cobbe (1966) adota o valor de $1,2 \mathrm{~m} / \mathrm{s}$, reduzindo esse valor no caso de travessias muito intensas e defende ainda um tempo predefinido de travessia entre 6 e 10 segundos dependendo do fluxo de pedestre na interseção e um período de 2 a 8 segundos de vermelho total para os veículos, em interseções que não possuam fase exclusiva para os pedestres.

Se a interseção possui um alto volume de pedestres, estes devem ser orientados a fazer a travessia juntos, ou seja, em pelotões. Entretanto, as velocidades dos pelotões são inferiores às velocidades livre dos pedestres. Densidade de 0,72 pedestres $/ \mathrm{m}^{2}$ impõe restrições à velocidade dos pedestres mais lentos. Densidades inferiores a 0,27 pedestres $/ \mathrm{m}^{2}$ garantem aos pedestres mais apressados e jovens caminhar a velocidades livres de 1,6m/s. A densidade critica de congestionamento de pedestres em passeio é de 4,3 pedestres $/ \mathrm{m}^{2}$ para a qual a velocidade é nula (TRB, 2000).

Para um correto dimensionamento da fase de pedestres em um semáforo, devem ser analisados parâmetros essenciais como nível de serviço, velocidade de caminhada, horários de pico, demanda, entre outros fatores que mal calculados possam comprometer a segurança dos pedestres durante a travessia. 
Antes da implantação de semáforo para travessia de pedestres deve se analisar a situação existente para essa travessia verificando se estão projetadas e colocadas corretamente as faixas de pedestres e as placas de orientação para travessia. A sinalização para a travessia segura de pedestres deve sempre ser clara tanto para os pedestres como para os condutores de veículos.

\subsubsection{Nível de serviço}

O nível de serviço é um parâmetro qualitativo, que retrata as condições de fluidez, segurança e conforto em um determinado espaço ocupado. O HCM 2000 define o nível de serviço com um critério baseado em medidas que podem sofrer algumas imprecisões, sobretudo de pedestres caminhando em passeios (calçadas). A velocidade é um importante critério na análise do nível de serviço, pois pode ser facilmente observada e medida.

São três as metodologias comumente usadas na Brasil: CET-SP (2002), DENATRAN (1979) e HCM (2000). As três são muita parecidas, diferindo somente em alguns valores muito pequenos entre um nível e outro.

As descrições para os níveis de serviço, de acordo com o HCM 2000 são:

- Nível A: existe espaço suficiente para permitir a escolha livre da velocidade e para ultrapassagem de outros pedestres. Não existem conflitos sérios com o fluxo de sentido oposto.

- Nível B: existe espaço suficiente para permitir a escolha da velocidade normal e para ultrapassar outros pedestres em fluxos unidirecionais. 
Onde existir fluxos em duas direções pode ocorrer pequenos conflitos com fluxo de sentido oposto e haver maior dificuldade em se locomover à velocidade normal.

- Nível C: restrição para escolha da velocidade individual e para ultrapassagem de outros pedestres. Existem $50 \%$ de probabilidade de haver conflitos com fluxos de sentido oposto. A velocidade e a direção dos pedestres devem frequentemente ser ajustadas.

- Nível D: a maioria das pessoas têm sua velocidade restringida e dificuldades na ultrapassagem de outros pedestres. Conflitos múltiplos com fluxo de sentido oposto.

- Nível E: todos os pedestres são obrigados frequentemente a modificar sua velocidade. Com área de ocupação próxima de $0,5 \mathrm{~m}^{2} /$ pessoa, os avanços são difíceis. O espaço disponível é insuficiente para permitir a ultrapassagem dos pedestres mais vagarosos, existem paradas e interrupções no fluxo.

- Nível F: Avanço difícil, velocidade bastante baixa, é impossível ao pedestre escolher sua velocidade, o contato físico é inevitável entre as pessoas e as ultrapassagens são quase impossíveis.

As diferenças entre as três metodologias são mais acentuadas nos níveis $B$ e C: para o HCM 2000 no nível B, a escolha de velocidade e a ultrapassagem de outros pedestres é livre e os fluxos cruzam sem conflitos. Para CET-SP (2002), os fluxos cruzando-se em condições médias são toleráveis. 
No nível C, a velocidade individual é sem restrições e o fluxo no sentido oposto ocorre com pequenos conflitos para o HCM 2000, enquanto que para a CETSP (2002) eles são numerosos, mas mesmo assim são toleráveis. A Tabela 2.2 mostra os valores adotados nos três métodos.

Os valores adotados por DENATRAN (1979) e CET-SP (2002) são bastante próximos, enquanto que o HCM 2000 estipula taxas de fluxo menores entre os níveis $A$ e $D$, adotando uma maior amplitude para o nível $\mathrm{E}$ o que reflete uma maior exigência no conforto pedestre.

Tabela 2. 2 - Valores associados aos níveis de serviço nos três métodos.

\begin{tabular}{|c|c|c|c|c|c|c|}
\hline \multirow{2}{*}{ Metodologia } & \multicolumn{5}{|c|}{ Níveis de Serviços (Ped/m/min) } \\
\cline { 2 - 7 } & A & B & C & D & E & F \\
\hline CET & $<20$ & $20-30$ & $30-50$ & $50-70$ & $70-80$ & $>80$ \\
\hline DENATRAN & $<23$ & $23-33$ & $33-49$ & $49-66$ & $66-82$ & $>82$ \\
\hline HCM (2000) & $<6,6$ & $6,6-23,1$ & $23,1-33$ & $33-45,5$ & $45,5-82,5$ & $>82,5$ \\
Fonte: CET (2002). & & & & & & \\
\hline
\end{tabular}

\subsubsection{Travessia em duas etapas}

Em vias sem canteiros ou ilhas de proteção para pedestres, o correto é dimensionar o tempo de verde para que a travessia seja realizada em uma única etapa. Em vias mais largas com canteiro central e/ou ilhas de proteção é interessante à realização da travessia em duas etapas, o que gera desconforto para os pedestres por terem que esperar no meio da caminhada, mas que propicia uma maior segurança e permite que os tempos de ciclo não fiquem tão elevados para os veículos. 
Entretanto, o dimensionamento do tempo de verde para a travessia em duas etapas deve ser feito com muita cautela, sendo dimensionado para que 0 pedestre alcance o canteiro central e não sobre folgas de tempo, o que pode incentivar os pedestres a continuar a travessia na outra pista sem tempo suficiente causando, assim, graves acidentes. Outro fato importante em uma travessia segura de duas etapas é a sinalização vertical no local informando de que não é possível efetuar a travessia de uma única de vez.

Em alguns casos o uso de grades de proteção para um melhor direcionamento dos pedestres e formação de pelotões pode ser empregado.

\subsubsection{Estágio de pedestres demandado por botoeiras}

Este tipo de estágio é indicado para locais onde a concentração de pedestres não é muita intensa; traz a vantagem de diminuir os atrasos veiculares e de aumentar o repeito à sinalização.

Esse sistema é simples e de fácil utilização, os pedestres devem apertar 0 botão próximo à placa de instrução e aguardar o sinal verde. A Figura 2.4 representa um cruzamento com travessia realizada por botoeira. 


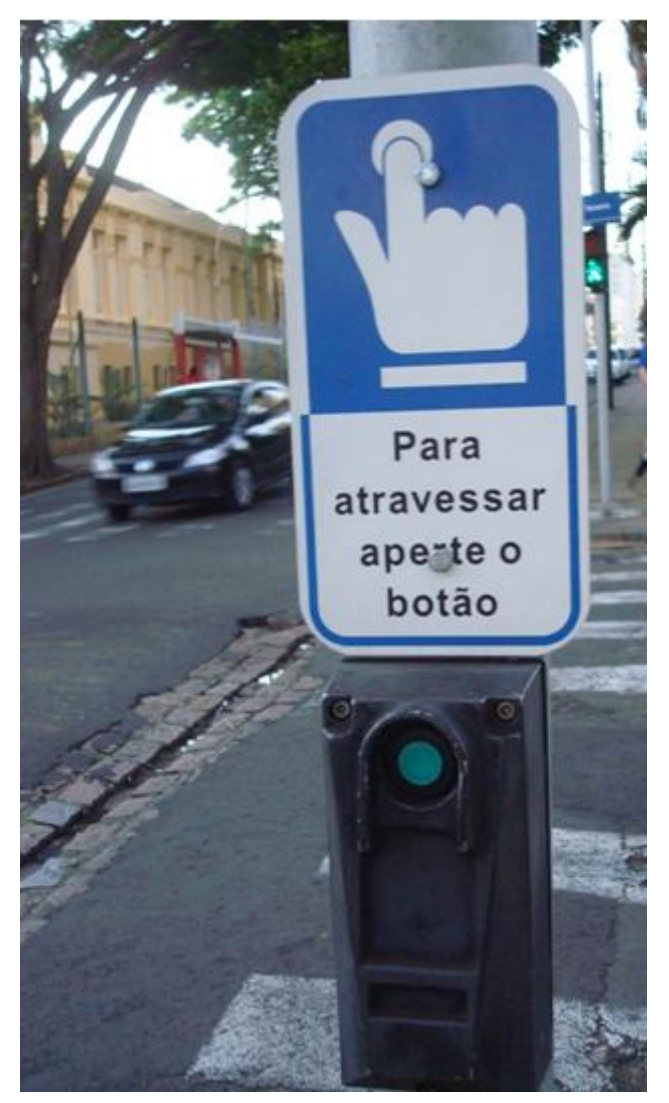

Figura 2. 4- Travessia demandada por botoeira.

A travessia realizada por botoeiras deve ser feita preferencialmente em esquinas, mais nada impede de ocorrer em meio de quadra, em alguns casos é um pouco mais perigosa por não haver tanta atenção dos motoristas.

O cálculo do tempo de verde para esse tipo de estágio deve ser feito da mesma maneira do tempo de verde em estágio exclusivos para a travessia de pedestres. 


\subsection{Tipos de controladores}

Os comandos para acender e apagar as lâmpadas dos focos semafóricos podem ser controlados por diferentes dispositivos como os controladores por tempo fixo e controladores atuados.

Os controladores de tempo fixo são os mais utilizados no Brasil. São mais fáceis de serem programados e, pois, o ciclo é constante e a duração e os instantes de mudança das fases de verde e vermelho tem sempre a mesma duração. Esses controladores são usados com sucesso na maioria dos sistemas interligados. Os controladores modernos são equipados com configurações para alterar o tempo ao longo do dia para atender as diferentes condições de tráfego.

Controladores atuados são dispositivos que controlam a interseção de acordo com o volume de tráfego no local. São mais caros, mais complexos, pois possuem detectores de veículos e lógica de decisão. Esses controladores ajustam os tempos de verde de acordo com o fluxo da via, dando assim um tempo correto para cada corrente de tráfego de acordo com as variações de fluxo da via (FERRAZ, 2005).

\subsection{Fluxo de saturação}

O conceito de fluxo de saturação supõe que o tráfego é escoado a uma taxa constante durante todo o tempo de verde do ciclo considerado, é um parâmetro fictício de cada aproximação de uma interseção semaforizada e corresponde ao volume de carros de passageiro que podem passar pela aproximação no 
tempo de uma hora de sinal aberto, ou seja, como se o semáforo permanecesse com a luz verde acesa durante uma hora ininterrupta e nesse período a fila de veículos a montante da interseção nunca terminasse.

O fluxo de saturação corresponde ao intervalo entre os veículos em condições de fila. Por exemplo, veículos partindo de uma fila com um headway médio de 2,2 segundos têm um fluxo de saturação de 3600/2,2 = 1636 veículos por hora por faixa. O fluxo de saturação numa faixa é a função das velocidades dos veículos e da separação entre eles (TRB, 2000).

O fluxo de saturação representa o número de veículos que podem passar pela interseção em apenas uma única faixa de tráfego quando o sinal estiver verde e enquanto a fila no semáforo não terminar. O valor do fluxo de saturação é um valor teórico que é útil para quantificar o fluxo em um cruzamento semaforizado em relação a cada uma das aproximações e determinar o volume máximo que pode ser acomodado pela via, correspondendo à capacidade de fluxo contínuo (SETTI, 2002).

O modelo em interseções semaforizadas assume um comportamento no qual todo veículo em uma dada faixa de tráfego consome em média " $h$ " segundos do tempo de verde para entrar na interseção. Portanto, se todos os veículos consomem " $h$ " segundos do tempo de verde e se no semáforo passa " $s$ " veículos por hora, então o fluxo de saturação é dado pela equação abaixo.

$$
S=\frac{3.600}{h}
$$


Sendo:

s: fluxo de saturação $\mathrm{v} / \mathrm{h}$;

$h:$ headway de saturação $=$ v/s.

O fluxo de saturação pode ser multiplicado pelo número de faixas, para se obter o fluxo de saturação por aproximação (ROESS, et al, 2004).

Depois de alguns segundos do início do período de verde a fila de veículos se dissipa mais ou menos numa taxa constante chamada de fluxo de saturação. $O$ fluxo de saturação, sendo expresso geralmente em veículos por hora por faixa (WEBSTER e COBBE, 1966).

O modelo básico do fluxo em semáforos assume que quando o semáforo muda para o período de verde, o fluxo através da linha de parada aumenta rapidamente. A média das partidas é baixa durante os primeiros segundos, quando os veículos aceleram normalmente, similarmente a partida média é baixa durante o período após o final do verde porque alguns veículos param e outros não (AKÇELIK, 1993).

O fluxo de saturação depende de alguns parâmetros, como o número e largura das faixas, número de faixas em uso, declividades, fatores que inibem os motoristas como a presença ou ausência de conflitos entre veículos ou entre tráfego e pedestres, zonas de estacionamentos, movimento de ônibus, entre outros.

Os fluxos de saturação variam, de acordo com os tipos de movimentos, tempo e localização, entre 1.500 a 2.000 carros por hora por faixa. O HCM 2000 coloca uma serie de técnicas detalhadas de estimativas e de medidas de fluxos 
de saturação. Essas medidas não devem ser muito diferentes dos valores ideais para fluxo de saturação que é em torno de 1,9 passageiros por carro e por faixa.

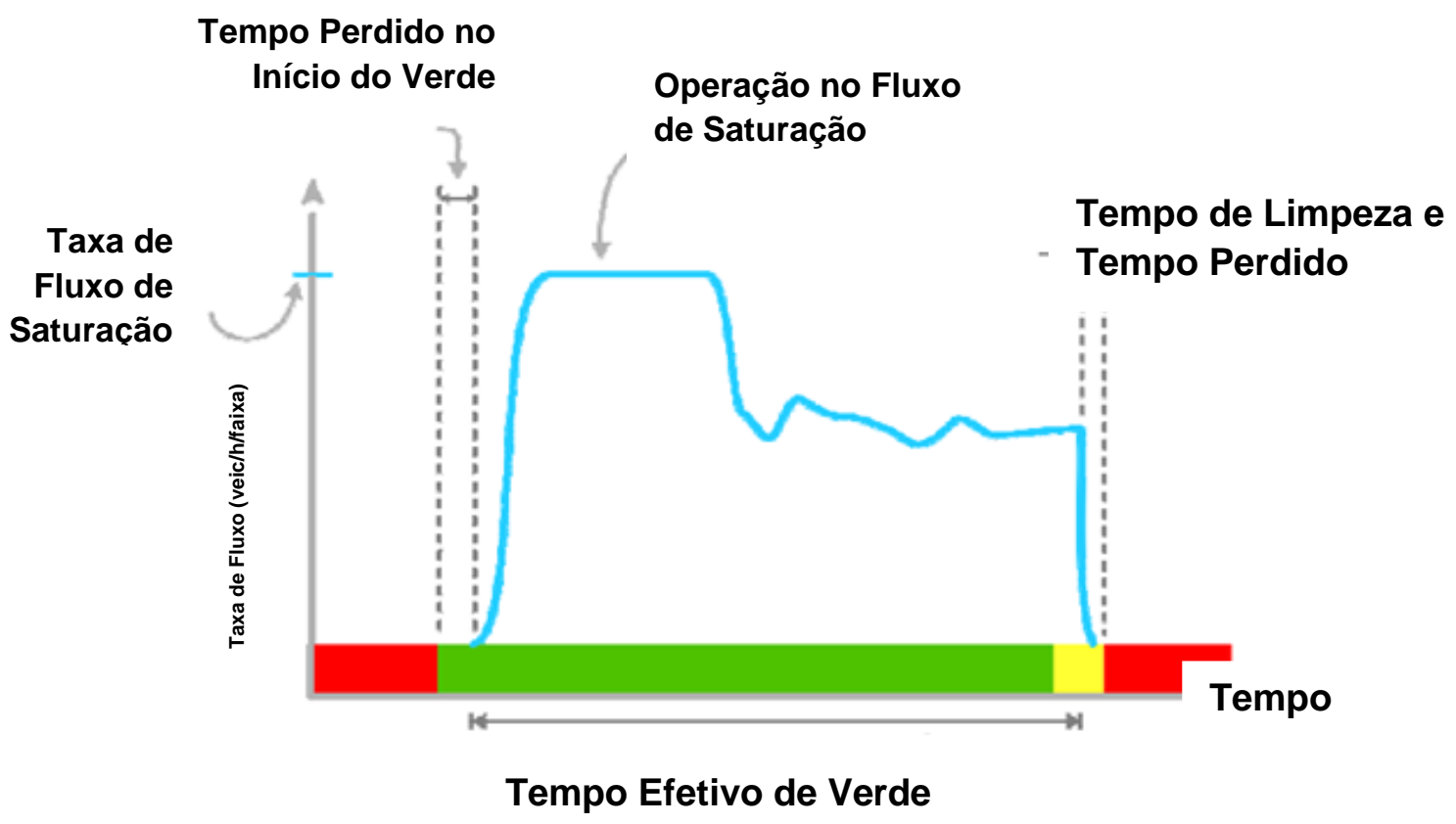

Figura 2. 5- Representação gráfica do fluxo de saturação.

Fonte: Luna (2003).

\subsubsection{Métodos de medida do fluxo de saturação}

A taxa de fluxo de saturação pode ser estimada por intermédio de modelos teóricos ou de levantamentos em campo. 
Nos levantamentos de campo são usados recursos tecnológicos como câmeras de filmagens, computadores portáteis, palms entre outros equipamentos que ajudam na coleta de dados e diminuem os erros.

Os principais métodos de levantamento de campo são:

- Método DENATRAN, (1979);

- Método Akçelik (1993);

- Método HCM (2000);

- Método de SHANTEAU (1988).

A seguir são esclarecidos esses quatro métodos.

\subsubsection{Método DENATRAN}

A metodologia proposta pelo DENATRAN (1979) consiste na medida do número de veículos que passam pela aproximação em pequenos intervalos de tempo, geralmente de cinco em cinco segundos. Com os dados de fluxo e tempo obtidos nas contagens é possível montar um gráfico em forma de histograma, onde o patamar superior obtido no histograma determina o fluxo de saturação da aproximação. Como em todos os outros métodos algumas condições essenciais têm que ser obedecidas para que o histograma reflita 0 real fluxo de saturação como: demanda suficiente, fluxo não congestionado, número de amostras superior ou igual a dez.

A Figura 2.6 ilustra o processo em forma de histograma e o cálculo da média de cada intervalo (que é a média de veículos liberados) para obtenção de um conjunto de valores médios que permite a construção da curva. 


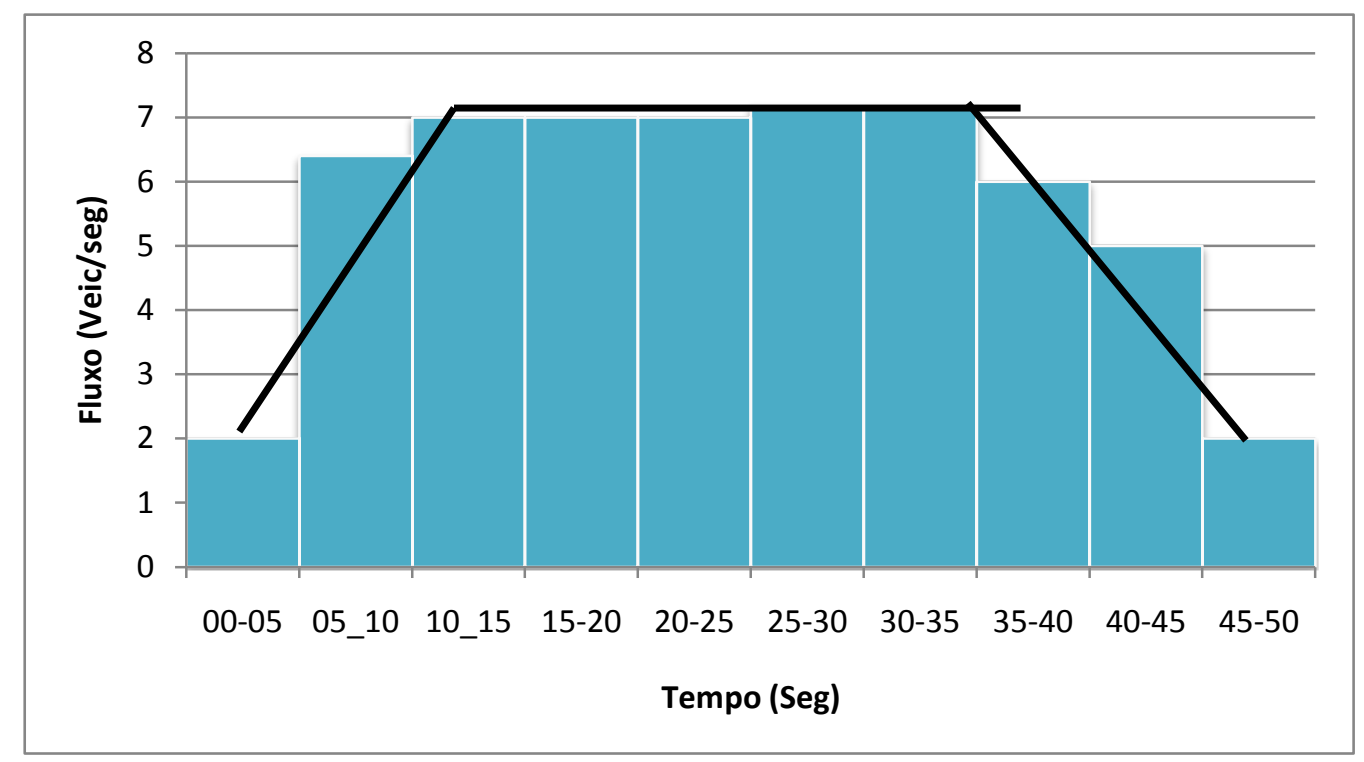

Figura 2. 6- Histograma de descarga de fila- DENATRAN.

Fonte: Denatran (1979).

Essa curva dificilmente terá essa configuração perfeita, uma vez que a chegada e a saída dos fluxos são aleatórias, portanto a curva real apresenta grandes descontinuidades, e o valor adotado como sendo o da capacidade deverá ser o mais representativo dentre os vários máximos possíveis (DENATRAN, 1979).

\subsubsection{Método Akçelik}

Esse método é aplicável tanto para os casos de aproximações com semáforos de tempo fixo quanto para semáforos atuados pelo tráfego. Consiste basicamente em proceder à contagem do número de veículos partindo da interseção em três intervalos de tempo:

- Primeiro intervalo: corresponde aos primeiros 10 segundos do tempo de início de verde; 
- Segundo intervalo: corresponde ao resto do tempo de verde (descontados os 10 segundos iniciais) e enquanto a fila não for dissipada;

- Terceiro intervalo: corresponde aos tempos de amarelo e vermelho total.

As contagens devem ser feitas por um número considerável de ciclos, dos quais um número razoável deve ser completamente saturado e as observações deveram ser feitas para cada faixa de tráfego. $O$ primeiro passo é fazer a contagem usando um formulário contendo: uma coluna com o número de ciclos, 3 colunas cada uma para um intervalo, uma coluna para o tempo de saturação e uma coluna para o tempo de verde, como apresentado na Figura 2.7.

\begin{tabular}{|c|c|c|c|c|c|}
\hline \multicolumn{4}{|c|}{ Fluxo de Saturação e Tempo Perdido } & \multirow{2}{*}{$\begin{array}{c}\text { Tempo de } \\
\text { Saturação } \\
\text { (Seg) }\end{array}$} & \multirow{3}{*}{$\begin{array}{l}\text { Tempo de } \\
\text { Verde (seg) }\end{array}$} \\
\hline \multirow{2}{*}{ № de Ciclos } & \multicolumn{3}{|c|}{ Fila (Veículos) } & & \\
\hline & $1^{\circ}$ Intervalo & $2^{\circ}$ Intervalo & Intervalo Final & & \\
\hline 1 & & & & & \\
\hline 2 & & & & & \\
\hline 3 & & & & & \\
\hline 4 & & & & & \\
\hline 5 & & & & & \\
\hline 6 & & & & & \\
\hline 7 & & & & & \\
\hline 8 & & & & & \\
\hline 9 & & & & & \\
\hline 10 & & & & & \\
\hline 11 & & & & & \\
\hline
\end{tabular}




\begin{tabular}{|c|l|l|l|l|l|}
\hline 12 & & & & & \\
\hline 13 & & & & & \\
\hline 14 & & & & & \\
\hline 15 & & & & & \\
\hline 16 & & & & & \\
\hline 17 & & & & & \\
\hline 18 & & & & & \\
\hline 19 & & & & & \\
\hline 20 & & & & & \\
\hline 21 & & & & & \\
\hline 22 & & & & & \\
\hline 23 & & & & & \\
\hline 24 & & & & & \\
\hline 25 & & & & & \\
\hline 26 & & & & & \\
\hline 27 & & & & & \\
\hline 28 & & & & & \\
\hline 29 & & & & & \\
\hline 30 & & & & & \\
\hline Total & & & & & \\
\hline Amostras & & & & & \\
\hline
\end{tabular}

Figura 2. 7- Formulário de contagem de fluxo de saturação.

Após a contagem, podem ser feitos os cálculos para encontrar o fluxo de saturação em veículos por segundo, fluxo de saturação por hora, tempo perdido no início e no final de cada fase e o tempo efetivo de verde.

O fluxo de saturação, em veículos por segundo, é dado pela seguinte expressão.

$$
S *=\frac{X_{2}}{X_{4}-10 \times n_{4}}
$$


Sendo:

$X_{2}$ : Soma do número de veículos partindo no segundo intervalo de todos os ciclos considerados;

$X_{4}$ : Soma do tempo de saturação de todos os ciclos considerados, em segundos;

$n_{4}$ : Número de ciclos com tempo de saturação igual ou superior a 10 segundos.

O fluxo de saturação em veículos por hora de tempo de verde (s) é calculado pela seguinte fórmula.

$$
S=3600 \times S *
$$

O tempo perdido é calculado pela expressão:

$$
l=I+10-\frac{1}{s^{*}} \times\left(\frac{x_{1}}{n_{1}}+\frac{x_{3}}{n_{3}}\right)
$$

Sendo:

I: Entreverdes em segundos;

$s *$ : Fluxo de saturação em veículos por segundo. 
$x_{1}$ : Soma do número de todos os veículos que passaram no primeiro intervalo.

$n_{1}$ : Número de ciclos considerados.

$x_{3}$ : Número de ciclos completamente saturados.

Os "tempos de saturação" obtidos na contagem que forem inferiores a 10 segundos devem ser descartados, assim como devem ser desconsiderados os ciclos que ficaram totalmente saturados, ou seja, quando a fila ainda existe no final do verde (AKÇELIK, 1993).

\subsubsection{Método HCM 2000}

O método proposto pelo HCM 2000 para a medição do fluxo de saturação "in loco", não propicia diretamente a determinação do tempo perdido. Esse método calcula o headway médio durante o período de saturação através do headway médio de desmanche da fila.

O período de saturação começa após 10 segundos do inicio do tempo de verde

e termina quando o pára-choque traseiro do ultimo veiculo da fila ainda no tempo de verde passa sobre a linha de retenção.

Para medir o fluxo de saturação pelo método do HCM 2000, deve-se primeiro determinar uma faixa de tráfego e registrar os seguintes dados:

- O tempo em segundos compreendido entre o início do tempo de verde e a passagem do ultimo veículo que entrou na fila quando o sinal mudou para verde. 
- Do tempo do ultimo veículo que entrou na fila antes da abertura do verde deve- se subtrair 10 segundos.

As fórmulas preconizadas pelo HCM 2000 são:

$$
\begin{gathered}
h_{m}=\frac{n-n_{10}}{N-4} \\
S=3600 / h_{m}
\end{gathered}
$$

Sendo:

$\mathrm{h}_{\mathrm{m}}$ : Headway médio em segundo.

$n$ : Tempo em segundos do ultimo veiculo a entrar na fila

$\mathrm{n}_{10}: 10$ segundos.

N : Número de veículos na fila.

Assim, para que todos os métodos propostos reflitam as reais condições da interseção é necessário que a saída de veículos esteja desimpedida quanto a fatores estranhos ao tráfego, como caminhões fazendo carga e descarga, carros fazendo manobras de estacionamento, entre outros, e principalmente que a aproximação esteja liberando o máximo possível de veículos refletindo a real capacidade da via (TRB, 2000). 


\subsubsection{Método de SHANTEAU}

O método desenvolvido por Shanteau (1988) é um método essencialmente gráfico, consiste em traçar um gráfico acumulado ao longo do tempo de verde do número médio de veículos a cruzar a faixa de retenção. Portanto, esse método requer que sejam registrados os instantes que cada veículo cruzou a faixa de retenção ao longo de vários ciclos e a cada 2 segundos de verde calcula-se o número médio acumulado de veículos registrados.

O gráfico resultante, em caso de períodos saturados, tem um padrão em forma de "S" que corresponde a 3 trechos da descarga de veículos:

1. Aceleração inicial da fila;

2. Estabilização dos headways;

3. Uso do entreverdes.

Assim, o trecho de estabilização do headway tende a ter um comportamento linear e determina o fluxo de saturação pelo coeficiente angular da reta que melhor se ajustar a esse trecho, convertido em uma faixa horária.

Shanteau (1988) recomenda que o esse método deve ser usado apenas para interseções com semáforos de tempo fixo e com ciclos totalmente saturados. $\mathrm{O}$ emprego de cinco a dez ciclos saturados já fornece uma boa estimativa.

O método de Shanteau (1988) está representado na Figura 2.8 (LUNA, 2003). 


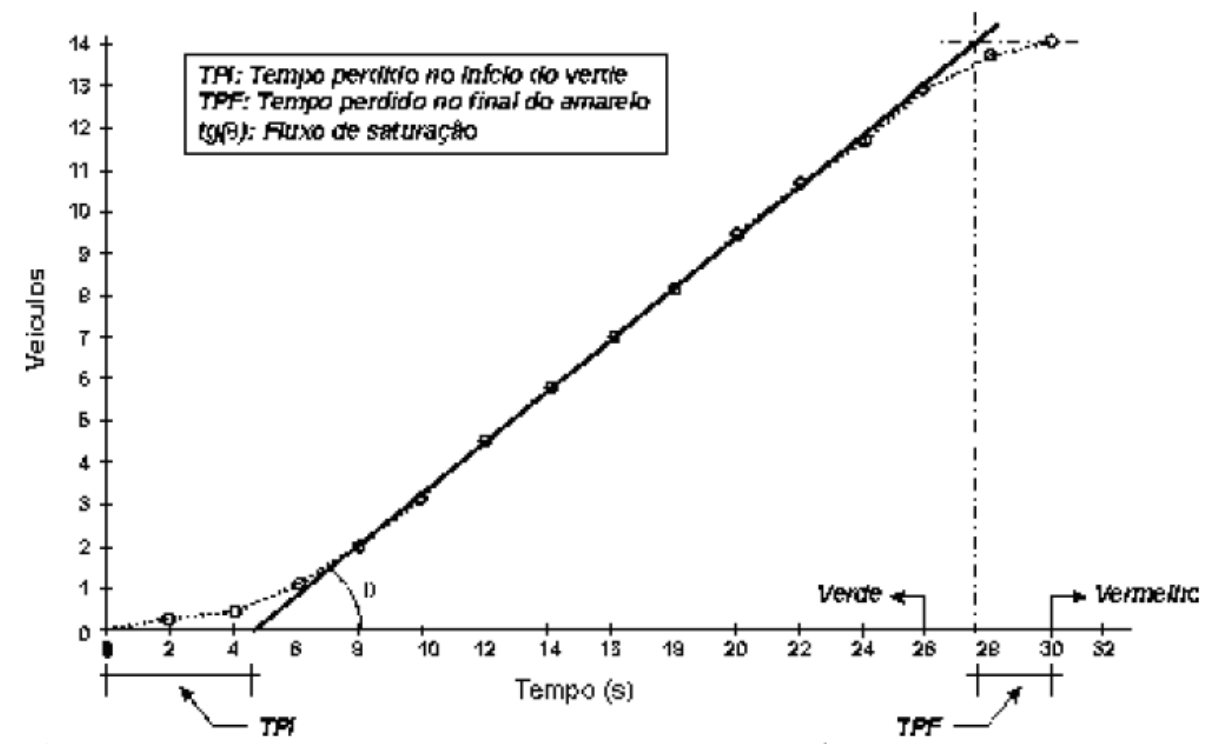

Figura 2. 8- Gráfico proposto por Shanteau (1988).

Fonte: Shanteau (1988).

\subsection{Tempo perdido e tempo de verde efetivo}

Quando a luz do semáforo fica verde a saída da fila de veículos não é instantânea, havendo um tempo perdido no início de cada fase.

Também no final do entreverdes há um tempo não aproveitado por razões de segurança.

Assim, o tempo total perdido de cada fase é dado pela equação abaixo:

$$
l_{i}=l_{1}+l_{2}
$$

Sendo: 
$l_{i}:$ Tempo perdido total;

$l_{1}:$ Tempo perdido no início da fase;

$l_{2}$ : Tempo perdido no final da fase.

O HCM 2000 preconiza um tempo perdido de cada fase igual a 4 segundos. Dessa forma, o verde efetivo por fase é dado pela seguinte fórmula.

$$
G e i=G i+Y i+R i-L i
$$

Sendo:

Gei: Tempo de verde efetivo;

$G i:$ Tempo de verde real;

$Y i$ : Tempo de amarelo;

$R i$ : Vermelho total na fase;

$L_{i}:$ Tempo total perdido.

O tempo total perdido por ciclo é a soma dos tempos perdidos em cada fase, pode ser calculado pela seguinte equação:

$$
L=\sum_{i}^{n} L i
$$


Sendo:

$L$ : Tempo total perdido por ciclo em segundos;

$L i$ : Tempo perdido por fase $i$ em segundos.

\subsection{Tempo de amarelo}

A luz amarela indica para o tráfego veicular que a indicação verde está sendo finalizada e que a luz vermelha será exibida imediatamente a seguir.

A duração do intervalo amarelo não pode variar de ciclo para ciclo. Um intervalo de amarelo deverá ter uma duração mínima de 3 segundos e uma máxima de 6 segundos, os intervalos mais longos devem ser utilizados em interseções onde as velocidades de aproximações são maiores (FHWA, 2008).

O tempo de amarelo é um tempo de transição entre o sinal verde e o sinal vermelho. Esse tempo deve ser suficiente para que os veículos que estão muito próximos do cruzamento, portanto sem condições de parar com segurança e conforto antes da faixa de retenção, possam prosseguir e passar por essa linha ainda no amarelo, ou seja, entrando na interseção já com o sinal vermelho, daí a importância do tempo de vermelho total (SETTI, 2002).

A principal função da indicação do sinal amarelo depois do verde é a de alertar os motoristas sobre o surgimento do sinal vermelho, para que assim esses tenham condições de escolher sobre a melhor decisão a ser tomada, ou seja, prosseguir ou parar. O tempo de amarelo é calculado usando equações 
simples da cinemática e pode ser seguido de um tempo de vermelho total para evitar possíveis conflitos entre veículos e pedestres. (FWHA, 2008).

A duração do tempo de amarelo deve ser calculada pela seguinte equação:

$$
Y=T p r+\frac{V}{2 a}
$$

Sendo:

$Y$ : Distância de frenagem em metros.

$V$ : Velocidade de aproximação em $\mathrm{m} / \mathrm{s}$.

Tpr : Tempo de percepção e reação em segundos (normalmente adorado 1 segundo).

$a=$ Desaceleração confortável na frenagem (neste caso adotada igual a 3 $\left.\mathrm{m} / \mathrm{s}^{2}\right)$.

A regulamentação dispõe que todos os veículos parem com segurança antes da linha de retenção quando o sinal amarelo aparecer. $O$ amarelo deve ser suficiente para que os veículos que entrarem no cruzamento não cruzem a linha de retenção já no tempo de vermelho. Portanto, a limpeza do cruzamento não é função do tempo de amarelo e sim do tempo de vermelho total (MAZZAMATI, 1992).

Pesquisas realizadas mostram que de 100 cruzamentos com maiores índices de colisões com vítimas na cidade de São Paulo 98 são semáforizados; Não se 
pode afirmar que isso se deve ao tempo de amarelo mal dimensionado, mas fica evidente a necessidade de uma maior atenção aos cálculos para o dimensionamento correto desse tempo (VILANOVA, 1985).

Algumas metodologias sugerem alguns tempos de amarelo de acordo com a velocidade de aproximação regulamentada da via. Porto (1995) defende velocidades diferentes da CET-SP (2002) como mostra a Tabela 2.3.

Tabela 2. 3 - Velocidade x Tempo de amarelo.

\begin{tabular}{|c|c|c|c|}
\hline \multicolumn{2}{|c|}{ CET - SP } & \multicolumn{2}{c|}{ PORTO } \\
\hline $\begin{array}{c}\text { Velocidade } \\
\text { regulamentada } \\
(\mathrm{Km} / \mathrm{h})\end{array}$ & $\begin{array}{c}\text { Velocidade } \\
\text { amarelo (Seg) }\end{array}$ & $\begin{array}{c}\text { regulamentada } \\
\text { (Km/h) }\end{array}$ & $\begin{array}{c}\text { Tempo de } \\
\text { amarelo (Seg) }\end{array}$ \\
\hline Até 40 & 3 & 50 & 3 \\
\hline 40 a 60 & 4 & 65 & 4 \\
\hline 60 a 80 & 5 & 80 & 6 \\
\hline 80 a 90 & 6 & 95 & 5 \\
\hline
\end{tabular}

Fonte: CET(2002), Porto (1995).

CET - SP (2002) recomenda em outras situações como, por exemplo, em vias com alto índice de veículos pesados ou com declives acentuados é necessário calcular o tempo de amarelo mais adequado e não devem adotar valores predeterminados.

Porto (1995) ressalta que os tempos de amarelo devem ser acrescidos de um tempo de vermelho total. Outro ponto defendido por Porto (1995) é o uso desses tempos de amarelo apenas para vias com tráfego com predominância de veículos de passeio, se houver um grande número de ônibus as velocidades de aproximação devem ser outras, como indicado na Tabela 2.4. 
Tabela 2. 4- Velocidade x Tempo de amarelo para ônibus.

\begin{tabular}{|c|c|}
\hline $\begin{array}{c}\text { Velocidade }(\mathrm{Km} / \mathrm{h}) \\
\text { Ônibus }\end{array}$ & Tempo de Amarelo (Seg) \\
\hline 25 & 3 \\
\hline 35 & 4 \\
\hline 45 & 5 \\
\hline 55 & 6 \\
\hline 65 & 7 \\
\hline 85 & 9 \\
\hline
\end{tabular}

Fonte: Porto (1995).

\subsection{Ciclo}

O ciclo de um semáforo é uma rotação completa de todas as indicações luminosas (ROESS, et al 2004).

Ciclo ótimo é aquele que garante a operação do semáforo com folgas que impedem a formação de filas decorrentes da aleatoriedade dos fluxos de tráfego. Existem algumas definições para as determinações e para os cálculos de ciclo ótimo, a mais utilizada e aceita é a proposta por Webster e Cobbe (1966), engenheiro de tráfego inglês, que realizou seus experimentos em 1958 e que são usados e válidos até os dias atuais (CET, 1998).

Existem diversos métodos para o dimensionamento dos tempos de ciclo. Atualmente, com o desenvolvimento de programas computacionais esse processo ficou ainda mais rápido e eficiente. Alguns métodos manuais 
desenvolvidos por engenheiros no século XX, que são utilizados até hoje são: Método de Homburguer e Kell, Método de Pignataro Método de Akçelik, Método de Webster.

O método desenvolvido por Homburguer e Kell foi proposto em 1988 e utiliza volumes de tráfego baseados na alocação dos tempos nas aproximações, mantendo os ciclos curtos fora do pico (entre 40 a 60 segundos) e ciclos mais longos nas horas pico favorecendo o fluxo nas vias principais.

O método de Pignataro foi desenvolvido em 1973 é uma boa alternativa para interseções com 4 aproximações e semáforos com 2 fases. Esse método considera o fator hora pico e o headway, como mostrado na equação abaixo (KHISTY, 2004).

$$
T=\frac{N_{1} S_{1}+N_{2} S_{2}}{4 * P H F}
$$

Sendo:

T: Ciclo;

$N_{1}$ : Volume crítico na faixa mais congestionada da via principal;

$N_{2}$ : Volume crítico na faixa mais congestionada da via secundária;

$S_{1}$ : Headway médio dos veículos na interseção $N_{1}$;

$S_{2}$ : Headway médio dos veículos na interseção $N_{2}$;

PHF : Fator hora pico. 
Akçelik (1993), também desenvolveu uma fórmula para dimensionamento do ciclo ótimo. O método proposto por ele no Research Report - ARR 123 (1993) define alguns parâmetros para a obtenção do tempo de ciclo mínimo usando na seguinte equação.

$$
P=D+K H
$$

Sendo:

$\mathrm{P}=$ Temo de ciclo

$K$ : Tempo perdido;

$D:$ Atraso total;

$H$ : Número de paradas

Esses parâmetros são usados para todos os movimentos em interseções isoladas e são usados na equação definida por Akçelik (1993) para obtenção do ciclo ótimo.

$$
c_{o}=\frac{(1,4+k) L+6}{1-y}
$$

Sendo:

$c_{o}$ : Ciclo ótimo em segundos; 
$L:$ Tempo perdido na interseção em segundos;

y: somatória das taxas de ocupação críticas das fases/subfases veiculares críticas;

$k$ : Valor em função do parâmetro a ser otimizado, como segue:

$k=0,4$ para consumo mínimo de combustível;

$k=0,2$ para custo mínimo;

$k=0$ para atraso mínimo.

A duração do ciclo ótimo proposta por Webster e Cobbe (1966) é aquela que minimiza o atraso médio experimentado pelos veículos na interseção, sendo determinada pela seguinte equação.

$$
C_{o}=\frac{1,5 \times L+5}{1-y}
$$

Sendo:

$C_{o}=$ duração do ciclo ótimo em segundos;

$L=$ tempo perdido no ciclo em segundos;

$y$ = somatória das taxas de ocupação das fases/subfases veiculares críticas.

Webster e Cobbe (1966) recomenda que o valor máximo aceitável de ciclo é de 120 segundos. 
A maioria das ferramentas de análises desenvolvidas para a seleção de comprimento do ciclo é para fluxos de baixa saturação. As ferramentas também não consideraram as restrições dos cruzamentos para além do tempo perdido e taxa de fluxo de saturação (FHWA, 2008).

Atualmente, com o desenvolvimento de programas computacionais o cálculo do tempo de espera e tempo de ciclo nos semáforos é realizado de maneira rápida e precisa, seja através da fórmula proposta por Webster ou qualquer outro método descrito anteriormente, utilizando modelos de fila ou de simulação. Assim, para a determinação do ciclo ótimo, deve se calcular a espera para diversos tempos de ciclo, sendo possível por comparação determinar aquele que proporciona uma mínima espera como representado na Figura 2.9 (PARREIRA, 1983).

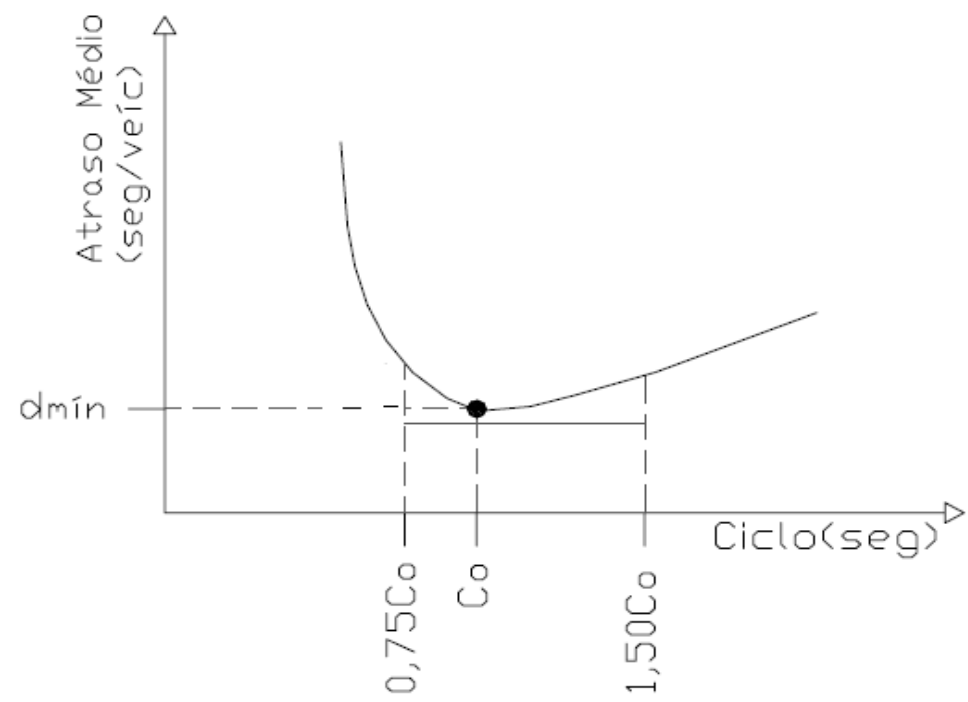

Figura 2. 9- Representação do ciclo ótimo segundo Webster. 


\subsection{Parâmetros de desempenho em semáforos isolados}

Diversos parâmetros têm sido utilizados na avaliação do desempenho do tráfego em interseções semaforizadas. Os principais são: tempo que os veículos permanecem parados, atraso (tempo perdido pelos veículos, igual à diferença entre o tempo efetivamente gasto para passar, incluindo desaceleração, parada e aceleração, e o tempo supondo que a velocidade fosse constante), número de paradas, tamanho médio das filas de veículos, tamanho máximo das filas, proporção de veículos que param pelo menos uma vez, consumo de combustível, emissão de poluentes, etc.

A seguir são colocadas algumas expressões desenvolvidas por Webster e Cobbe (1966) para o cálculo desses parâmetros no caso de semáforos isolados.

\subsubsection{Atraso médio}

O atraso total médio experimentado pelos veículos (acréscimo de tempo devido à presença do semáforo em relação à situação sem semáforo) é dado pela expressão abaixo.

$$
d=\frac{c(1-\lambda)^{2}}{2(1-\lambda x)}+\frac{x^{2}}{2 q(1-x)}-0,65\left(\frac{c}{q^{2}}\right)^{1 / 3} X^{(2+5 \lambda)}
$$

Sendo:

$d=$ Atraso médio em seg/veíc. 
$c=$ Ciclo em segundos.

$\lambda=\mathrm{Ge} / \mathrm{C}$ : fração do verde efetivo no ciclo.

$X=$ Índice de congestionamento.

$q$ = Volume de tráfego em veíc/seg.

Considerando que o terceiro termo da fórmula anterior representa na ordem de 5 a $15 \%$ da soma dos dois primeiros, a seguinte expressão simplificada pode ser utilizada como alternativa para o cálculo do atraso médio como na equação abaixo.

$$
d=0,9 \times\left(\frac{c(1-\lambda)^{2}}{2(1-\lambda * x)}+\frac{x^{2}}{2 q(1-x)}\right)
$$

\subsubsection{Tamanho da fila}

O tamanho médio da fila crítica (no final do vermelho ou início do verde) é calculado dado pela expressão abaixo.

$$
n=\operatorname{Maior}\left[q *\left(\frac{R e}{2}+d\right) q * R e\right]
$$


Sendo:

$n$ : Tamanho médio da fila crítica em veículos.

$q, \operatorname{Re}$ e $d:$ já definidos anteriormente.

O tamanho da fila que é excedido em $5 \%$ e $1 \%$ das vezes - o que pode ter interesse em razão do bloqueio que as filas podem provocar em interseções próximas ou entradas e saídas de garagens - são fornecidos nas Tabelas 2.6 e 2.7 em função de $\mathrm{m}=\mathrm{q} \times \mathrm{C}$ (número médio de veículos que chegam num ciclo), x e, que já foram definidos anteriormente.

A Tabela 2.6 mostra valores do tamanho da fila superado em $5 \%$ dos ciclos e a Tabela 2.7 os valores do tamanho da fila superado em apenas $1 \%$ do ciclo. 
Tabela 2. 5- Tamanho da fila crítica.

\begin{tabular}{|c|c|c|c|c|c|c|}
\hline$X$ & $\mathrm{~m}$ & 2,5 & 5,0 & 10,0 & 20,0 & 40,0 \\
\hline \multirow{3}{*}{$0-3$} & $0-4$ & 5 & 7 & 12 & 20 & 34 \\
\hline & $0-5$ & 4 & 5 & 9 & 15 & 24 \\
\hline & $0-8$ & 3 & 4 & 6 & 9 & 15 \\
\hline \multirow{4}{*}{$0-5$} & $0-2$ & 6 & 7 & 15 & 20 & 47 \\
\hline & $0-4$ & 5 & 7 & 12 & 20 & 35 \\
\hline & $0-6$ & 4 & 5 & 9 & 15 & 24 \\
\hline & $0-8$ & 3 & 4 & 6 & 9 & 15 \\
\hline \multirow{4}{*}{$0-7$} & $0-2$ & 7 & 9 & 15 & 25 & 44 \\
\hline & $0-4$ & 6 & 8 & 12 & 20 & 34 \\
\hline & $0-6$ & 5 & 7 & 9 & 15 & 25 \\
\hline & $0-8$ & 5 & 5 & 7 & 9 & 15 \\
\hline \multirow{4}{*}{$0-8$} & $0-2$ & 9 & 12 & 16 & 25 & 46 \\
\hline & $0-4$ & 8 & 11 & 14 & 21 & 35 \\
\hline & $0-6$ & 8 & 9 & 11 & 16 & 25 \\
\hline & $0-8$ & 7 & 8 & 9 & 11 & 16 \\
\hline \multirow{4}{*}{$0-9$} & $0-2$ & 19 & 18 & 22 & 30 & 49 \\
\hline & $0-4$ & 19 & 17 & 20 & 23 & 39 \\
\hline & $0-6$ & 19 & 16 & 17 & 21 & 34 \\
\hline & $0-8$ & 18 & 13 & 15 & 18 & 22 \\
\hline \multirow{4}{*}{$0-95$} & $0-2$ & 36 & 28 & 33 & 40 & 55 \\
\hline & $0-4$ & 35 & 27 & 30 & 35 & 47 \\
\hline & $0-6$ & 34 & 26 & 25 & 34 & 39 \\
\hline & $0-8$ & 34 & 25 & 27 & 27 & 32 \\
\hline \multirow{4}{*}{$0-975$} & $0-2$ & 74 & 63 & 65 & 62 & 84 \\
\hline & $0-4$ & 74 & 57 & 65 & 59 & 75 \\
\hline & $0-6$ & 69 & 61 & 63 & 54 & 65 \\
\hline & $0-8$ & 65 & 56 & 61 & 52 & 64 \\
\hline
\end{tabular}


Fonte: Webster e Cobbe(1966).

Tabela 2. 6- Tamanho da fila crítica.

\begin{tabular}{|c|c|c|c|c|c|c|}
\hline$X$ & $m$ & $2-5$ & $5-0$ & $10-0$ & $20-0$ & $40-0$ \\
\hline \multirow{3}{*}{$0-3$} & $0-4$ & 6 & 9 & 14 & 23 & 38 \\
\hline & $0-6$ & 5 & 6 & 11 & 17 & 28 \\
\hline & $0-8$ & 3 & 5 & 7 & 12 & 17 \\
\hline \multirow{4}{*}{$0-5$} & $0-2$ & 7 & 9 & 17 & 29 & 53 \\
\hline & $0-4$ & 6 & 9 & 14 & 23 & 38 \\
\hline & $0-6$ & 5 & 7 & 11 & 17 & 28 \\
\hline & $0-8$ & 4 & 5 & 7 & 12 & 18 \\
\hline \multirow{4}{*}{$0-7$} & $0-2$ & 9 & 12 & 17 & 28 & 50 \\
\hline & $0-4$ & 9 & 9 & 15 & 23 & 39 \\
\hline & $0-6$ & 8 & 9 & 12 & 18 & 28 \\
\hline & $0-8$ & 7 & 7 & 8 & 12 & 18 \\
\hline \multirow{4}{*}{$0-8$} & $0-2$ & 13 & 15 & 19 & 28 & 50 \\
\hline & $0-4$ & 12 & 13 & 17 & 24 & 38 \\
\hline & $0-6$ & 12 & 13 & 14 & 20 & 28 \\
\hline & $0-8$ & 11 & 12 & 12 & 15 & 18 \\
\hline \multirow{4}{*}{$0-9$} & $0-2$ & 29 & 25 & 29 & 38 & 55 \\
\hline & $0-4$ & 28 & 24 & 27 & 33 & 46 \\
\hline & $0-6$ & 27 & 24 & 26 & 28 & 42 \\
\hline & $0-8$ & 27 & 23 & 24 & 25 & 29 \\
\hline \multirow{4}{*}{$0-95$} & $0-2$ & 40 & 36 & 38 & 47 & 65 \\
\hline & $0-4$ & 40 & 34 & 37 & 44 & 55 \\
\hline & $0-6$ & 40 & 32 & 30 & 42 & 48 \\
\hline & $0-8$ & 39 & 32 & 34 & 36 & 40 \\
\hline \multirow{4}{*}{$0-975$} & $0-2$ & 82 & 70 & 79 & 69 & 93 \\
\hline & $0-4$ & 83 & 66 & 75 & 65 & 82 \\
\hline & $0-6$ & 82 & 70 & 69 & 58 & 79 \\
\hline & $0-8$ & 79 & 65 & 66 & 56 & 79 \\
\hline
\end{tabular}

Fonte: Webster e Cobbe(1966). 


\subsubsection{Número médio de paradas}

O número médio de paradas por veículo no semáforo é dado pelas seguintes expressões:

$$
\begin{array}{ll}
p=\frac{n}{q \times c \times(1-q / 5)} & \text { se } \mathrm{n}<(\mathrm{s}-\mathrm{q}) \cdot \mathrm{Ge} \\
(2.23) & \\
p=\frac{n}{q \times c} & \text { se } \mathrm{n}>(\mathrm{s}-\mathrm{q}) \cdot \mathrm{Ge}
\end{array}
$$

Sendo:

$p$ : Número médio de paradas por veículo em par/veíc.

$n, q, c$ e $G e$ : já definidos anteriormente.

\subsubsection{Proporção de veículos que param pelo menos uma vez}

A proporção de veículos que param pelo menos uma vez no semáforo é dada pela seguinte expressão: 


$$
Z=\frac{1-\lambda}{1-y}
$$

Sendo:

$Z=$ Proporção dos veículos que param pelo menos uma vez.

$\lambda$ e $y$ : já definidos anteriormente.

\subsubsection{Proporção de ciclos saturados}

A proporção de ciclos saturados: w (ciclos nos quais pelo menos um veículo da fila não pode ser atendido e, portanto, sobram veículos para o próximo verde), é dado na Figura 2.10 em função de $m$ e $x$, que já foram definidos anteriormente.

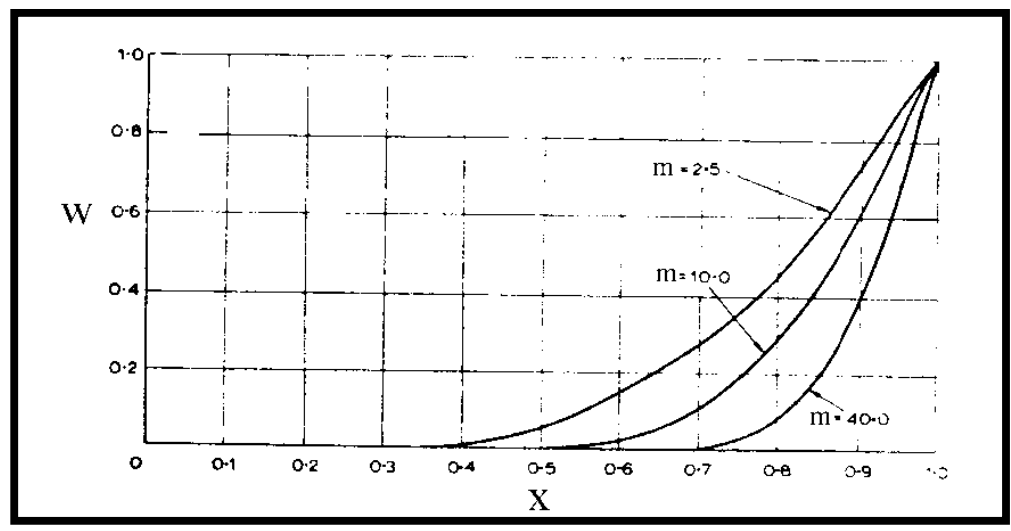

Figura 2. 10- Proporção de ciclos saturados, com base em Webster e Cobbe (1966)

Fonte: Webster e Cobbe(1966).

\subsubsection{Estimativa do atraso médio HCM 2000}

A seguir é descrita uma metodologia para a estimativa do atraso médio experimentado pelos veículos nos semáforos em função do tipo de chegada, tipo de controlador, etc., baseada no HCM 2000. 


\section{Tipos de chegada}

São considerados 6 tipos diferentes de chegadas dos veículos nos semáforos, conforme mostrado na Tabela 2.7.

O tipo de chegada deve sempre que possível ser observado no campo. Quando não se dispõe desse dado, um parâmetro que pode ser utilizado para caracterizar o tipo de chegada dos veículos num semáforo é a taxa de agrupamento, conforme se pode observar na Tabela 2.7, definida pela expressão abaixo.

$$
R_{p}=p / \lambda
$$

Sendo:

$R_{p}:$ Taxa de agrupamento.

$p$ : Proporção de veículos que chegam no semáforo durante o verde efetivo (grandeza que pode ser estimada com base na análise do diagrama espaçotempo do movimento dos veículos entre os semáforos, ou avaliada no campo) $\lambda=$ relação verde efetivo/ciclo. 
Tipo de Valores de Rp* Caracteristicas da Chegada

\begin{tabular}{|c|c|c|}
\hline 1 & $\mathrm{Rp} \leq 0,50(0,333)$ & $\begin{array}{l}\text { Pelotão denso com mais de } 80 \% \text { dos veiculos chegando no inicio do } \\
\text { vermelho. Qualidade da progressão: Péssima. }\end{array}$ \\
\hline 2 & $0,50<\mathrm{Rp} \leq 0,85(0,667)$ & $\begin{array}{c}\text { Pelotão moderadamente denso chegando no meio do vermelho, ou } \\
\text { pelotão disperso com } 40 \text { a } 80 \% \text { dos veiculos chegando durante o } \\
\text { vermelho.Qualidade da progressão: Desfavorável. }\end{array}$ \\
\hline 3 & $0,85<R p \leq 1,15(1,000)$ & $\begin{array}{l}\text { Chega aleatórias com menos de } 40 \% \text { dos veículos no pelotão - Qualidade } \\
\text { da progressão: Regular. }\end{array}$ \\
\hline 4 & $1,15<R p \leq 1,50(1,333)$ & $\begin{array}{l}\text { Pelotão moderadamente denso chegando no meio do verde, ou pelotão } \\
\text { disperso com } 40 \text { a } 80 \% \text { dos veículos chegando durante o verde. } \\
\text { Qualidade da progressão: Regular para Boa. }\end{array}$ \\
\hline 5 & $1,50<\mathrm{Rp} \leq 2,00(1,667)$ & $\begin{array}{l}\text { Pelotão denso com mais de } 80 \% \text { dos veículos chegando no início do verde } \\
\qquad- \text { Qualidade de progressão: Boa }\end{array}$ \\
\hline 6 & $R p>2,000(2,000)$ & $\begin{array}{l}\text { Pelotão denso com quase todos os veiculos chegando no início do verde - } \\
\text { Qualidade da progressão: ótima }\end{array}$ \\
\hline
\end{tabular}

Fonte: TRB (2000)

* Os valores de Rp entre parêntesis correspondem aos valores mais comumente observados.

\section{Expressão do atraso médio}

A expressão genérica para determinação do atraso médio dos veículos em semáforos de tempo fixo não congestionados $(x \leq 1)$ é dada pelas Expressões abaixo.

$$
\begin{aligned}
& d=d_{1} \times P_{F}+d_{2} \\
& d_{1}=\frac{C(1-\lambda)^{2}}{2(1-\lambda x)} \\
& d_{2}=900 T\left[(x-1)+\sqrt{(x-1)^{2}+\frac{4 I x^{2}}{3600 q}}\right]
\end{aligned}
$$

Sendo: 
$d_{1}$ e $d_{2}:$ Parcelas do atraso médio.

$P_{F}:$ Fator função do tipo de coordenação existente entre os semáforos.

$T$ : Período de análise em horas.

$I$ = Fator que depende do grau de saturação do fluxo que segue em frente relativo ao semáforo anterior e $C, \lambda, x$ e $q$ : já definidos anteriormente.

O valor de PF é dado pela seguinte expressão:

$$
P F=\frac{(1-p) \times(f p a)}{1-\lambda}
$$

Sendo:

$P F:$ Fator que depende do tipo de coordenação.

$p, f$ e $\lambda$ : já definidos anteriormente.

Valores típicos de PF e f $f_{P A}$ estão relacionados na Tabela 2.8.

Tabela 2. 8 -Valores típicos de Pf e fPA.

\begin{tabular}{|c|c|c|c|c|c|c|}
\hline \multirow{2}{*}{$\lambda=\mathbf{G e} / \mathbf{C}$} & \multicolumn{7}{|c|}{ Tipo de chegada } \\
\cline { 2 - 7 } & $\mathbf{1}$ & $\mathbf{2}$ & $\mathbf{3}$ & $\mathbf{4}$ & $\mathbf{5}$ & $\mathbf{6}$ \\
\hline $\mathbf{0 . 2 0}$ & 1.167 & 1.007 & 1.000 & 1.000 & 0.833 & 0.750 \\
$\mathbf{0 . 3 0}$ & 1.286 & 1.063 & 1.000 & 0.986 & 0.714 & 0.571 \\
$\mathbf{0 . 4 0}$ & 1.445 & 1.136 & 1.000 & 0.895 & 0.555 & 0.333 \\
$\mathbf{0 . 5 0}$ & 1.667 & 1.240 & 1.000 & 0.767 & 0.333 & 0.000 \\
$\mathbf{0 . 6 0}$ & 2.001 & 1.395 & 1.000 & 0.576 & 0.000 & 0.000 \\
\hline
\end{tabular}




\begin{tabular}{|c|c|c|c|c|c|c|}
\hline $\mathbf{0 . 7 0}$ & 2.556 & 1.653 & 1.000 & 0.256 & 0.000 & 0.000 \\
& & & & & & \\
& & & & & & \\
\hline $\mathbf{f P A}$ & 1.000 & 0.930 & 1.000 & 1.150 & 1.000 & 1.000 \\
$\mathbf{R}_{\mathbf{p}}$ & 0.333 & 0.667 & 1.000 & 1.333 & 1.667 & 2.000 \\
\hline
\end{tabular}

Fonte: TRB (2000)

Os valores de I são fornecidos na Tabela 2.9.

Tabela 2. 9 - Valores de I em função dos valores de $\mathrm{x}$ do fluxo que segue em frente relativo ao semáforo anterior.

\begin{tabular}{|c|c|c|c|c|c|c|c|}
\hline $\mathrm{X}$ & 0,40 & 0,50 & 0,60 & 0,70 & 0,80 & 0,90 & $\geq 1,00$ \\
\hline $\mathrm{L}$ & 0,922 & 0,858 & 0,769 & 0,650 & 0,500 & 0,314 & 0,090 \\
\hline
\end{tabular}

Fonte: $\operatorname{TRB}(2000)$

\subsubsection{Nível de serviço para cruzamentos semaforizados}

O parâmetro proposto pelo HCM 2000 para caracterizar a qualidade da operação (nível de serviço) nos cruzamentos semaforizados é o atraso médio (tempo parado mais tempo de desaceleração e aceleração) experimentado pelos veículos. A classificação preconizada é mostrada na Tabela 2.10.

Tabela 2. 10 - Nível de serviço $x$ atraso.

\begin{tabular}{|c|c|c|}
\hline Nível de serviço (NS) & Qualidade da operação & Valores do atraso médio (seg) \\
\hline A & Ótima & $\mathrm{d} \leq 10,0$ \\
\hline B & Boa & $10,0<\mathrm{d} \leq 20,0$ \\
\hline C & Regular & $20,0<\mathrm{d} \leq 35,0$ \\
\hline
\end{tabular}




\begin{tabular}{|c|c|c|}
\hline D & Ruim & $35,0<d \leq 55,0$ \\
\hline E & Muito ruim & $55,0<d \leq 80,0$ \\
\hline F & Péssima (inaceitável) & $\mathrm{d}>80.0$ \\
\hline
\end{tabular}

Fonte: TRB (2000).

No HCM 1985, o parâmetro proposto para caracterizar o nível de serviço era o tempo médio parado. Os valores preconizados são mostrados na Tabela 2.11.

Tabela 2. 11- Nível de serviço x tempo parado.

\begin{tabular}{|c|c|c|}
\hline $\begin{array}{c}\text { Nível de serviço } \\
\text { (NS) }\end{array}$ & Qualidade da operação & $\begin{array}{c}\text { Valores do atraso médio } \\
\text { (seg) }\end{array}$ \\
\hline A & Ótima & $\mathrm{d} \leq 5,00$ \\
\hline B & Boa & $5<\mathrm{d} \leq 15$ \\
\hline C & Regular & $15<\mathrm{d} \leq 25,0$ \\
\hline D & Ruim & $25,0<\mathrm{d} \leq 40,0$ \\
\hline E & Muito ruim & $40,0<\mathrm{d} \leq 60,0$ \\
\hline F & Péssima (inaceitável) & $\mathrm{D}>60.0$ \\
\hline
\end{tabular}

Fonte: TRB (1985). 


\subsubsection{Repartição do verde}

A divisão do verde efetivo proporcionalmente às taxas de ocupação, como visto, conduz ao menor atraso global dos veículos no cruzamento e na igualdade dos índices de congestionamento das faixas críticas das diversas fases. Isso não implica, contudo, que os valores médios do atraso resultem iguais nas faixas críticas.

O HCM 2000 recomenda que o verde efetivo deva ser distribuído de modo a que os atrasos médios nas faixas críticas resultem próximos, a que os níveis de serviço das faixas críticas de cada fase sejam os mesmos. Para se conseguir isso são necessárias algumas iterações no processo de cálculo dos tempos de verde.

\subsubsection{Generalização do conceito de ciclo ótimo}

Como visto, a metodologia de Webster e Cobbe (1966) propõe uma expressão para o ciclo que minimiza o atraso médio dos veículos no cruzamento, visando o conforto (comodidade) dos passageiros.

Na realidade, é necessário contemplar também outros aspectos na escolha da duração do ciclo, como o número de paradas (também ligado ao conforto dos passageiros), o consumo de combustível (ligado à conservação de energia), a emissão de poluentes (ligado à preservação do meio ambiente), etc.

Diversos estudos tratando do assunto foram desenvolvidos. Na Figura 2.11 são mostradas curvas típicas do comportamento dos parâmetros atraso, número de 
paradas, consumo de combustível e emissão de poluentes em função da duração do ciclo.

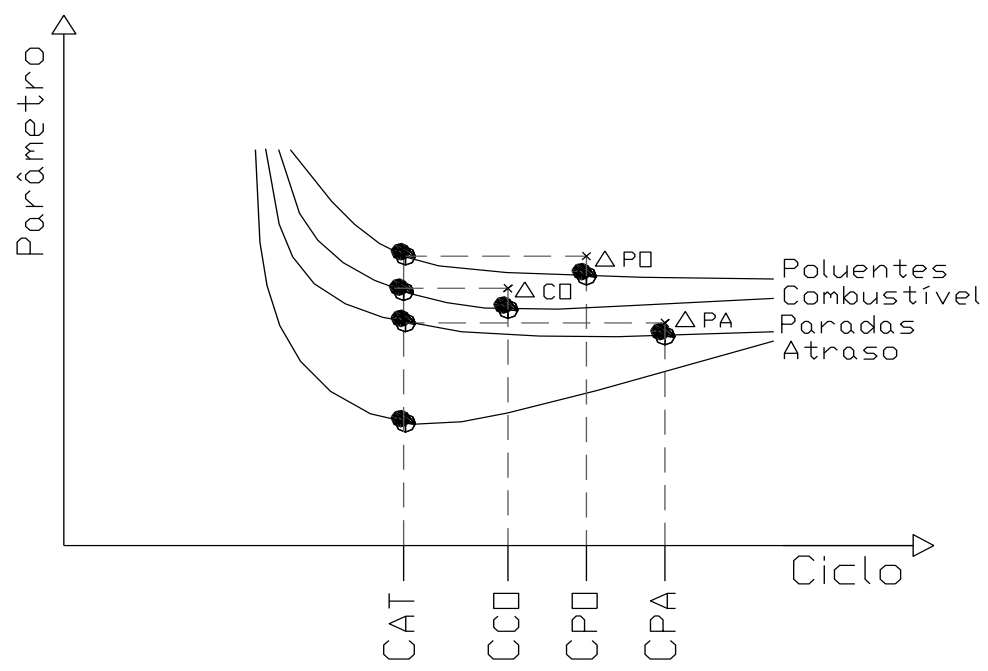

Figura 2. 11- Variação típica dos principais parâmetros em função do ciclo. Fonte: Bezerra (2007).

As seguintes conclusões relevantes podem ser depreendidas com base na Figura 2.11:

- O tempo médio parado e o atraso diminuem com o aumento do ciclo, passam por um mínimo e depois aumentam. $O$ valor do ciclo correspondente ao mínimo valor do tempo parado (ciclo ótimo com relação ao tempo parado $-\mathrm{C}_{\mathrm{TP}}$ ) é um pouco menor do que o ciclo ótimo relativo ao atraso $\left(\mathrm{C}_{\mathrm{AT}}\right)$.

- O número de paradas diminui com o aumento do ciclo e depois permanece constante. O valor do ciclo a partir do qual o número de paradas permanece constante e igual ao mínimo $\left(\mathrm{C}_{\mathrm{PA}}\right)$ é maior do que o ciclo ótimo correspondente ao atraso. 
- Como o consumo de combustível e a emissão de poluentes são função do tempo parado e do número de paradas (devido à aceleração e à desaceleração), as durações do ciclo correspondentes aos mínimos valores desses parâmetros estão entre os valores ótimos relativos ao tempo parado e o número de paradas. Os valores ótimos correspondentes ao consumo de combustível e a emissão de poluentes são referidos, respectivamente, por $\mathrm{C}_{\mathrm{CO}}$ e $\mathrm{C}_{\mathrm{PO}}$.

O ciclo ideal, portanto, está entre o ciclo que minimiza o tempo parado e o ciclo a partir do qual o número de paradas é constante e igual ao mínimo. Isso corresponderia a algo como minimizar um parâmetro definido em função do atraso e do número de paradas, que, inclusive, já é utilizado em alguns simuladores de tráfego. A Expressão 2.31 expressa matematicamente à ideia:

$$
I=a+K+p
$$

Sendo:

$I$ : Índice de desempenho a ser minimizado.

$a:$ Atraso médio.

$K$ : Fator de penalidade associado a cada parada expresso em unidades de tempo.

$p:$ Número médio de paradas. 
A utilização do ciclo que minimiza o atraso não leva a grandes diferenças nos valores dos outros parâmetros em relação aos seus ciclos ótimos. Assim, a utilização do ciclo ótimo fornecido pela expressão de Webster é satisfatória na prática. 



\section{SIMULADORES DE TRÁFEGO}

\subsection{Introdução}

Simulação é uma técnica computacional que tem como objetivo a representação do funcionamento de um sistema real de uma forma simplificada e muitas vezes idealizada.

A principal vantagem em se realizar simulações é analisar situações em que não se pode ou é muito difícil desenvolver experimentos na prática, ou ainda quando não é possível intervir no sistema real por questões de custos, segurança, etc.

Em vista do exposto, a simulação computacional é uma importante ferramenta utilizada nos estudos da Engenharia de Tráfego, pois proporciona condições de avaliação do sistema de trânsito sem intervenções no sistema real, facilita a otimização de operações e análises dos volumes de veículos e dos diferentes impactos que esses volumes causam.

Atualmente, existem vários simuladores que procuram representar as características do tráfego através de códigos computacionais e valores numéricos. Usualmente os modelos de simulação são classificados em microscópicos, macroscópicos e mesoscópicos.

Os modelos microscópicos representam os movimentos individuais dos veículos a velocidade e a posição de cada um. São exemplos de simuladores 
microscópicos: INTEGRATION, NETFLO, FRESIM, CORSIM, DRÁCULA e PARAMICS.

Os modelos macroscópicos consideram as relações entre as características da corrente de tráfego, como fluxo, densidade, velocidade. São exemplos de simuladores macroscópicos: CORFLO, FREFLO, FREQ e TEXAS.

Os modelos mesoscópicos incorporam características dos modelos microscópicos e macroscópicos. Alguns autores classificam como mesoscópicos os seguintes simuladores: DYNAMIT, DYNEMO e DYNASMART (BEZERRA, 2007).

\subsection{Simulador Corsim}

O simulador CORSIM (CORridor traffic Simulation Model) foi desenvolvido na década de 1970 nos EUA pela Federal Highway Administration (FHWA). Consiste na integração de dois modelos de simulação microscópica de tráfego: NETSIM e FRESIM. O FRESIM faz a representação em freeways (rodovias), enquanto que o NETSIM fornece a representação de tráfego na área urbana. (ARAUJO, 2007).

O CORSIM é um dos modelos de simulação mais utilizados pela comunidade científica e profissional, devido à sua capacidade de simular sistemas combinados de vias arteriais e expressas, diferentes geometria da via, várias condições de tráfego (até mesmo fluxo saturado), diversos tipos de interseções (com semáforos atuados ou com ciclos pré-definidos), além de variação no 
número de faixas. Além disso, possui uma apresentação visual de alta qualidade de simulação e uma interface amigável com o usuário.

A interface com o usuário é implementada em ambiente Windows, através do TSIS (Traffic Software Integrated System). No pacote TSIS está incluído o pósprocessador gráfico TRAFVU (TRAF Visualization Utility), que possibilita a visualização da rede simulada e o arquivo gráfico TRAFED (CUNHA, 2007).

O CORSIM é um programa de simulação microscópico projetado para simular fluxos de tráfego em redes integradas de rodovias e áreas urbanas. É um modelo estocástico em que tanto as características dos motoristas e veículos como os processos de tomada de decisão são definidos de forma aleatória.

No CORSIM as operações de tráfego mudam a cada 1 segundo; ou seja, cada veículo é modelado como um objeto que se move a cada 1 segundo, cada tipo de controle de tráfego na rede também é atualizado a cada 1 segundo.

No CORSIM há um total de nove tipos diferentes de veículos que são usados para caracterizar a frota, que é dividida em quatro grupos: ônibus, caminhões, automóvel e carpool. Isso permite uma representação mais precisa da rede simulada (ARAUJO, 2007).

O simulador CORSIM é baseado em um modelo de redes de nós e tramos (links). Os nós representam o início e o final das interseções entre duas vias ou quaisquer pontos onde ocorra mudança nas características das vias, como mudança no número de faixas e magnitude do greide, ou ainda interseções e acessos. Os tramos ou links promovem a ligação entre os nós e representam as vias por onde os veículos trafegam. 
Cada tramo é definido por sua origem e destino. Para que ocorra a simulação é necessário que os dados de entrada estejam estruturados através de arquivos numerados estruturados em um único arquivo geral, chamado de Record Type (RT). Cada $R T$ trata de parte do conjunto de entradas necessárias à simulação e podem ser obrigatórios ou opcionais. Os obrigatórios são os arquivos de demanda de tráfego e características da via, enquanto que os opcionais são os que tratam do comportamento dos motoristas e desempenho veicular, há também RT específicos para FRESIM ou NETSIM (CUNHA, 2007).

O CORSIM é capaz de produzir o arquivo gráfico TRAFED que permite a visualização da simulação, como mostra a como mostra a Figura 3.1 e o arquivo gráfico TRAFED representado na Figura 3.2.

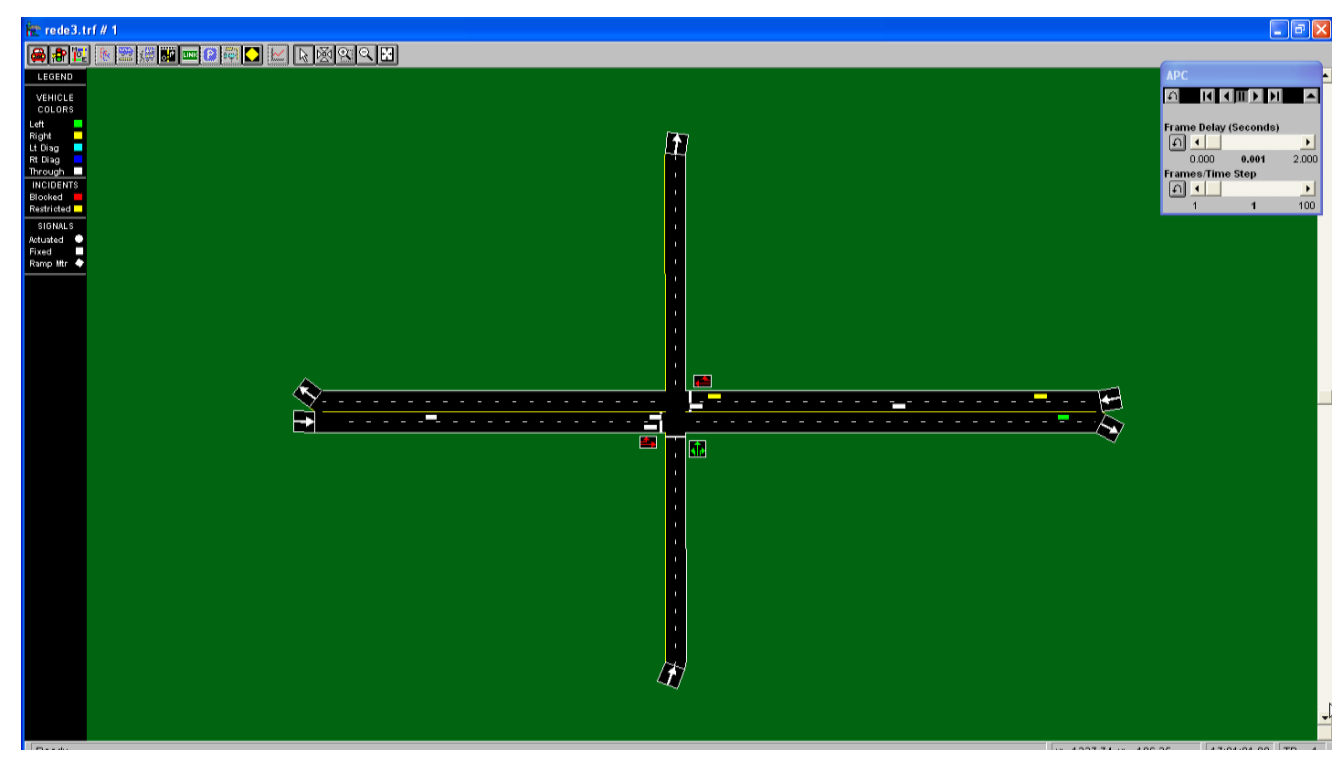

Figura 3. 1 - Representação gráfica de um cruzamento semáforizado simulado no CORSIM. 


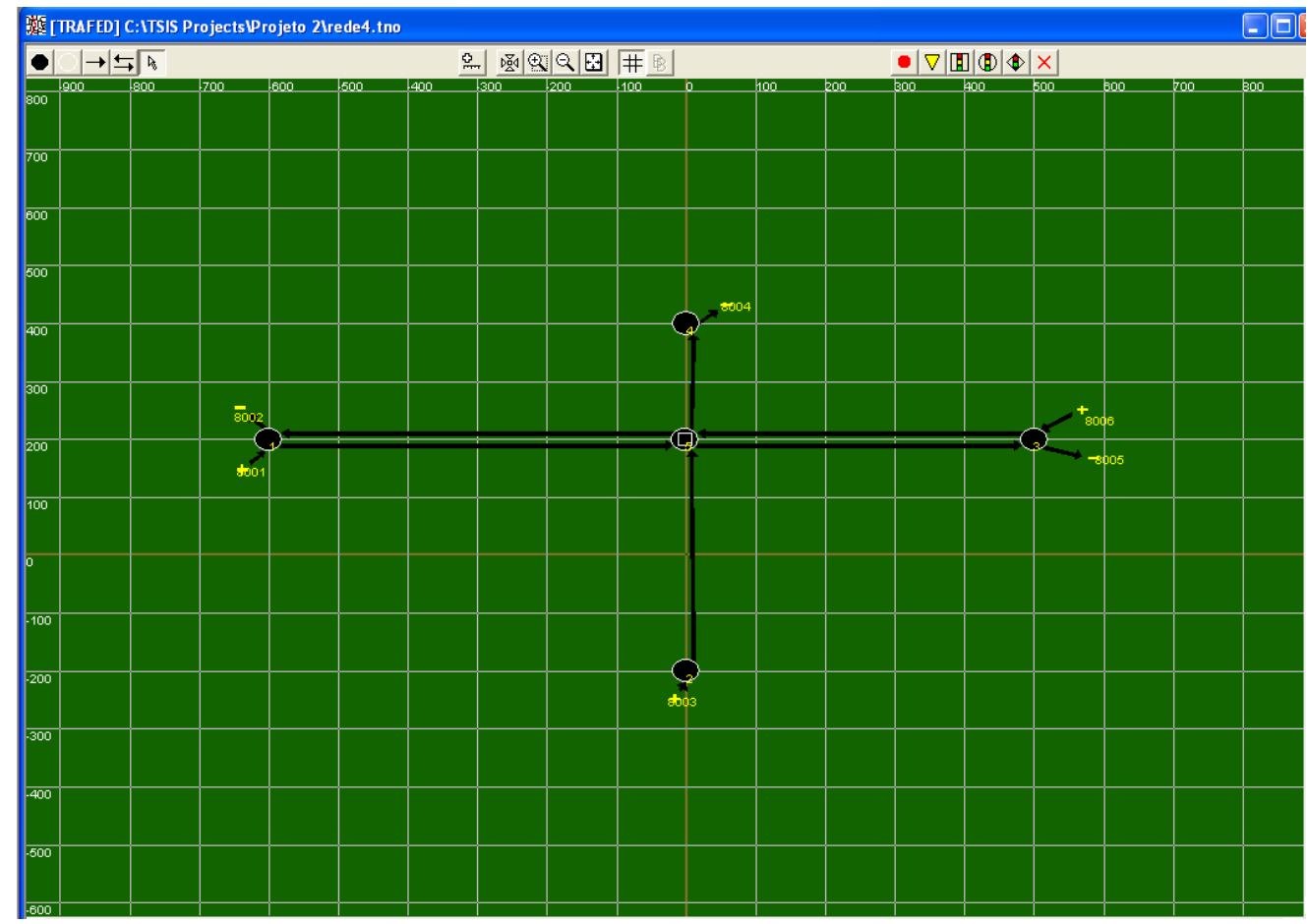

Figura 3. 2 - llustração do editor gráfico TRAFED.

\subsection{Simulador Integration}

O INTEGRATION é um programa de simulação microscópico baseado em viagens, que acompanha o movimento dos veículos da origem ao destino. As atualizações acontecem a cada 0,1 segundo e os movimentos podem ser laterais, como as mudanças de faixas, e longitudinais, como a progressão dos veículos nos links (SETTI, 2004).

O INTEGRATION é composto por nós e tramos, os nós representam o início e o final das interseções entre duas vias ou quaisquer pontos onde ocorra mudança nas características das vias, como mudança no número de faixas e magnitude do greide. Os tramos ou Links promovem a ligação entre os nós e representam as vias por onde os veículos trafegam. Cada tramo é definido por sua origem e destino. 
Para programar o INTEGRATION são necessários 6 arquivos obrigatórios (SETTI, 2004):

1. Arquivo Mestre: contém as informações sobre os nomes dos arquivos de dados, sua localização e o tempo de simulação.

2. Arquivo de Nós: contêm as coordenadas cartesianas dos nós da rede, as distâncias em relação às coordenadas e as zonas de origem e destinos de cada nó.

3. Arquivo de Tramos ou Links: contém os comprimentos dos tramos, os números de faixa de cada tramo e os parâmetros que definem a relação fluxo-Velocidade, ou seja, a velocidade de fluxo livre, a velocidade na capacidade, a capacidade e a densidade de congestionamento.

4. Arquivo de elementos de Controle: contém informações sobre programação semafórica; se o cenário programado não possuir vias com fluxo interrompido a programação terá que conter esses arquivos em branco para que o programa possa funcionar.

5. Arquivo de demandas: contém a matriz de origem/destino, indicando o tamanho de cada demanda, o instante de inicio e fim de sua geração, o padrão de geração das viagens e a composição veicular.

6. Arquivo de Incidentes: contém informações que permitem simular a ocorrência de incidentes, tais como o bloqueio temporário de uma faixa de tráfego. Mesmo que nenhum incidente seja simulado, um arquivo em branco é necessário para rodar o programa.

Esses 6 arquivos são os arquivos básicos para que o INTEGRATION funcione. Com isso obtém 4 tipos de resultados: a animação na tela do monitor, erros de execução, que aparecem no arquivo RUNNER.OUT, resumos concisos das 
estatísticas da simulação, que ficam no arquivo SUMMARY.OUT, e os resultados detalhados no arquivo FILE 10.OUT.

A animação da simulação na tela ajuda a verificar se a rede está correta, identificar erros de codificação em links, sinais, cruzamentos, identificar interrupções de fluxos e outros comportamentos indesejáveis, além de ser fácil acompanhar a evolução dos congestionamentos.

O arquivo de saída Runner. out é criado no início da simulação e atualizado a cada 600 segundos; nesse arquivo é indicado o tamanho da rede e listados os erros encontrados durante a leitura dos dados ou na execução do programa.

O Summary.out também é um arquivo de saída que é criado no final da simulação, e fornece medidas de desempenho agregadas para toda a rede simulada. Além desses arquivos, o INTEGRATION possui arquivos opcionais que melhoram a qualidade da simulação (SETTI, 2004).

A Figura 3.3 apresenta a tela de simulação de um cruzamento semaforizado pelo INTEGRATION.

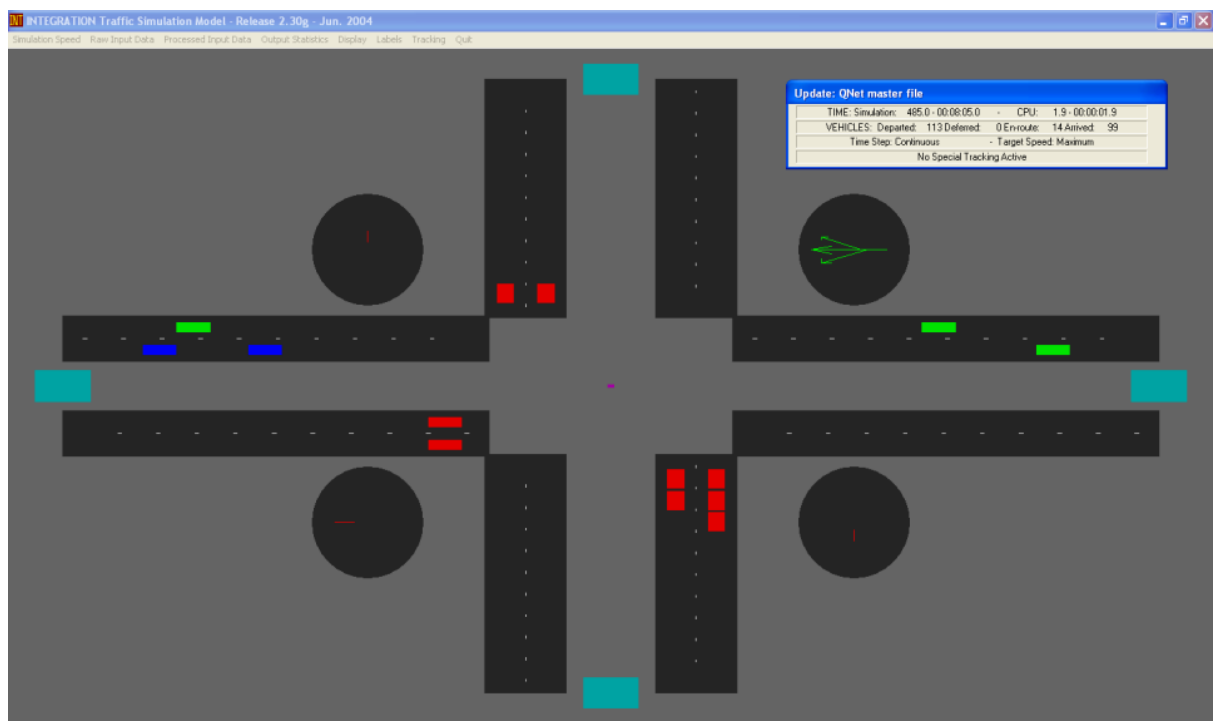

Figura 3. 3 - Tela de simulação do INTEGRATION. 



\section{RESULTADOS E ANÁLISES DAS PESQUISAS DE CAMPO}

\subsection{Considerações iniciais}

As pesquisas de campo foram realizadas em São Carlos, cidade situada no centro do Estado de São Paulo (cerca de 240 km da capital São Paulo).

De acordo com o IBGE (2009), o município de São Carlos possui uma área territorial de $1.141 \mathrm{~km}^{2}, 220.463$ habitantes e 95\% da população vivendo na área urbana. A frota total na cidade, segundo dados do DENATRAN (2008), é de 114.085 veículos, incluindo automóveis, caminhões, ônibus, micro-ônibus e motocicletas.

\subsection{Tempo perdido no início da fase e fluxo de saturação}

De acordo com a literatura, os intervalos de tempo entre a passagem de veículos consecutivos na linha de retenção em semáforos é maior para os quatro primeiros veículos da fila, conforme indicado na Figura 4.1.

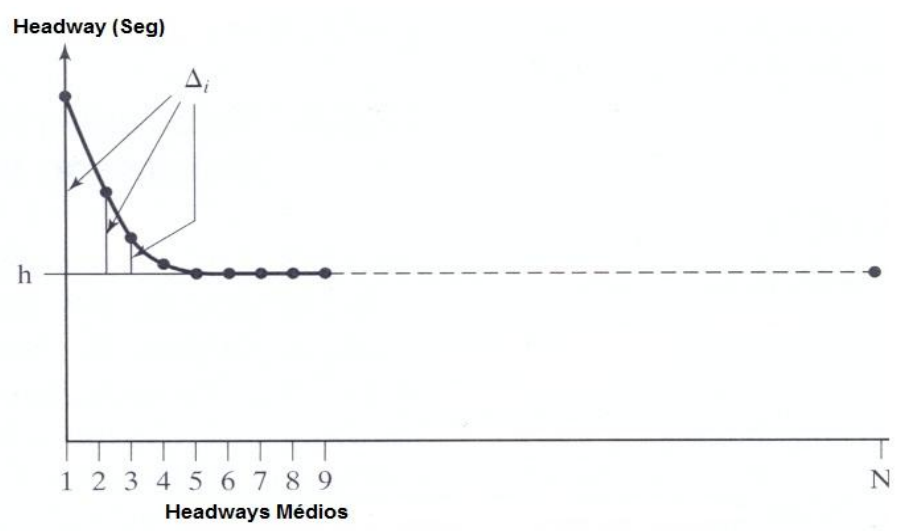

Figura 4. 1 - Headways numa fila de veículos num semáforo. 
Em vista do exposto, para a obtenção do fluxo de saturação e do tempo perdido no início de cada fase semafórica foi empregada à metodologia descrita a seguir.

Quando o tempo de verde começava, o cronômetro era disparado. No instante em que o para-choque dianteiro do $4^{\circ}$ e $10^{\circ}$ veículos da fila que passavam pela linha de retenção eram registrados os tempos (observando que esse último veículo estava na fila quando surgiu a luz de verde).

As seguintes condições foram observadas no experimento: o fluxo fluía livre e sem interrupções, não havia veículos fazendo conversões e nem interferências como manobras de estacionamento e/ou outras situações que modificassem a fluidez do trânsito, além disso, o fluxo observado era constituído apenas de veículos de passeio.

Uma vez obtidos os instantes anteriormente mencionados, foram utilizadas as seguintes expressões para a determinação das grandezas pesquisadas.

$$
\begin{gathered}
h_{i}=\frac{T_{4}}{4} \\
\mathrm{~h}_{\mathrm{n}}=\frac{T_{10}-T_{4}}{6} \\
T_{p i}=4 *\left(h_{i}-h_{n)}\right.
\end{gathered}
$$


Sendo:

$h_{i}:$ Headway médio para os 4 primeiros veículos;

$\mathrm{h}_{\mathrm{n}}$ : Headway médio após a passagem do $4^{\circ}$ veículo;

$T_{10}$ : Instante de passagem do $10^{\circ}$ veículo da fila;

$T_{4}$ : Instante de passagem do 4ํveículo da fila;

$T_{p i}:$ Tempo perdido inicial.

Seguem os resultados obtidos nos cruzamentos pesquisados.

\section{Cruzamento 1: Av. São Carlos x XV de Novembro}

A coleta de dados no cruzamento da Av. São Carlos com XV de Novembro foi feito no dia 22 de fevereiro de 2010, no horário das 17:30h as 18:30h. Foram observados 24 ciclos semafóricos em cada via. As médias dos resultados obtidos no cruzamento encontram-se na Tabela 4.1.

Tabela 4. 1 - Resultados obtidos para o cruzamento 1.

\begin{tabular}{|c|c|c|c|c|c|}
\hline \multirow{2}{*}{ Via } & \multicolumn{2}{|c|}{ Tempo perdido (s) } & \multicolumn{2}{c|}{ Headway (s) } & $\begin{array}{c}\text { Valor médio do } \\
\text { fluxo de saturação } \\
\text { (v/h) }\end{array}$ \\
\cline { 2 - 6 } & Valor Médio (s) & Desvio Padrão & Valor Médio (s) & Desvio Padrão & 1752,11 \\
\hline $\begin{array}{c}\text { XV de } \\
\text { novembro }\end{array}$ & 3,12 & 1,601 & 2,08 & 0,228 & 1622,76 \\
\hline $\begin{array}{c}\text { Av. São } \\
\text { Carlos }\end{array}$ & 2,05 & 1,233 & 2,25 & 0,259 & 1687,43 \\
\hline Ambas & 2,585 & 1,417 & 2,165 & 0,2435 & 1 \\
\hline
\end{tabular}




\section{Cruzamento 2: Av. São Carlos x Dr. Carlos Botelho}

As coletas de dados no cruzamento da Av. São Carlos com a Av. Dr. Carlos Botelho foram realizados no dia 23 de fevereiro de 2010 também no horário das 17:30h as 18:30h. Também nesse cruzamento foram observados e coletados 24 ciclos em cada aproximação. Os resultados encontrados estão na Tabela 4.2.

Tabela 4. 2 - Resultados obtidos para o cruzamento 2.

\begin{tabular}{|c|c|c|c|c|c|}
\hline \multirow{2}{*}{ Via } & \multicolumn{2}{|c|}{ Tempo perdido (s) } & \multicolumn{2}{|c|}{ Headway (s) } & \multirow{2}{*}{$\begin{array}{l}\text { Valor médio do } \\
\text { fluxo de } \\
\text { saturação (v/h) }\end{array}$} \\
\hline & $\begin{array}{c}\text { Valor Médio } \\
\text { (s) }\end{array}$ & $\begin{array}{l}\text { Desvio } \\
\text { Padrão }\end{array}$ & $\begin{array}{c}\text { Valor Médio } \\
\text { (s) }\end{array}$ & $\begin{array}{l}\text { Desvio } \\
\text { Padrão } \\
\end{array}$ & \\
\hline $\begin{array}{l}\text { Dr. Carlos } \\
\text { Botelho }\end{array}$ & 2,51 & 1,156 & 2,2 & 0,208 & 1647,61 \\
\hline $\begin{array}{c}\text { Av. São } \\
\text { Carlos }\end{array}$ & 2,52 & 0,68 & 2,33 & 0,238 & 1556,40 \\
\hline Ambas & 2,515 & 0,918 & 2,265 & 0,223 & 1602,00 \\
\hline
\end{tabular}

\section{Cruzamento 3: Av. São Carlos x Rua Padre Teixeira}

Os dados coletados nesse cruzamento foram realizados no dia 24 de fevereiro de 2010, no horário de pico das 17:30h as 18:30h; foram observados 24 ciclos semafóricos em cada via num total de 48 ciclos. A Tabela 4.3 apresenta os resultados encontrados no cruzamento. 
Tabela 4. 3 - Resultados obtidos para o cruzamento 3.

\begin{tabular}{|c|c|c|c|c|c|}
\hline \multirow{2}{*}{ Via } & \multicolumn{2}{|c|}{ Tempo perdido (s) } & \multicolumn{2}{|c|}{ Headway (s) } & \multirow{2}{*}{$\begin{array}{l}\text { Valor médio do } \\
\text { fluxo de } \\
\text { saturação (v/h) }\end{array}$} \\
\hline & $\begin{array}{c}\text { Valor Médio } \\
\text { (s) }\end{array}$ & $\begin{array}{l}\text { Desvio } \\
\text { Padrão }\end{array}$ & $\begin{array}{c}\text { Valor Médio } \\
\text { (s) }\end{array}$ & $\begin{array}{l}\text { Desvio } \\
\text { Padrão }\end{array}$ & \\
\hline $\begin{array}{c}\text { Padre } \\
\text { Teixeira }\end{array}$ & 2,50 & 0,797 & 2,35 & 0,111 & 1531,81 \\
\hline $\begin{array}{c}\text { Av. São } \\
\text { Carlos }\end{array}$ & 2,87 & 1,84 & 2,35 & 0,394 & 1531,81 \\
\hline Ambas & 2,685 & 1,319 & 2,35 & 0,253 & 1531,81 \\
\hline
\end{tabular}

\section{Valores médios globais para todos os cruzamentos}

A Tabela 4.4 apresenta os valores médios do headway, tempo perdido e fluxo de saturação dos 3 cruzamentos considerados em conjunto.

Tabela 4. 4 - Valores médios globais.

\begin{tabular}{|c|c|c|c|c|}
\hline \multicolumn{2}{|c|}{ Tempo perdido (s) } & \multicolumn{2}{c|}{ Headway (s) } & \multirow{2}{*}{$\begin{array}{c}\text { Fluxo de } \\
\text { saturação (v/h) }\end{array}$} \\
\cline { 1 - 3 } $\begin{array}{c}\text { Valor Médio } \\
\text { (s) }\end{array}$ & $\begin{array}{c}\text { Desvio } \\
\text { Padrão }\end{array}$ & $\begin{array}{c}\text { Valor Médio } \\
\text { (s) }\end{array}$ & $\begin{array}{c}\text { Desvio } \\
\text { Padrão }\end{array}$ & \\
\hline 2,60 & 1,218 & 2,26 & 0,240 & 1607,08 \\
& & & & \\
\hline
\end{tabular}




\subsection{Tempo perdido no final do amarelo}

Para obtenção do tempo perdido no final do amarelo foram coletados, com o uso de um cronômetro, o instante de passagem do último veículo da fila após o aparecimento da luz amarela. As medidas foram efetuadas no cruzamento da Avenida São Carlos com a Avenida Dr. Carlos Botelho. Na Tabela 4.5 estão indicados os valores médios dos tempos de passagem do último veículo da fila, bem como os valores médios dos tempos perdidos no final do tempo amarelo (no caso com duração de 3s).

Tabela 4. 5 - Média dos tempos de passagem após o aparecimento da luz amarela e tempo perdido.

\begin{tabular}{|c|c|c|c|}
\hline \multirow{2}{*}{ Via } & \multicolumn{2}{|c|}{ Instante de passagem (s) } & Tempo perdido (s) \\
\cline { 2 - 4 } & Valor Médio (s) & Desvio Padrão & Valor Médio (s) \\
\hline $\begin{array}{c}\text { Dr. Carlos } \\
\text { Botelho }\end{array}$ & 2,39 & 0,916 & 0,61 \\
\hline $\begin{array}{c}\text { Av. São Carlos } \\
\text { Ambas }\end{array}$ & 2,56 & 0,938 & 0,44 \\
\hline
\end{tabular}

\subsection{Tempo total perdido por fase e fluxo de saturação}

Considerando os resultados médios globais, o tempo total (no início e no final) perdido no verde mais amarelo por fase resulta igual a 3,12s. Para obter 0 tempo total perdido por fase deve ser adicionado a esse valor o tempo de vermelho total, ou seja:

$$
T p=3,12+R t
$$


Sendo:

$T p:$ Tempo de travessia dos pedestres;

$R t:$ Tempo de vermelho total $=2$ segundos.

Considerando ser igual a 2s o valor do vermelho total na cidade, resulta um tempo total perdido por ciclo de cerca de $5 \mathrm{~s}$. Cabe reiterar, no entanto, que esse valor vale para interseções praticamente sem declividade - em conformidade com a pesquisa.

O valor médio do fluxo de saturação considerando todas as aproximações é igual a $1607 \mathrm{v} / \mathrm{h}$. Esse valor, é importante dizer, foi obtido para fluxos se conversão e em interseções praticamente sem declividade.

No caso de interseções com acentuada declividade e grande porcentagem de veículos realizando conversões, esses valores devem ser determinados no campo ou estimados com base em modelos teóricos.

\subsection{Velocidade dos pedestres}

As interseções onde foram realizadas as medições são as seguintes: Av. São Carlos esquina com a Rua General Osório, Rua Episcopal esquina com a Rua Comendador Alfredo Maffei, Av. São Carlos esquina com a Rua Padre Teixeira e Rua Desembargador Julio de Faria esquina com a Av. Sallum. 
As medições foram realizadas entre os dias 24 de novembro de 2009 e $1^{\circ}$ de dezembro de 2009. Em cada interseção foram coletados em média 130 tempos de travessia de pedestres.

Os resultados das velocidades dos pedestres obtidos, considerando globalmente todas as interseções encontram-se na Tabela 4.6.

Tabela 4. 6 - Distribuição da velocidade em função da quantidade de pedestres.

\begin{tabular}{|c|c|c|}
\hline Velocidade (m/s) & $\begin{array}{c}\text { Total de } \\
\text { pedestres }\end{array}$ & $\begin{array}{l}\text { Porcentagem } \\
\text { de pedestres }\end{array}$ \\
\hline 0,8 & 12 & $2,39 \%$ \\
\hline 0,9 & 22 & $4,38 \%$ \\
\hline 1 & 52 & $10,36 \%$ \\
\hline 1,1 & 74 & $14,74 \%$ \\
\hline 1,2 & 84 & $16,73 \%$ \\
\hline 1,3 & 82 & $16,33 \%$ \\
\hline 1,4 & 63 & $12,55 \%$ \\
\hline 1,5 & 47 & $9,36 \%$ \\
\hline 1,6 & 33 & $6,57 \%$ \\
\hline 1,7 & 19 & $3,78 \%$ \\
\hline 1,8 & 8 & $1,59 \%$ \\
\hline 1,9 & 3 & $0,60 \%$ \\
\hline 2 & 2 & $0,40 \%$ \\
\hline 2,1 & 1 & $0,20 \%$ \\
\hline Total & 502 & $100 \%$ \\
\hline
\end{tabular}

A curva associada aos valores obtidos é mostrada na Figura 4.2. 


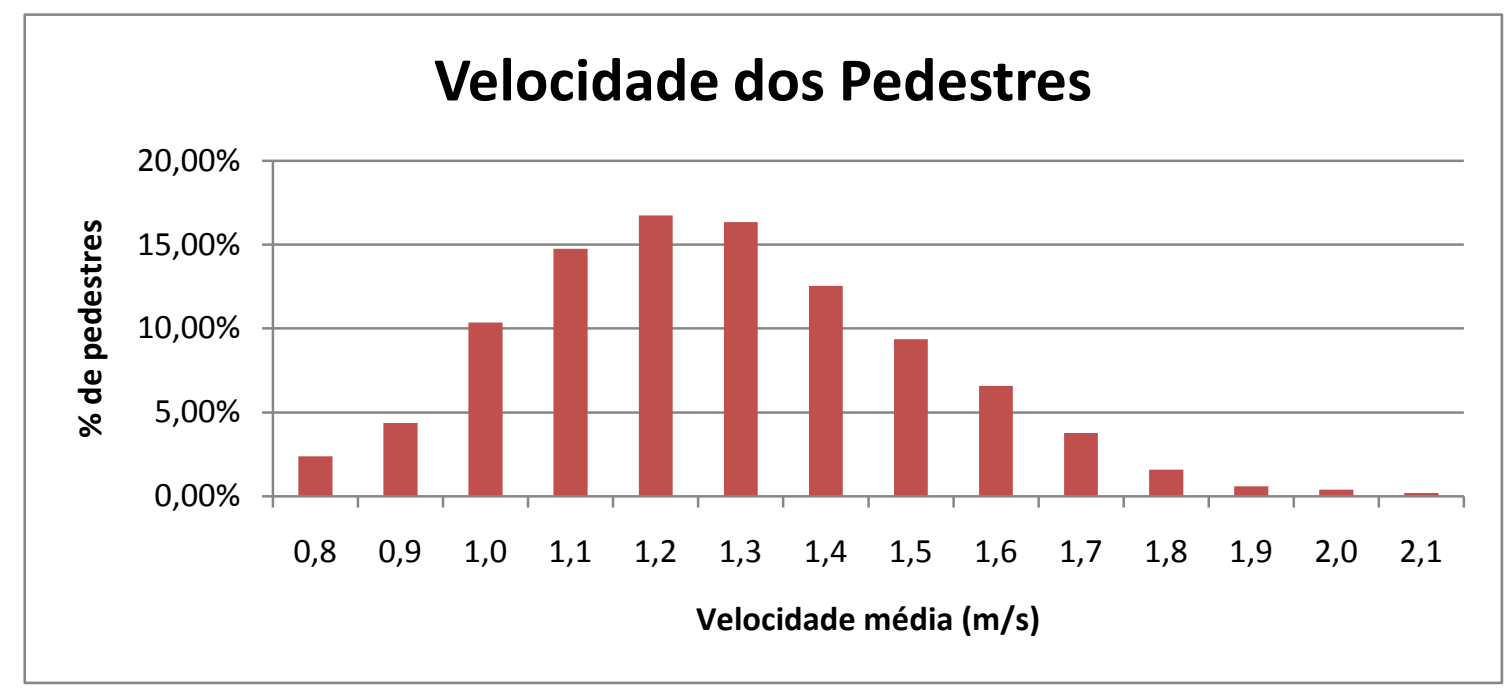

Figura 4. 2 - Distribuição da velocidade dos pedestres.

Os valores notáveis associados aos resultados obtidos são os seguintes:

- Velocidade média dos pedestres $=1,28 \mathrm{~m} / \mathrm{s}^{2}$

- Desvio padrão em torno da velocidade média $=0,236$

- Velocidade abaixo da qual transitam apenas $15 \%$ dos pedestres $(85 \%$ transitam com velocidade maior $)=1,00 \mathrm{~m} / \mathrm{s}^{2}$. 



\section{ANÁLISE DOS RESULTADOS DO ATRASO FORNECIDOS POR DIFERENTES MÉTODOS}

\subsection{Considerações iniciais}

Neste capítulo é feita uma análise dos resultados do atraso em semáforos fornecidos pelos seguintes métodos: Webster, HCM 2000, Simulador Integration e Simulador Corsim.

O estudo foi feito considerando o caso simples do cruzamento de duas vias com apenas uma faixa de tráfego e controle realizado por semáforo de 2 fases veiculares, conforme ilustrado na Figura 5.1. Os fluxos veiculares foram considerados iguais nas duas aproximações.

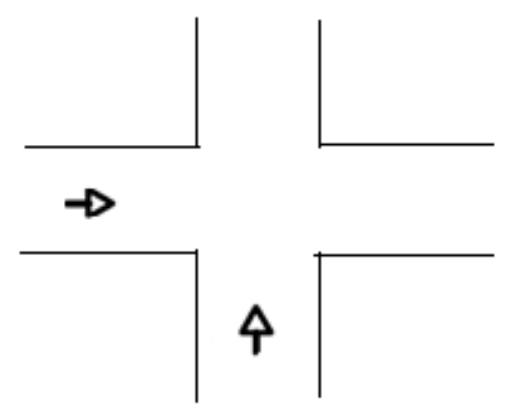

Figura 5. 1 - Croqui da interseção estudada.

Os valores do atraso foram obtidos para os seguintes valores do fluxo total: $600,700,800,900,1000,1100$ e 1200 veículos/hora. Para cada um desses volumes de tráfego, foram determinados os valores do atraso médio para os 
seguintes tempos de ciclo do semáforo: $30,40,50,60,70,80,90,100,110$ e 120 segundos.

As seguintes hipóteses foram consideradas nos cálculos: velocidade de fluxo livre $=50 \mathrm{~km} / \mathrm{h}$, velocidade na capacidade $=30 \mathrm{~km} / \mathrm{h}$, fluxo de saturação $=$ $1500 \mathrm{v} / \mathrm{h}$, densidade de congestionamento $=100 \mathrm{v} / \mathrm{km}$, tempo de amarelo $=3 \mathrm{~s}$, tempo de vermelho total $=2 \mathrm{~s}$ e tempo perdido por fase $=5 \mathrm{~s}$.

Nos casos dos simuladores Integration e do simulador Corsim os resultados foram obtidos após um tempo de simulação de 1 hora.

Com um tempo perdido por fase igual a 5 s, o tempo total perdido por ciclo resulta igual a 10 s e a capacidade de tráfego veicular considerando as duas aproximações com uma faixa cada uma é dada pela seguinte expressão:

$$
V=1500 \times \frac{C-10}{C}
$$

Sendo:

$V:$ Volume total de veículos $(\mathrm{v} / \mathrm{h})$;

C: Ciclo do semáforo (s).

Com essa expressão obtém-se os valores indicados na Tabela 5.1 para a capacidade em função do tempo de ciclo do semáforo. 
Tabela 5. 1- Valores da capacidade em função do tempo de ciclo do semáforo.

\begin{tabular}{|c|c|c|c|c|c|c|c|c|c|c|}
\hline Ciclo & 30 & 40 & 50 & 60 & 70 & 80 & 90 & 100 & 110 & 120 \\
\hline Capacidade (v/h) & 1000 & 1125 & 1200 & 1250 & 1286 & 1313 & 1333 & 1350 & 1364 & 1375 \\
\hline
\end{tabular}

Quando o volume de veículos que chega à interseção se aproxima da capacidade da mesma durante um grande período de tempo, ocorre congestionamento e os valores do atraso teoricamente tendem ao infinito. Em vista disso, não serão calculados os valores do atraso nesses casos.

\subsection{Resultados obtidos}

Na seqüência são apresentados os resultados obtidos para o atraso médio dos veículos no semáforo, nas condições anteriormente explicitadas.

Na Tabela 5.2 e a na Figura 5.2 são mostrados os valores do atraso médio para um fluxo total de $600 \mathrm{v} / \mathrm{h}$ (300 v/h em cada aproximação). 
Tabela 5. 2 - Atraso x Ciclo para um fluxo total de $600 \mathrm{v} / \mathrm{h}$.

\begin{tabular}{|c|c|c|c|c|}
\hline Ciclo & INTEGRATION & CORSIM & WEBSTER & HCM - 2000 \\
\hline 30 & 15,75 & 14,95 & 12,11 & 13,58 \\
\hline 40 & 12,30 & 13,00 & 12,4 & 13,36 \\
\hline 50 & 13,80 & 12,80 & 13,47 & 14,21 \\
\hline 60 & 15,55 & 13,80 & 14,75 & 15,38 \\
\hline 70 & 16,20 & 15,80 & 16,14 & 16,71 \\
\hline 80 & 18,40 & 17,35 & 17,5 & 18,10 \\
\hline 90 & 18,05 & 18,35 & 19,05 & 19,55 \\
\hline 100 & 19,85 & 20,55 & 20,58 & 21,02 \\
\hline 110 & 22,15 & 21,05 & 22,04 & 22,51 \\
\hline 120 & 24,30 & 20,95 & 23,55 & 24,01 \\
\hline
\end{tabular}

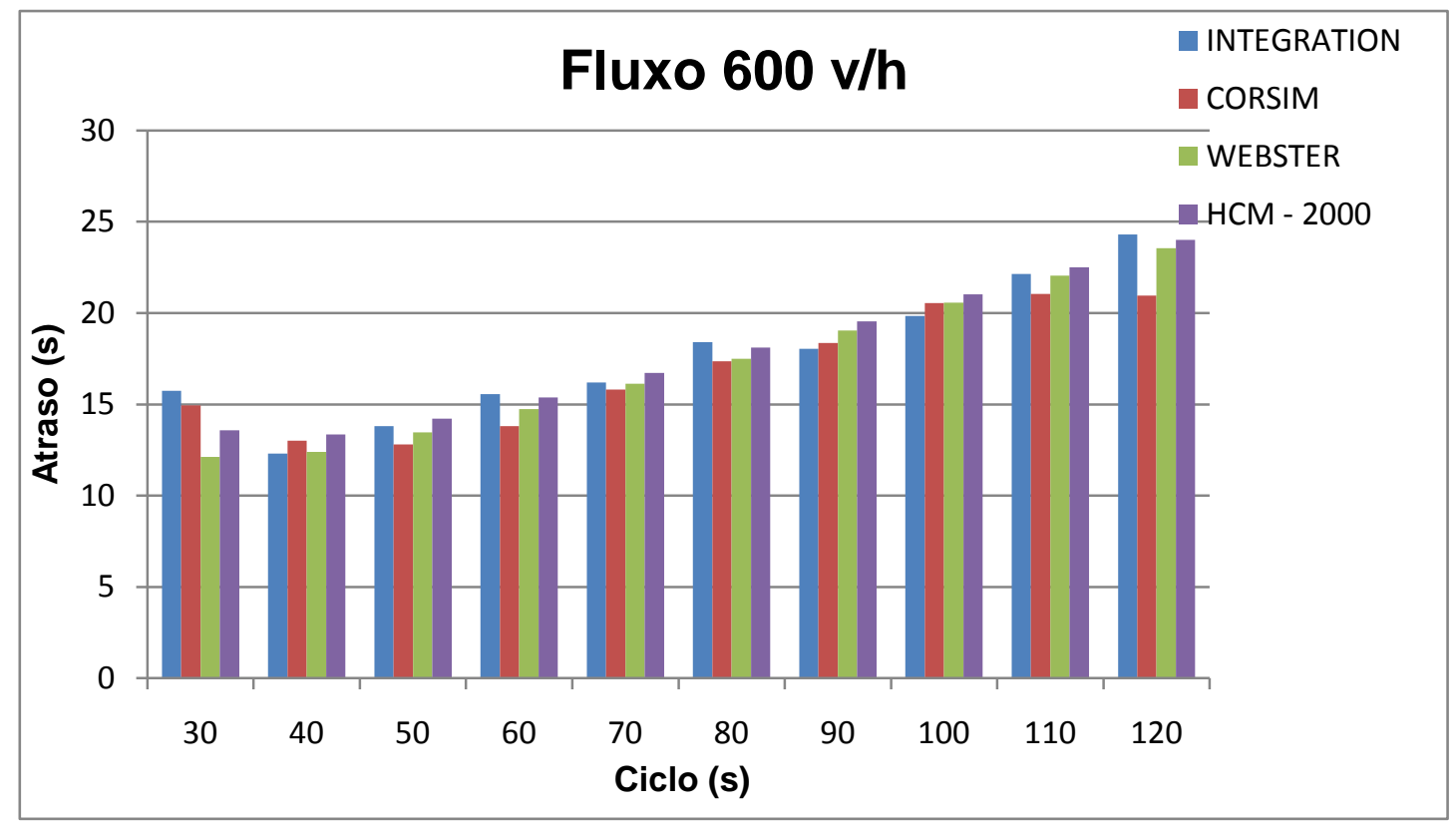


Figura 5. 2 - Atraso x Ciclo para um fluxo total de $600 \mathrm{v} / \mathrm{h}$.

Na Tabela 5.3 e a na Figura 5.3 são mostrados os valores do atraso médio para um fluxo total de $700 \mathrm{v} / \mathrm{h}$ (350 v/h em cada aproximação).

Tabela 5. 3 - Atraso x Ciclo para um fluxo total de $700 \mathrm{v} / \mathrm{h}$.

\begin{tabular}{|c|c|c|c|c|}
\hline Ciclo & INTEGRATION & CORSIM & WEBSTER & HCM - 2000 \\
\hline 30 & 17,90 & 22,80 & 14,51 & 16,63 \\
\hline 40 & 13,85 & 15,00 & 13,79 & 15,3 \\
\hline 50 & 14,95 & 14,20 & 14,63 & 15,84 \\
\hline 60 & 16,10 & 14,95 & 15,85 & 16,91 \\
\hline 70 & 16,90 & 16,45 & 17,23 & 18,20 \\
\hline 80 & 17,35 & 19,10 & 18,69 & 19,59 \\
\hline 90 & 19,75 & 19,65 & 20,19 & 21,05 \\
\hline 100 & 21,85 & 20,80 & 21,79 & 22,56 \\
\hline 110 & 22,20 & 22,25 & 23,28 & 24,09 \\
\hline 120 & 25,20 & 23,90 & 24,84 & 25,64 \\
\hline
\end{tabular}

Neste caso, o valor fornecido pelo Corsim é muito diferente do fornecido pelos outros métodos, mostrando que o método não fornece resultados aceitáveis para

$\mathrm{C}=30 \mathrm{~s}$ e fluxo igual a $700 \mathrm{v} / \mathrm{h}$. 


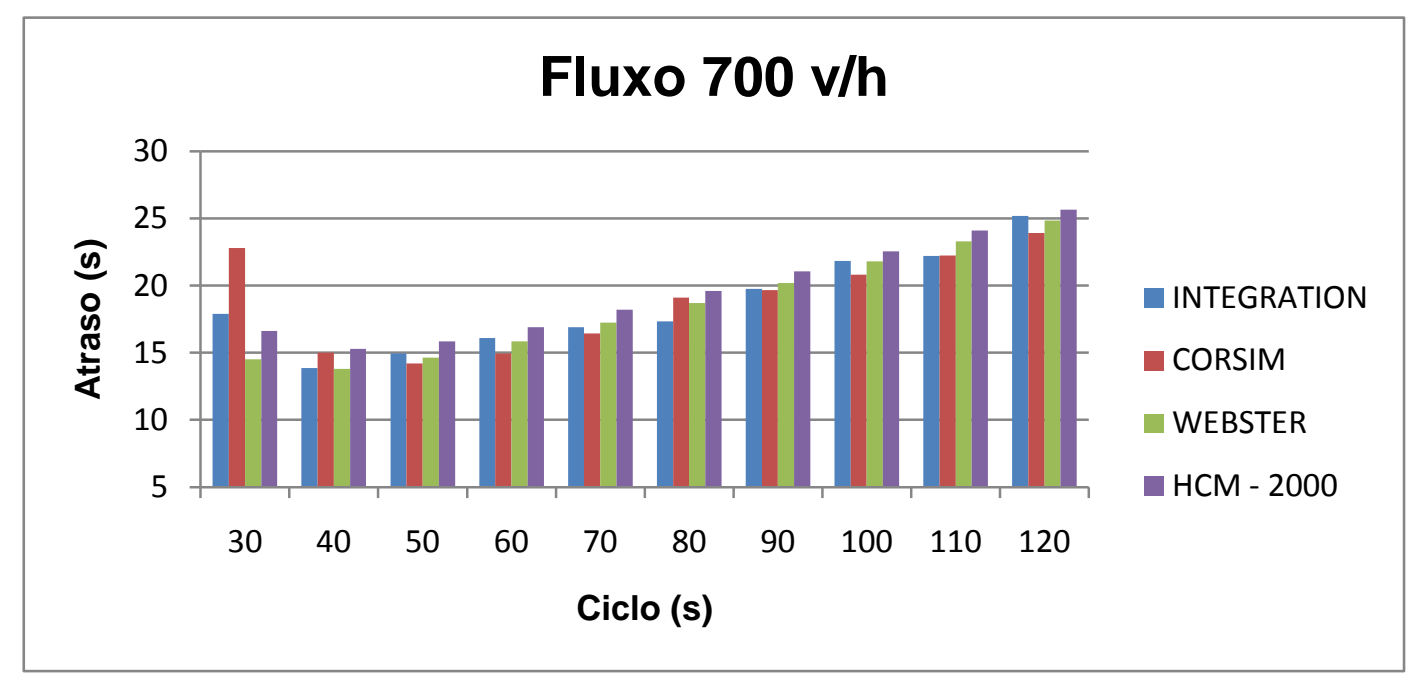

Figura 5. 3 - Atraso x Ciclo para um fluxo total de $700 \mathrm{v} / \mathrm{h}$.

Na Tabela 5.4 e a na Figura 5.4 são mostrados os valores do atraso médio para um fluxo total de $800 \mathrm{v} / \mathrm{h}$ (400 v/h em cada aproximação).

Tabela 5.4 - Atraso x Ciclo para um fluxo total de $800 \mathrm{v} / \mathrm{h}$.

\begin{tabular}{|c|c|c|c|c|}
\hline Ciclo & INTEGRATION & CORSIM & WEBSTER & HCM - 2000 \\
\hline 30 & 24,00 & 42,70 & 19,64 & 21,71 \\
\hline 40 & 14,85 & 16,50 & 15,96 & 18,1 \\
\hline 50 & 15,75 & 15,55 & 16,23 & 18,05 \\
\hline 60 & 17,10 & 16,10 & 17,23 & 18,88 \\
\hline 70 & 18,05 & 16,65 & 18,57 & 20,07 \\
\hline 80 & 19,40 & 18,30 & 20,02 & 21,44 \\
\hline 90 & 20,75 & 19,70 & 21,53 & 22,9 \\
\hline 100 & 22,20 & 21,50 & 23,2 & 24,42 \\
\hline 110 & 22,30 & 23,8 & 24,68 & 25,99 \\
\hline 120 & 24,00 & 25,50 & 26,29 & 27,58 \\
\hline
\end{tabular}

Neste caso, o valor fornecido pelo Corsim é bastante diferente do fornecido pelos outros métodos, mostrando que o Corsim não fornece resultados aceitáveis para $\mathrm{C}=30 \mathrm{~s}$ e fluxo igual a $800 \mathrm{v} / \mathrm{h}$. Por razões de escala, esse valor não está representado na figura 5.4. 


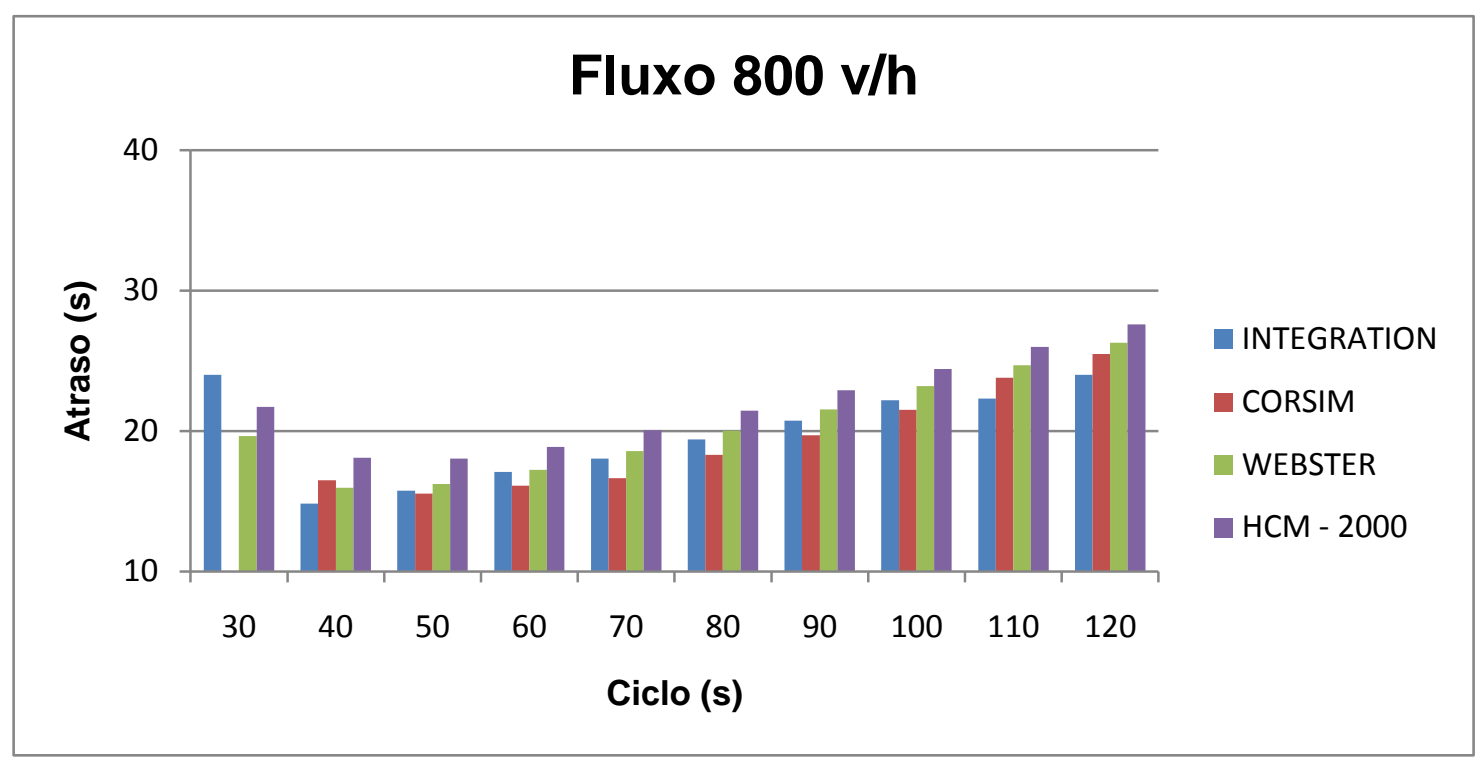

Figura 5. 4 - Atraso x Ciclo para um fluxo total de $800 \mathrm{v} / \mathrm{h}$.

$\mathrm{Na}$ Tabela 5.5 e a na Figura 5.5 são mostrados os valores do atraso médio para um fluxo total de $900 \mathrm{v} / \mathrm{h}$ (450 v/h em cada aproximação).

Tabela 5.5 - Atraso x Ciclo para um fluxo total de $900 \mathrm{v} / \mathrm{h}$.

\begin{tabular}{|c|c|c|c|c|}
\hline Ciclo & INTEGRATION & CORSIM & WEBSTER & HCM - 2000 \\
\hline 30 & 39,35 & 108,3 & 36,44 & 31,34 \\
\hline 40 & 17,50 & 23,55 & 20,22 & 22,52 \\
\hline 50 & 18,40 & 17,55 & 18,83 & 21,23 \\
\hline 60 & 18,90 & 17,65 & 19,33 & 21,59 \\
\hline 70 & 19,30 & 18,20 & 20,42 & 22,57 \\
\hline 80 & 19,75 & 19,75 & 21,76 & 23,83 \\
\hline 90 & 21,45 & 22,35 & 23,23 & 25,24 \\
\hline 100 & 21,80 & 24,05 & 24,96 & 26,76 \\
\hline 110 & 22,85 & 24,95 & 26,39 & 28,34 \\
\hline 120 & 25,05 & 27,80 & 28,03 & 29,96 \\
\hline
\end{tabular}


Neste caso, o valor fornecido pelo Corsim é bastante diferente do fornecido pelos outros métodos, mostrando que o Corsim não fornece resultados aceitáveis para $\mathrm{C}=30 \mathrm{~s}$ e fluxo igual a $900 \mathrm{v} / \mathrm{h}$. Por razões de escala, esse valor não está representado na figura 5.5.

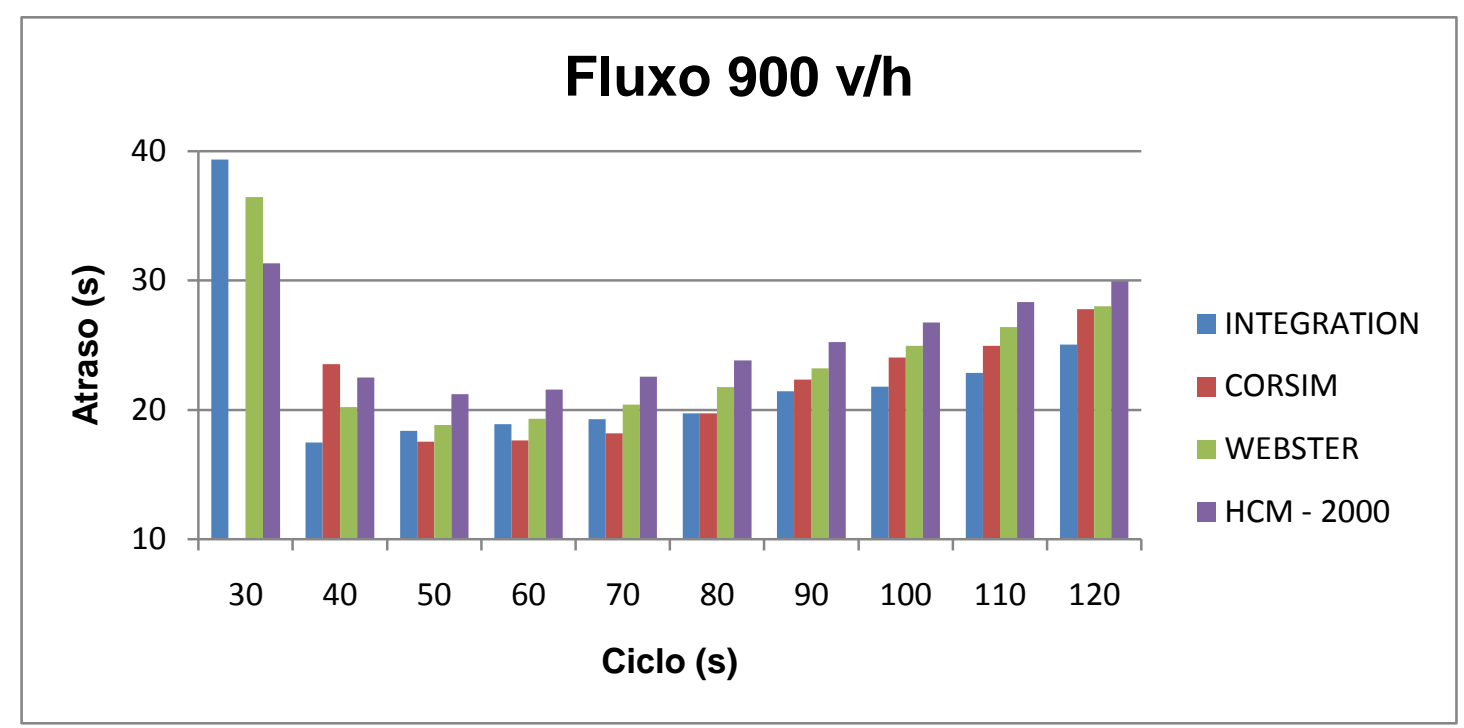

Figura 5.5 - Atraso x Ciclo para um fluxo total de $900 \mathrm{v} / \mathrm{h}$.

Na Tabela 5.6 e a na Figura 5.6 são mostrados os valores do atraso médio para um fluxo total de $1000 \mathrm{v} / \mathrm{h}$ (500 v/h em cada aproximação). Os valores correspondentes a $C=30$ s não foram calculados por estarem no limite da capacidade da interseção. 
Tabela 5. 6 - Atraso x Ciclo para um fluxo total de $1000 \mathrm{v} / \mathrm{h}$.

\begin{tabular}{|c|c|c|c|c|}
\hline Ciclo & INTEGRATION & CORSIM & WEBSTER & HCM - 2000 \\
\hline 30 & - & - & - & - \\
\hline 40 & 18,80 & 53,10 & 32,07 & 30,36 \\
\hline 50 & 18,25 & 23,15 & 24,20 & 26,31 \\
\hline 60 & 19,75 & 19,60 & 23,02 & 25,64 \\
\hline 70 & 20,40 & 21,50 & 23,42 & 26,13 \\
\hline 80 & 22,25 & 21,30 & 24,42 & 27,14 \\
\hline 90 & 22,25 & 23,70 & 25,71 & 28,42 \\
\hline 100 & 22,90 & 24,30 & 27,41 & 29,86 \\
\hline 110 & 23,95 & 26,50 & 28,72 & 31,42 \\
\hline 120 & 24,25 & 28,85 & 30,34 & 33,03 \\
\hline
\end{tabular}

Neste caso, o valor fornecido pelo Corsim é bastante diferente do fornecido pelos outros métodos, mostrando que o Corsim não fornece resultados aceitáveis para $C=40 \mathrm{~s}$ e fluxo igual a $1000 \mathrm{v} / \mathrm{h}$. Por razões de escala, esse valor não está representado na figura 5.6. 


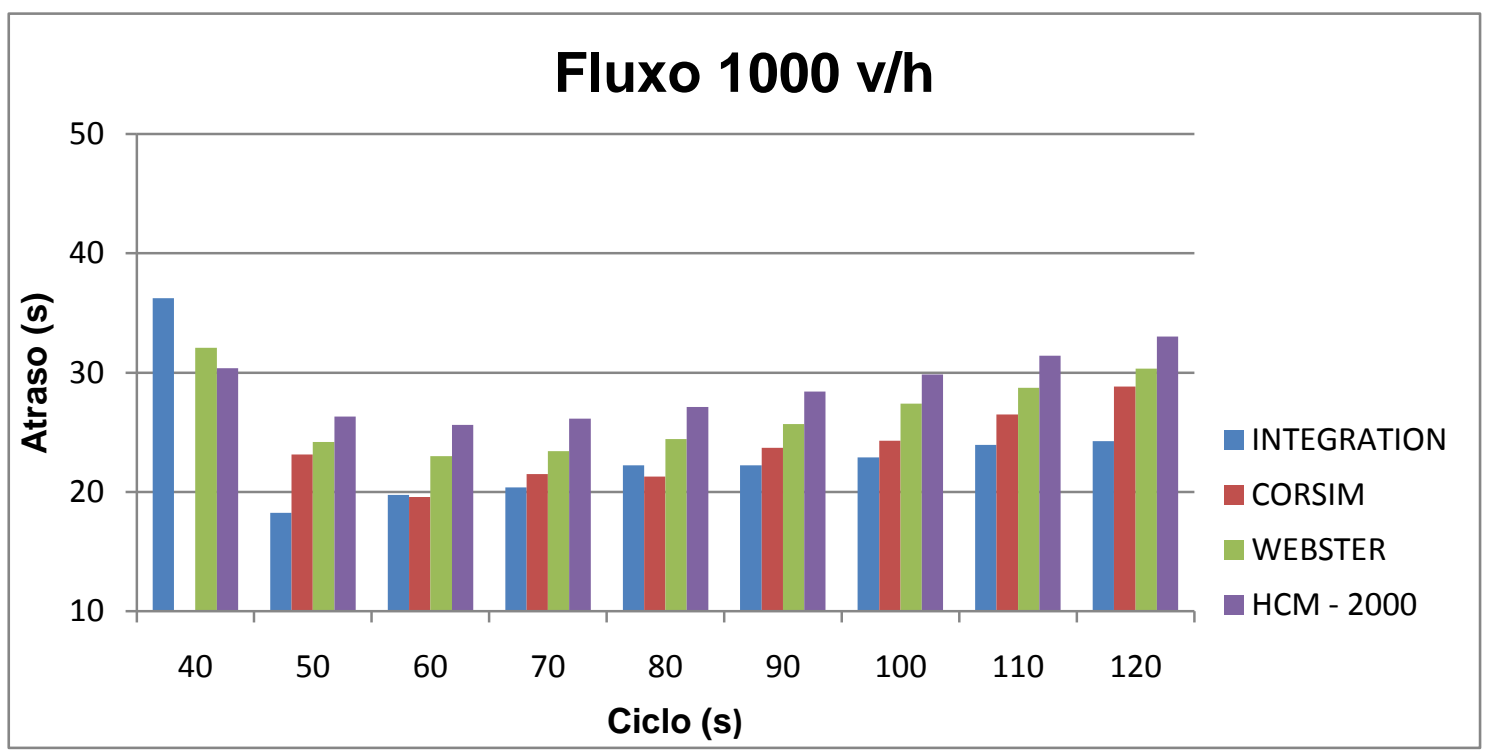

Figura 5.6 - Atraso x Ciclo para um fluxo total de $1000 \mathrm{v} / \mathrm{h}$.

Na Tabela 5.7 e a na Figura 5.7 são mostrados os valores do atraso médio para um fluxo total de $1100 \mathrm{v} / \mathrm{h}$ (550 v/h em cada aproximação). Os valores correspondentes a $C=30$ s e $C=40$ s não foram calculados por estarem no limite da capacidade da interseção.

Tabela 5.7 - Atraso x Ciclo para um fluxo total de $1100 \mathrm{v} / \mathrm{h}$.

\begin{tabular}{|c|c|c|c|c|}
\hline Ciclo & INTEGRATION & CORSIM & WEBSTER & HCM - 2000 \\
\hline 30 & - & - & - & - \\
\hline 40 & - & - & - & - \\
\hline 50 & 21,45 & 57,70 & 41,30 & 35,32 \\
\hline 60 & 21,10 & 24,40 & 31,96 & 32,35 \\
\hline 70 & 23,05 & 23,15 & 29,72 & 31,74 \\
\hline 80 & 22,80 & 22,55 & 29,51 & 32,15 \\
\hline 90 & 22,95 & 24,25 & 30,14 & 33,07 \\
\hline 100 & 23,35 & 26,80 & 31,54 & 34,30 \\
\hline 110 & 24,05 & 28,20 & 32,50 & 35,72 \\
\hline 120 & 23,75 & 29,80 & 33,96 & 37,27 \\
\hline
\end{tabular}


Neste caso, o valor fornecido pelo Corsim é bastante diferente do fornecido pelos outros métodos, mostrando que o Corsim não fornece resultados aceitáveis para $\mathrm{C}=50 \mathrm{~s}$ e fluxo igual a $1100 \mathrm{v} / \mathrm{h}$. Por razões de escala, esse valor não está representado na figura 5.7 .

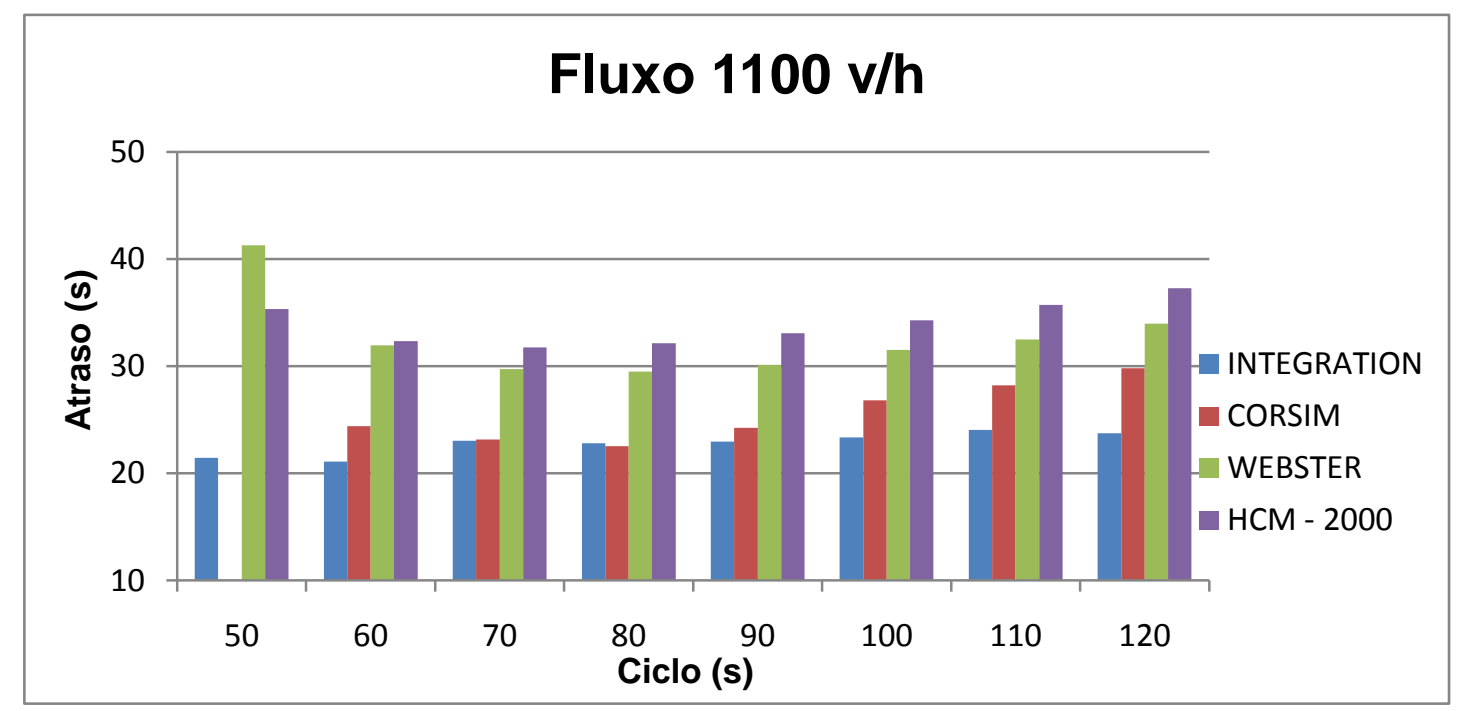

Figura 5. 7 - Atraso x Ciclo para um fluxo total de $1100 \mathrm{v} / \mathrm{h}$.

Na Tabela 5.8 e a na Figura 5.8 são mostrados os valores do atraso médio para um fluxo total de $1200 \mathrm{v} / \mathrm{h}$ (600 v/h em cada aproximação). Os valores correspondentes a $C=30 \mathrm{~s}, \mathrm{C}=40 \mathrm{~s}, \mathrm{C}=50 \mathrm{~s}$ e $\mathrm{C}=60$ s não foram calculados por estarem no limite da capacidade da interseção.

Tabela 5.8 - Atraso x Ciclo para um fluxo total de $1200 \mathrm{v} / \mathrm{h}$.

\begin{tabular}{|c|c|c|c|c|}
\hline Ciclo & INTEGRATION & CORSIM & WEBSTER & HCM - 2000 \\
\hline 30 & - & - & - & - \\
\hline 40 & - & - & - & - \\
\hline 50 & - & - & - & - \\
\hline 60 & - & - & - & - \\
\hline 70 & 26,45 & 40,90 & 51,6 & 41,47 \\
\hline
\end{tabular}




\begin{tabular}{|c|c|c|c|c|}
80 & 24,85 & 26,50 & 44,00 & 40,54 \\
\hline 90 & 25,25 & 30,45 & 41,29 & 40,64 \\
\hline 100 & 25,70 & 30,00 & 40,98 & 41,33 \\
\hline 110 & 25,75 & 29,75 & 40,68 & 42,39 \\
\hline 120 & 23,65 & 32,10 & 41,39 & 43,69 \\
\hline
\end{tabular}

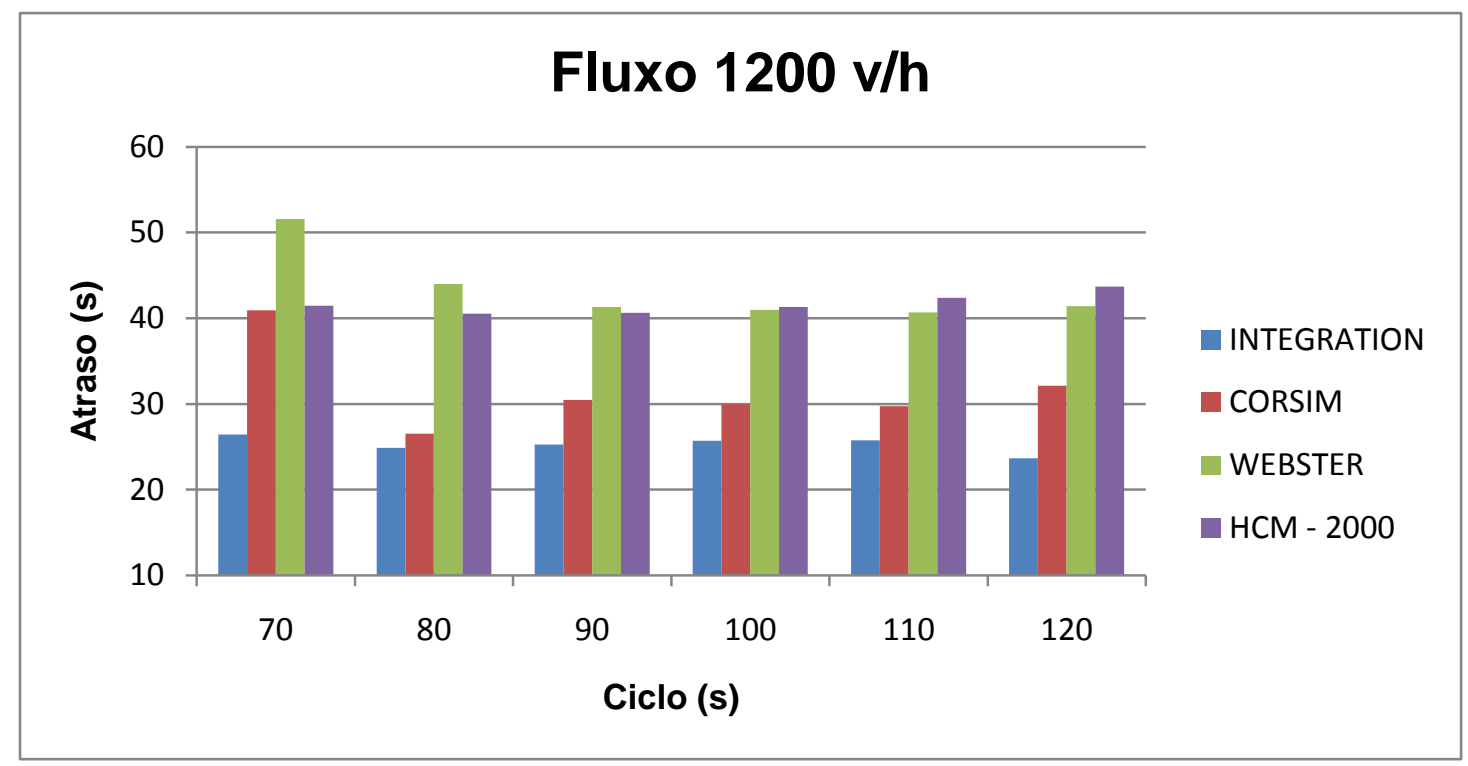

Figura 5.8 - Atraso x Ciclo para um fluxo total de $1200 \mathrm{v} / \mathrm{h}$.

\subsection{Interpretação dos resultados}

Para ciclos muito pequenos, como visto, o Simulador Corsim fornece resultados muito diferentes dos outros métodos.

Outra observação importante é que o Simulador Integration fornece resultados um tanto menores em relação aos outros métodos, quando o fluxo de veículos aumenta.

Os simuladores Integration e Corsin e os métodos HCM e Webster, apresentam faixa de ciclo ótimo semelhantes quando os fluxos encontram-se não saturados, aproximadamente até 1.000 veículos por hora na interseção. 


\section{DETERMINACÃO DOS TEMPOS DA FASE PARA A TRAVESSIA DE PEDESTRES}

\subsection{Considerações iniciais}

Existem diversos métodos propostos para a determinação da duração dos tempos que compõem a fase destinada à travessia de pedestres em semáforos.

Neste trabalho serão apresentados e discutidos os seguintes métodos: Webster/DENATRAN, CET-SP, Ferraz e MUTCD.

\subsection{Método Webster/DENATRAN}

Webster e Cobbe (1966) propuseram, e DENATRAN (1979) adotou a Expressão 6.1 para a determinação da fase destinada à travessia de pedestres.

$$
T p=\frac{L}{V p}+T S
$$

Sendo:

$T p$ : Duração da fase para a travessia de pedestres (s);

$L$ : Largura da via $(m)$;

$V p:$ Velocidade dos pedestres (normalmente adotar 1,2 m/s). 
Durante o tempo de segurança (Ts), o semáforo deverá estar com indicação de vermelho piscante e durante a diferença de tempo $(T p-T s=L / V p)$ deverá ter indicação verde.

Não há qualquer referência sobre o emprego de vermelho total após o término do vermelho piscante - e, obviamente, sobre a duração deste tempo.

\subsection{Método CET-SP}

O manual de semáforos da CET-SP (2002) preconiza a Expressão 6.2 para o cálculo do tempo de verde da fase de pedestres:

$$
T v=\frac{L}{V p}
$$

Sendo:

$T v$ : Duração do verde para os pedestres (s);

$L:$ Largura da via $(\mathrm{m})$

$V p:$ Velocidade dos pedestres (usualmente adotada igual a 1,2 m/s).

Para o vermelho piscante, o manual da CET-SP diz que a sua duração deve corresponder, aproximadamente, a metade do tempo de travessia, como indicado na Tabela 6.1 para diferentes valores da largura da via a ser cruzada. 
Tabela 6. 1 - Tempo de vermelho piscante, segundo CET.

\begin{tabular}{|c|c|}
\hline Largura da Interseção & $\begin{array}{c}\text { Vermelho piscante } \\
\text { (Segundos) }\end{array}$ \\
\hline $6 m \leq 8 m$ & 3 \\
\hline $8 m \leq 14 m$ & 4 \\
\hline $14 m \leq 18 m$ & 5 \\
\hline$\geq 18 m$ & 6 \\
\hline
\end{tabular}

Não são recomendados valores superiores a 6 segundos, pois, segundo 0 manual, podem incentivar os pedestres a iniciarem a travessia durante 0 vermelho piscante.

Não há qualquer referência explícita no manual sobre o emprego de vermelho total após o término do vermelho piscante - e, obviamente, sobre a duração deste tempo.

\subsection{Método Ferraz}

Para a duração da fase de pedestres, Ferraz (2005) preconiza o emprego da seguinte Expressão 6.3.

$$
F p=G+R^{*}+R t
$$


Sendo:

$G$ : Tempo de verde para os pedestres (entre 3 e $8 \mathrm{~s}$, em função da quantidade de pedestres - 3 seg no caso de poucos pedestres e 8 s quando se trata de grandes concentrações de pedestres);

$R^{*}$ : Tempo de vermelho piscante (tempo suficiente para que os pedestres que iniciaram a travessia no instante final do verde possam completá-la com segurança).

Rt : Tempo de vermelho total antes da luz ficar verde para as filas de veículos que cruzam as faixas de travessia de pedestres (preconizado no mínimo igual a 2s).

O tempo de vermelho piscante deve ser calculado mediante a Expressão 6.4.

$$
R^{*}=\frac{L}{V p}
$$

Sendo:

$L:$ Largura da via a ser cruzada $(\mathrm{m})$;

$V p$ : Velocidade dos pedestres em $\mathrm{m} / \mathrm{s}$ (preconizado igual a $1,25 \mathrm{~m} / \mathrm{s}$ ). 


\subsection{Método MUTCD}

De acordo com o MUTCD (Manual on Uniform Traffic Control Devices) de 2009, a fase para a travessia de pedestres deve ser calculada em três intervalos, como segue:

- O primeiro intervalo (luz verde) deverá ter 7 segundos de duração, em vias onde o volume de pedestres não é tão alto; em vias não muito largas esse tempo poderá cair para 4 segundos.

- O segundo intervalo (vermelho piscante) deverá ter o tempo calculado de acordo com a seguinte espressão:

$$
R^{*}=\frac{L}{V p}
$$

Sendo:

$L$ : Largura da via a ser cruzada $(m)$;

$V p$ : Velocidade dos pedestres em $\mathrm{m} / \mathrm{s}$ (preconizado igual a $1,2 \mathrm{~m} / \mathrm{s}$ ).

- O terceiro intervalo (vermelho total) deverá ser igual a 3s.

\subsection{Considerações}

Os métodos Webster/Denatran e CET-SP são similares. Apresentam o inconveniente de "assustar" os pedestres que estão no meio da travessia (longe da calçada de destino) com o aparecimento da luz vermelha, ainda que a questão da segurança possa ser garantida com o emprego de um período longo de vermelho total (não explicitado nos métodos) após o vermelho 
piscante. Se o tempo de vermelho total for pequeno, a luz verde para o fluxo de veículos surgirá antes de parte dos pedestres concluírem a travessia, havendo grande risco de ocorrência de acidentes.

O que os métodos Ferraz (2005) e MUTCD (2008) fazem é, de certa forma, reduzir o tempo de verde e aumentar o vermelho piscante, para evitar o "susto" dos pedestres que estão no meio da travessia (longe da calçada de destino) quando aparece a luz vermelha.

Os métodos Ferraz e MUTCD são análogos, com pequenas diferenças nos valores da velocidade adotada (maior no método Ferraz) e do tempo de vermelho total após o vermelho piscante (menor no método Ferraz se for utilizado o valor mínimo de 2s). Com isso, pode-se dizer que há, teoricamente, uma ligeira margem a favor da segurança na travessia de pedestres, em detrimento da capacidade veicular, no método MUTCD em relação ao de Ferraz. Nas pesquisas realizadas em São Carlos, a velocidade média dos pedestres resultou igual a $1,28 \mathrm{~m} / \mathrm{s}$, ligeiramente acima dos valores adotados por Ferraz $(1,25)$ e MUTCD $(1,2)$.

Essa diferença pode ser constatada mediante a observação dos valores apresentados na Tabela 6.2, onde estão indicadas a duração da fase de pedestres e dos valores da velocidade mínima para a travessia segura por ambos os métodos para diferentes larguras de vias (em ambos os métodos foi adotado um tempo verde de $5 \mathrm{~s}$, no método Ferraz foi adotado um vermelho total igual ao mínimo preconizado de 2 s e os valores foram arredondados para o inteiro mais próximo). 
Tabela 6. 2 - Velocidade mínima nos dois métodos.

\begin{tabular}{|l|c|c|c|c|c|c|c|c|c|}
\hline Método & $\mathrm{L}(\mathrm{m})$ & $\mathbf{6}$ & $\mathbf{8}$ & $\mathbf{1 0}$ & $\mathbf{1 2}$ & $\mathbf{1 4}$ & $\mathbf{1 6}$ & $\mathbf{1 8}$ & $\mathbf{2 0}$ \\
\hline Ferraz & $\begin{array}{c}\mathrm{Fp} \\
(\mathbf{s})\end{array}$ & 12 & 13 & 15 & 17 & 18 & 20 & 21 & 23 \\
\hline MUTCD & $\begin{array}{c}\mathrm{Fp} \\
(\mathbf{s})\end{array}$ & 13 & 15 & 16 & 18 & 20 & 21 & 23 & 25 \\
\hline Ferraz & $\begin{array}{c}\mathrm{Vp} \\
(\mathbf{m} / \mathbf{s})\end{array}$ & 0,88 & 0,95 & 1,00 & 1,03 & 1,06 & 1,08 & 1,10 & 1,11 \\
\hline MUTCD & $\begin{array}{c}\mathrm{Vp} \\
(\mathbf{m} / \mathbf{s})\end{array}$ & 0,75 & 0,85 & 0,88 & 0,92 & 0,95 & 0,98 & 1,00 & 1,02 \\
\hline
\end{tabular}

Nas pesquisas realizadas em São Carlos, a velocidade correspondente aos $15 \%$ com menor velocidade resultou igual a $1,00 \mathrm{~m} / \mathrm{s}$; de certa forma satisfeita nos métodos Ferraz e MUTCD.

$\mathrm{Na}$ Tabela 6.3 estão indicadas as durações das indicações luminosas que compõem a fase de pedestre para os quatro métodos considerando a travessia de uma via com largura de 10m (situação típica no mundo real). No caso dos métodos MUTCD e Ferraz foi adotado um verde igual a 5s, no método Ferraz foi adotado um vermelho total igual ao mínimo de 3 s e nos métodos Webster/DENATRAN e CET-SP foram estabelecidos tempos de vermelho total para garantir o mesmo nível de segurança para os pedestres do método Ferraz. 
Tabela 6. 3 - Duração das indicações luminosas que compõe a fase de pedestre.

\begin{tabular}{|c|c|c|c|c|}
\hline Método & GP & $\mathbf{R}^{*} \mathbf{p}$ & $\mathbf{R}^{*} \mathbf{t}$ & Fase \\
\hline Ferraz & 5 & 8 & 2 & 15 \\
\hline MUTCD & 5 & 8 & 3 & 16 \\
\hline DENATRAN & 8 & 5 & 5 & 18 \\
\hline CET -SP & 8 & 4 & 6 & 18 \\
\hline
\end{tabular}

De forma clara, os métodos Ferraz e MUTCD são mais indicados que os Webster/Denatran e CET-SP, uma vez que proporcionam adequada segurança sem assustar os pedestres e com o mínimo de prejuízo no tocante à capacidade do fluxo veicular. 


\section{CENÁRIOS SIMULADOS E ANÁLISE DOS RESULTADOS OBTIDOS}

\subsection{Caracterização dos cenários}

Neste capítulo 7 são apresentados os resultados obtidos com o Simulador Integration considerando os seguintes dois casos: operação de semáforo com 2 fases veiculares e com 3 fases, sendo duas veiculares $e$ uma fase exclusiva para pedestres.

O objetivo é determinar os intervalos de ciclo mais indicados em cada caso e avaliar a influência no atraso dos veículos da utilização de uma fase exclusiva para pedestres.

O estudo foi feito considerando o caso simples do cruzamento de duas vias com apenas uma faixa de tráfego e controle realizado por semáforo de 2 fases veiculares, conforme ilustrado na Figura 7.1. Os fluxos veiculares foram considerados iguais nas duas aproximações.

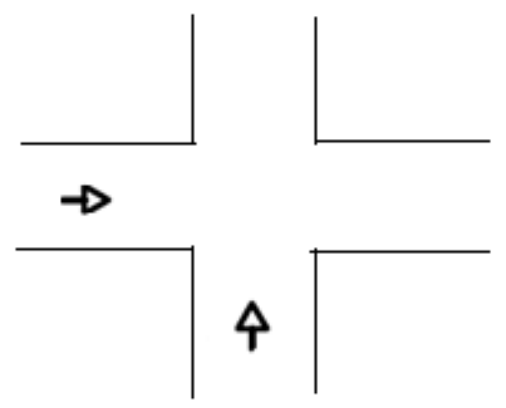

Figura 7. 1 - Croqui da interseção estudada. 
Os valores do atraso foram obtidos para os seguintes valores do fluxo total: $600,800,1000,1100$ e 1200 veículos/hora. Para cada um desses volumes de tráfego, foram determinados os valores do atraso médio para os seguintes tempos de ciclo do semáforo: $30,40,50,60,70,80,90,100,110$ e 120 segundos.

As seguintes hipóteses foram consideradas nos cálculos: velocidade de fluxo livre $=50 \mathrm{~km} / \mathrm{h}$, velocidade na capacidade $=30 \mathrm{~km} / \mathrm{h}$, fluxo de saturação $=$ $1500 \mathrm{v} / \mathrm{h}$, densidade de congestionamento $=100 \mathrm{v} / \mathrm{km}$, tempo de amarelo $=3 \mathrm{~s}$, tempo de vermelho total $=2 \mathrm{~s}$ e tempo perdido por fase $=5 \mathrm{~s}$, duração da fase de pedestres $-13 \mathrm{~s}$.

Os valores do atraso foram obtidos após um tempo de simulação de 1 hora.

\subsection{Resultados obtidos}

Na seqüência são apresentados os resultados obtidos para o atraso médio dos veículos no semáforo, nas condições anteriormente explicitadas.

As Tabelas 7.1 e 7.2 ilustram todos os valores de ciclo $x$ atraso encontrado nos 10 cenários simulados. 
Tabela 7. 1 - Ciclo x atraso com fase de pedestres.

\begin{tabular}{|c|c|c|c|c|c|c|c|c|c|}
\hline \multicolumn{10}{|c|}{ Cenários com fase de pedestres } \\
\hline \multicolumn{2}{|c|}{ Fluxo 600 } & \multicolumn{2}{|c|}{ Fluxo 800 } & \multicolumn{2}{c|}{ Fluxo 1000 } & \multicolumn{2}{c|}{ Fluxo 1100 } & \multicolumn{2}{c|}{ Fluxo 1200 } \\
\hline Ciclo & Atraso & Ciclo & Atraso & Ciclo & Atraso & Ciclo & Atraso & Ciclo & Atraso \\
\hline 30 & 73,60 & 30 & 91,25 & 30 & 95,9 & 30 & 94,95 & 30 & 96,90 \\
\hline 40 & 23,65 & 40 & 53,65 & 40 & 62,95 & 40 & 63,05 & 40 & 65,20 \\
\hline 50 & 19,10 & 50 & 25,95 & 50 & 42,5 & 50 & 46,80 & 50 & 48,45 \\
\hline 60 & 18,20 & 60 & 22,30 & 60 & 29,7 & 60 & 35,80 & 60 & 39,95 \\
\hline 70 & 20,10 & 70 & 21,55 & 70 & 25,7 & 70 & 33,45 & 70 & 37,20 \\
\hline 80 & 22,25 & 80 & 22,55 & 80 & 26,95 & 80 & 29,40 & 80 & 34,90 \\
\hline 90 & 20,75 & 90 & 24,20 & 90 & 26,45 & 90 & 27,90 & 90 & 33,50 \\
\hline 100 & 22,25 & 100 & 25,20 & 100 & 25,85 & 100 & 28,30 & 100 & 32,60 \\
\hline 110 & 24,85 & 110 & 25,85 & 110 & 26,8 & 110 & 28,45 & 110 & 31,75 \\
\hline 120 & 26,25 & 120 & 27,05 & 120 & 27,15 & 120 & 27,40 & 120 & 30,45 \\
\hline
\end{tabular}

Tabela 7. 2 - Ciclo $x$ atraso sem fase de pedestres.

\begin{tabular}{|c|c|c|c|c|c|c|c|c|c|}
\hline \multicolumn{10}{|c|}{ Cenários sem fase para pedestres } \\
\hline \multicolumn{2}{|c|}{ Fluxo $\mathbf{6 0 0}$} & \multicolumn{2}{|c|}{ Fluxo 800} & \multicolumn{2}{c|}{ Fluxo 1000} & \multicolumn{2}{c|}{ Fluxo 1100} & \multicolumn{2}{c|}{ Fluxo 1200 } \\
\hline Ciclo & Atraso & Ciclo & Atraso & Ciclo & Atraso & Ciclo & Atraso & Ciclo & Atraso \\
\hline 30 & 15,75 & 30 & 24,00 & 30 & 47,00 & 30 & 50,40 & 30 & 51,90 \\
\hline 40 & 12,30 & 40 & 14,85 & 40 & 18,80 & 40 & 24,30 & 40 & 31,25 \\
\hline 50 & 13,80 & 50 & 15,75 & 50 & 18,25 & 50 & 21,45 & 50 & 28,15 \\
\hline 60 & 15,55 & 60 & 17,10 & 60 & 19,75 & 60 & 21,10 & 60 & 26,05 \\
\hline 70 & 16,20 & 70 & 18,05 & 70 & 20,40 & 70 & 23,05 & 70 & 26,45 \\
\hline 80 & 18,40 & 80 & 19,40 & 80 & 22,25 & 80 & 22,80 & 80 & 24,85 \\
\hline 90 & 18,05 & 90 & 20,75 & 90 & 22,25 & 90 & 22,95 & 90 & 25,25 \\
\hline 100 & 19,85 & 100 & 22,20 & 100 & 22,90 & 100 & 23,35 & 100 & 25,70 \\
\hline 110 & 22,15 & 110 & 22,30 & 110 & 23,95 & 110 & 24,05 & 110 & 25,75 \\
\hline 120 & 24,30 & 120 & 24,00 & 120 & 24,20 & 120 & 23,75 & 120 & 23,65 \\
\hline
\end{tabular}

As Figuras 7.1,7.2 e 7.3 mostram como ficaram as curvas dos atrasos de todas as simulações para ciclos com fase de pedestres e sem fase de pedestres. 


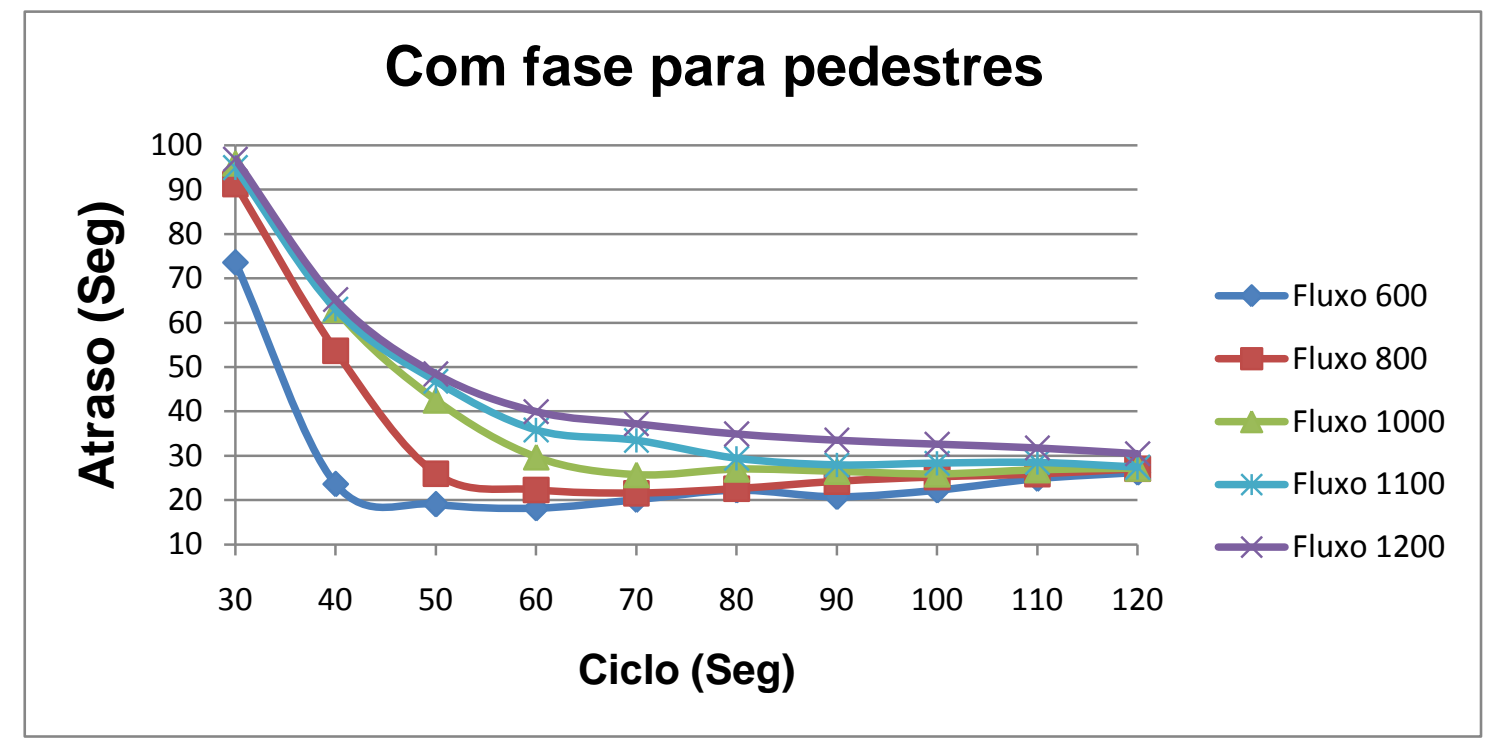

Figura 7. 2 - Curvas de ciclo ótimo x Fluxo de veículos.

As curvas de atraso para ciclos com fase de pedestres são bem parecidas, não sofrendo grandes variações em relação ao fluxo, ou seja, grandes atrasos nos ciclos menores e atrasos sem muitas variações a partir dos ciclos com mais de 70 segundos em todos os fluxos.

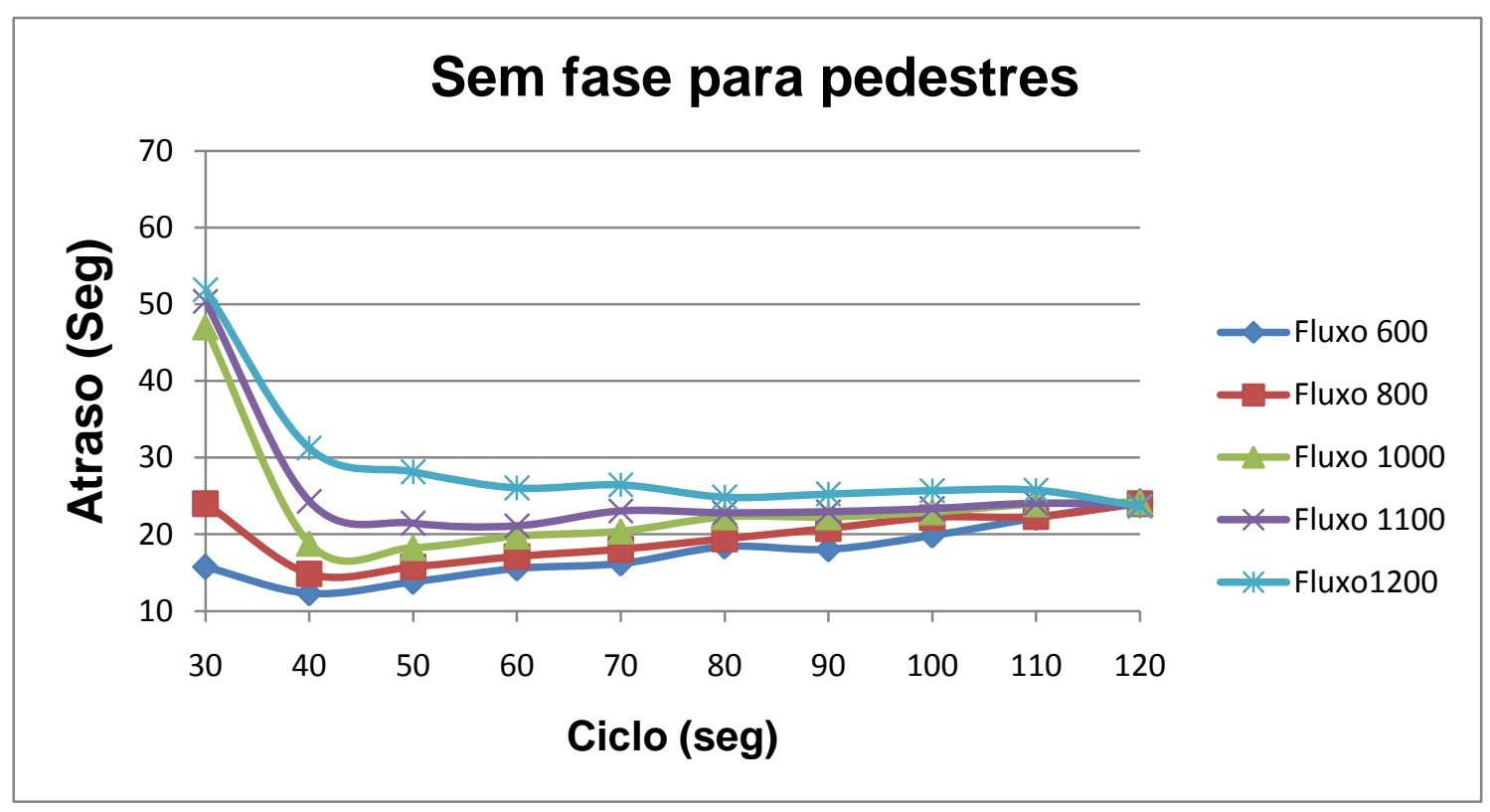

Figura 7. 3 - Curvas de ciclo ótimo x Fluxo de veículos. 
Tabela 7. 3 - Valores do ciclo ótimo e faixa de valores do ciclo para uso na prática.

\begin{tabular}{|c|c|c|c|c|c|c|}
\hline & Fluxo & 600 (veic/h) & 800 (veic/h) & 1000 (veic/h) & 1100 (veic/h) & 1200 (veic/h) \\
\hline \multirow{3}{*}{ Sem pedestres } & Ciclo Ótimo & 40 & 40 & 50 & 60 & 60 \\
\hline & $\begin{array}{c}\text { Faixa de } \\
\text { valores do ciclo } \\
\text { na prática } \\
\end{array}$ & $30-50$ & $40-60$ & $40-60$ & $50-60$ & $50-70$ \\
\hline & $\begin{array}{l}\text { Atraso médio } \\
\text { para o ciclo } \\
\text { ótimo(s/v) }\end{array}$ & 27,90 & 31,80 & 37,86 & 44,56 & 53,76 \\
\hline \multirow{3}{*}{ Com pedestres } & Ciclo Ótimo & 60 & 70 & 70 & 90 & 120 \\
\hline & $\begin{array}{c}\text { Faixa de } \\
\text { valores do ciclo } \\
\text { na prática }\end{array}$ & $50-70$ & $60-80$ & $70-90$ & $90-110$ & $100-120$ \\
\hline & $\begin{array}{l}\text { Atraso médio } \\
\text { para o ciclo } \\
\text { ótimo (s/v) }\end{array}$ & 38,26 & 44,26 & 52,73 & 56,43 & 63,20 \\
\hline \multicolumn{2}{|c|}{$\begin{array}{l}\text { Diferença nos } \\
\text { Valores dos } \\
\text { atrasos (s/v) }\end{array}$} & $\begin{array}{c}10,36 \\
(37,13 \%)\end{array}$ & $\begin{array}{c}12,46 \\
(39,18 \%)\end{array}$ & $\begin{array}{c}14,87 \\
(39,28 \%)\end{array}$ & $\begin{array}{c}11,87 \\
(26,64 \%)\end{array}$ & $\begin{array}{c}9,44 \\
(17,56 \%)\end{array}$ \\
\hline
\end{tabular}

As principais conclusões com base nos valores obtidos são as seguintes:

- Com fluxos veiculares até $1000 \mathrm{v} / \mathrm{h}$ o uso de fase para pedestres leva a um aumento do atraso veicular da ordem de $40 \%$.

- Com fluxos veiculares da ordem de $1100 \mathrm{v} / \mathrm{h}$ o uso de fase para pedestres leva a um aumento do atraso veicular da ordem de $25 \%$.

- Com fluxos veiculares da ordem de $1200 \mathrm{v} / \mathrm{h}$ o uso de fase para pedestres leva a um aumento do atraso veicular da ordem de $20 \%$.

A Figura 7.4 mostra a variação do ciclo ótimo em função do volume de tráfego para as duas situações analisadas. 


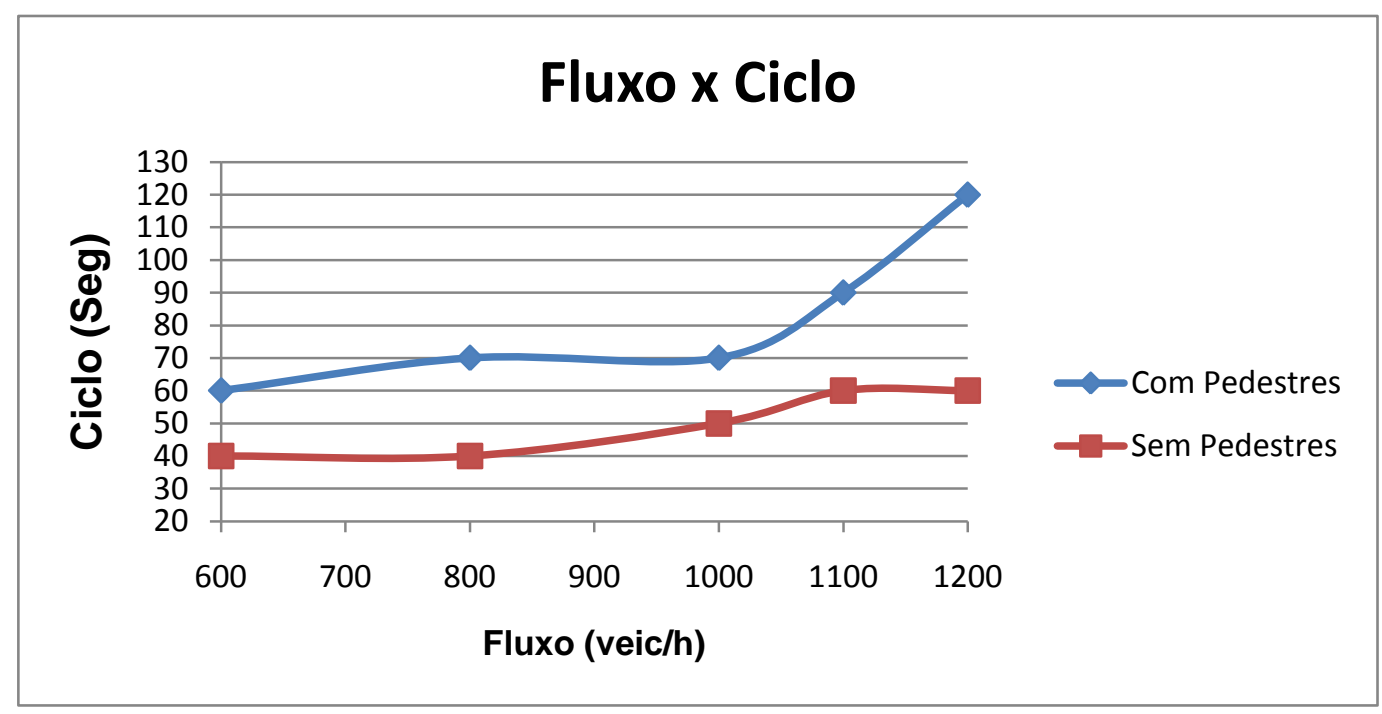

Figura 7. 4 - Variação do ciclo ótimo em função do fluxo de veículos. 


\section{CONCLUSÕES}

A pesquisa tinha como meta realizar investigações no campo da programação semafórica de tempo fixo. A meta e os objetivos propostos para esta pesquisa foram atingidos. As considerações obtidas para cada objetivo proposto são apresentadas a seguir.

Em relação ao primeiro objetivo, determinação dos parâmetros básicos para o dimensionamento de programações semafóricas na cidade de São Carlos, os valores obtidos: tempo médio total (no início e no final) perdido no verde mais amarelo por fase veicular nos semáforos igual a 3,12s (interseção em nível e fluxo sem conversão); o valor médio do fluxo de saturação encontrado para as interseções analisadas foi de $1607 \mathrm{v} / \mathrm{h}$ (para fluxos sem conversão e em interseções praticamente sem declividade); velocidade média dos pedestres na travessia em semáforos igual a $1,28 \mathrm{~m} / \mathrm{s}$ e velocidade correspondente ao $85^{\circ}$ percentil igual a $1,00 \mathrm{~m} / \mathrm{s}$.

Quanto ao segundo objetivo, sobre a compatibilidade dos resultados dos atrasos experimentados em semáforos isolados de tempo fixo de 2 fases, com exceção de alguns casos especiais, os valores do atraso fornecidos pelos métodos: Webster, HCM 2000, Simulador Integration e Simulador Corsim são da mesma magnitude e, portanto, perfeitamente viáveis de serem utilizados nos estudos práticos.

$\mathrm{Na}$ análise da determinação dos tempos que compõem a fase destinada à travessia de pedestres em semáforos, os métodos Ferraz e MUTCD são mais 
indicados que os métodos Webster/Denatran e CET-SP, uma vez que proporcionam adequada segurança sem "assustar" os pedestres e com o mínimo de prejuízo à capacidade do fluxo veicular.

Em relação ao último objetivo, o emprego de fase exclusiva para pedestres em semáforos com duas fases veiculares leva aos seguintes acréscimos aproximados nos valores do atraso médio dos veículos: 40\% para fluxos veiculares até $1000 \mathrm{v} / \mathrm{h}, 25 \%$ para fluxos veiculares da ordem de $1100 \mathrm{v} / \mathrm{h}$ e $20 \%$ para fluxos veiculares da ordem de 1200v/h. Quando for utilizado fase exclusiva de pedestre recomenda-se a utilização de ciclo mínimo de 50s, sendo a faixa de 70 - 90s a que acomoda a maior amplitude de variações de fluxo.

Este trabalho apresentou alguns resultados e conclusões sobre a operação de semáforos de tempo fixo. No entanto, os resultados apresentados não esgotam o tema e a necessidade de novas pesquisas sobre o assunto.

Como sugestão para pesquisas futuras recomenda-se a comparação de conflitos entre pedestres e veículos para os métodos Ferraz, MUTCD, Webster/Denatran e CET-SP; e pesquisa com os usuários (pedestres e condutores) sobre a utilização e a programação dos semáforos para pedestres. 


\section{Referências Bibliográficas}

AKÇELIK, R. (1993). Traffic Signals: Capacity and timing analysis. $45 f$. Research Report. Austrália.

ARAUJO, J.J. (2007). Estudo do Impacto de Veículos Pesados sobre a InfraEstrutura Rodoviária através de Simulação Microscópica de Tráfego. $176 f$. Tese (Doutorado) - Escola de Engenharia de São Carlos. Universidade de São Paulo, São Carlos, 2007.

BEZERRA, B.S. (2007). Semáforos: Gestão Técnica, Percepção do Desempenho, Duração dos Tempos. 236f. Tese (Doutorado) - Escola de Engenharia de São Carlos, Universidade de São Paulo, São Carlos, 2007.

BRASIL, Código de Trânsito Brasileiro. Código de Trânsito Brasileiro: instituído pela Lei no 9.503, de 23-9-97 - 3ำedição - Brasília: DENATRAN, 2008, 232 p. il.

BERTONCINI, B.V. (2002). Calibração do Simulador INTEGRATION para a Rede Viária da Região Central de Maringá. 42f. Relatório Final de Iniciação Cientifica. Departamento de Engenharia Civil, Universidade Estadual de Maringá, Maringá, 2002.

CAL, R. SPÍNDOLA, M. R.; GRISALES, J.C. (1995). Ingenieria de transito: Fundamentos y aplicaciones 7.ed.México: Alfaomega.

CET- Companhia de Engenharia de Tráfego, São Paulo. Apostila de Tempos Semafóricos - Métodos de Intervenção baseado em Observação de Campo, 35f., São Paulo, 1998. 
CET - Companhia de Engenharia de Tráfego, São Paulo. Manual de Sinalização Semafórica - Critérios de Programação, 137f, São Paulo, 2002.

CUNHA, A.L.B.N (2007). Avaliação do Impacto da Medida de Desempenho no Equivalente Veicular de Caminhões. 141f. Dissertação (Mestrado) Escola de Engenharia de São Carlos, Universidade de São Paulo, São Carlos, 2007.

DEMARCHI, S.H., SETTI, J.R.A., WIDMER, J.A. (1994). Comportamento de caminhões em Interseções em Nível. In: VII CONGRESSO DE PESQUISA E ENSINO EM TRANSPORTES, 1994, Recife. VII Congresso de Pesquisa e Ensino de Transportes, 1994.p.269-274

DENATRAN. Manual do Semáforo. Ministério da Justiça, Serviços de Engenharia (1979).

DENATRAN, Departamento Nacional de Transito, 2010. Anuário estatístico frota 2008. Disponível em: <http://www.denatran.gov.br/frota.htm>. Acesso em 05 de março de 2009.

DNER. Manual Interamericano de Trânsito. (1971).

DUTRA, C.B (2005). Avaliação da Eficiência de Métodos de Coordenação Semafórica em Vias Arteriais. 203f. Dissertação (Mestrado) - Escola de Engenharia de São Carlos, Universidade de São Paulo, São Carlos, 2005.

EIZENBERG, S. - Segurança na Temporização, Instituto nacional de segurança no trânsito, São Paulo. Apostila de cursos. 
FEDERAL HIGHWAY ADMINISTRATION - Manual on Uniform Traffic Control Devices (MUTCD) - for streets and Highways, (2003). Parte 4 Highway Traffic Signals. Washington, D.C, E.U.A., 2003.

FEDERAL HIGHWAY ADMINISTRATION - Traffic Signal Timing Manual,(MUTCD) (2008), Publicação número: FWHA - HOP - 08-024, Washington, D.C., E.UA, 2008.

FERRAZ, A.C.P. Tráfego Rodoviário (2005), Notas de Aula - Departamento de Engenharia de Transportes - Universidade de São Paulo, São Carlos.

IBGE, Instituto Brasileiro de Geografia e Estatística, 2010. IBGE cidades, São Paulo, São Carlos. Disponível em: <http://www.ibge.gov.br/cidadesat/topwindow.htm>

ITE,Institute of Transportation Engineers, 1989. Recommended Practice: Determining Vehicle Signal Change Intervals, Technical Committee 4A-16. ITE journal, Washington D.C., 1989.

KHISTY, C.J., LALL B. K. (2003). Transportation Engineering, Na Introduction, 3 ed. Prentice Hall. Upper Saddle River, New Jersey.

JAQUES, M.A.P.; ANASTÁCIO, E.R.; FELISARI, S.(1994). Avaliação dos Métodos Utilizados para a Medição do Fluxo de Saturação através de um estudo de Caso. In: VII CONGRESSO DE PESQUISA E ENSINO EM TRANSPORTES, 1994, Recife. VII Congresso de Pesquisa e Ensino em Transportes, 1994. P. 303-312.

LUNA, M.D.S (2003). Sobre o fluxo de Saturação: Conceituação, Aplicação, Determinação e Variação. 132f. Dissertação (Mestrado) - Programa de 
Mestrado em Engenharia de Transportes - Universidade Federal do Ceará, Ceará, 2003.

MAZZAMATI, M.V. (1992) - Notas técnicas da CET- NT 156/92 - Uma discussão obre Interseções Semaforizadas de Grande Extensão, sem caixas Intermediárias. São Paulo.

MACHADO, E.N. (1992). Fluxo de Saturação em Interseções Semaforizadas de Cidades Médias. Relatório Final de Iniciação Científica. 26f. Escola de Engenharia de São Carlos, Universidade de São Paulo, São Carlos, 1992.

PARREIRA, A.B. (1993). Verificação da Validade de Alguns Modelos teóricos de Comportamento de Tráfego em Interseções de Vias Urbanas. Dissertação (Mestrado) - Escola de Engenharia de São Carlos, Universidade de São Paulo, São Carlos, 1993.

PORTO, W.JR. (1995) - Apostila: Interseção com Controle Semafórico 74f. PET. COPPE. Universidade Federal do Rio de Janeiro, Rio de Janeiro, 1995.

PORTO, W.JR.;PACHECO, I.C.M.(2008). Aplicativo de Captação de Dados para Levantamento de Headways e Filas Veiculares. In: XXII CONGRESSO DE PESQUISA E ENSINO EM TRANSPORTES, 2008, Fortaleza. XXII Congresso de Pesquisa e Ensino em Transportes, 2008.

ROES, R.P.; PRASSAS, E.S.; MCSHANE, W.R.; (2004). Traffic Engineering, 3 ed. New Jersey. Prentice Hall.

SETTI, J.R.A., BARBUTO, L.S (1994). Caracterização do Tráfego em Interseções Semaforizadas de Cidades de Porte Médio. In VII Congresso de Pesquisa e Ensino em Transportes, 1994. P.361-373 
SETTI, J.R.A., (2004). Notas de Aulas - Integration.

SETTI J.R.A., (2005). Tecnologia de Transportes 214f. Escola de Engenharia de São Carlos, Universidade de São Paulo, São Carlos, 2002.

SHANTEAU, R. M., 1988, "Using Cumulative Curves To Measure Saturation Flow and Lost Time", ITE Journal, v. 58, n 10, pp. 27-31.

TRB. Highway Capacity Manual. Transportation Research Board. Washington D.C., 1985

TRB. Highway Capacity Manual. Transportation Research Board. Washington D.C.,C 2000.

TAPIA S.C.L. (2003). Avaliação de Alternativas de Operação de um Trecho de Via Semaforizado Utilizando o Simulador Integration. 153f. Dissertação (Mestrado) - Escola de Engenharia de São Carlos, Universidade de São Paulo, São Carlos, 2003.

VASCONCELOS, E.A., (1992). Apostila de Pesquisas e Levantamentos de Tráfego. São Paulo, Companhia de Engenharia de Tráfego, 1982. 184p., Boletim Técnico CET-S.P.

VILANOVA, L.M., Notas Técnicas da CET - NT -108/85 - Dimensionamento do Tempo de Amarelo. São Paulo.

WEBSTER, F.V.; COBBE, B.M. (1966) Traffic Signals, Londres: HMSO. 